\title{
Influence of Relative Sea Level Rise on Coastal Inlets and Tidal Basins
}

Are the Dutch Wadden capable of following the rising sea level?

\author{
M.A. van Goor \\ Supervisors: \\ prof. dr. ir. M.J.F. Stive \\ prof. drs. ir. J.K. Vrijling \\ dr. ir. Z.B. Wang \\ ir. T.J. Zitman \\ ir. H.A.H. Petit
}

April 2001 


\section{Preface}

The present M.Sc. thesis forms the completion of my education at the Delft University of Technology, Faculty of Civil Engineering and Geosciences, Department of Civil Engineering, Division of Hydraulic and Offshore Engineering.

The study concerns the influence of relative sea level rise on the morphological evolution of coastal inlets and tidal basins on the long-term to very-long term. In particular we are interested whether the morphological evolution of coastal inlets and tidal basins can keep pace with a rising sea level. Subjects of study are, besides theoretical configurations, the inlets of the Dutch Wadden Sea, as they enjoy broad scientific and social interest. The study has been carried out at WL | Delft Hydraulics and was funded by the Delft Cluster Project Coasts 03.01.03.

I would like to thank my supervisors, prof.dr.ir. M.J.F. Stive (Delft University of Technology and WL | Delft Hydraulics), prof.drs.ir. J.K. Vrijling (Delft University of Technology), dr.ir. Z.B. Wang (Delft University of Technology and WL | Delft Hydraulics), ir. H.A.H. Petit (Delft University of Technology and WL | Delft Hydraulics) and last but not least ir. T.J. Zitman (Delft University of Technology) for sharing their knowledge and support during this study. Furthermore, I am very grateful for the opportunity WL | Delft Hydraulics has offered me to complete my study at their institute and I would like to thank my temporary colleagues and fellow graduate students at WL | Delft Hydraulics for showing their interest and making my stay a very pleasant one. Finally, I would like to thank my family, girlfriend and friends for their support during the years I spent in Delft.

Michiel van Goor

Delft, April 2001 


\section{Samenvatting (in Dutch)}

De voorliggende studie is gericht op de lange tot zeer lange termijn voorspelling van de morfologische ontwikkeling van getijdebekkens onder invloed van zeespiegelstijging. Naast een theoretische beschouwing richt de studie zich op de Nederlandse Waddengebieden.

Onder invloed van een constante zeespiegelstijging zal de morfologische balans van een waddengebied permanent afwijken van de balans waarin het zou verkeren zonder zeespiegelstijging. Dit is nodig om een permanente behoefte aan sediment te genereren (in de geologie beschouwd als een positieve accommodatie ruimte) zodanig dat het waddengebied sediment gaat importeren. Als de mate waarmee het gebied sediment importeert overeenkomt met de snelheid waarmee de zeespiegel stijgt zal er een nieuwe morfologische balans ontstaan tussen de zeespiegelstijging en de ontwikkeling van het waddengebied. Echter, als de mate van sediment import achterblijft bij de zeespiegelstijging zal het waddengebied zich continue verdiepen (achterlopen bij de zeespiegelstijging) en zodoende verdrinken. In dit geval heeft de zeespiegelstijging een bepaalde verdrinkings (stabiliteit) limiet overschreden en ontstaat er geen nieuwe balans tussen de zeespiegelstijging en de morfologische ontwikkeling van het waddengebied. Uit gevoeligheid analyses blijkt dat de verdrinkingslimiet vooral gevoelig is voor een variatie van de volgende factoren:

- Vraag naar sediment door het waddengebied;

- Aanbod van sediment in de kustzone;

- Importerend vermogen van het waddengebied.

De vraag naar sediment in het waddengebied wordt bepaald door de afmetingen van het gebied en de snelheid waarmee de zeespiegel stijgt. Het aanbod van sediment is gerelateerd aan het golf-gedreven sediment transport langs de kustzone van de aangrenzende waddeneilanden en het importerend vermogen is gerelateerd aan de karakteristieke afmetingen van het systeem. Omdat er aanzienlijke onzekerheden bestaan omtrent het aanbod van sediment uit de kustzone en het importerend vermogen van het systeem bestaat er een significante onzekerheid in de voorspelling van de verdrinkingslimiet van een waddengebied. Om deze onzekerheid te ondervangen wordt de voorspelling van de verdrinkingslimiet probabilistisch benaderd.

De onzekerheden gerelateerd aan het aanbod van sediment uit de kustzone worden benaderd door een schatting van het bruto golf-gedreven sediment transport langs de kustzone. De onzekerheden gerelateerd aan het importerend vermogen van een waddengebied zijn benaderd door middel van een kalibratie van het morfologisch model met veldgegevens van de morfologische ontwikkeling van het Zoutkamperlaag Waddengebied na 1969. Probabilistische technieken gebruikt in deze studie leiden tot een kansverdeling voor de verdrinkingslimiet van een waddengebied. Deze aanpak hebben we toegepast op twee Nederlandse Waddengebieden, het Amelander Waddengebied $\left(269 \mathrm{~km}^{2}\right)$ en het Eierlandse Waddengebied $\left(161 \mathrm{~km}^{2}\right)$. Voor het Amelander Waddengebied resulteert dit voor het huidige golf klimaat in een kans van 32\% op verdrinking voor het realistische scenario van zeespiegelstijging (volgens een recente VN studie $56 \mathrm{~cm} /$ eeuw) en in een kans van $62 \%$ voor het extreme scenario van zeespiegelstijging $(85 \mathrm{~cm} /$ eeuw $)$. De kans op verdrinking voor het Eierlandse Waddengebied bedraagt voor het realistische scenario van zeespiegelstijging 7\% en voor het extreme scenario van zeespiegelstijging $24 \%$. De berekende kansen komen overeen met geologische bevindingen die suggereren dat onder invloed van een zeespiegelstijging van $80 \mathrm{~cm}$ en meer per eeuw de voormalige waddengebieden in het westelijk deel van Nederland verdronken waren. Overigens blijkt dat alvorens verdrinking optreedt er reeds aanzienlijke veranderingen in geul- en plaat dimensies zijn opgetreden. 


\section{Summary}

A major part of the Netherlands is situated below or around mean sea level. This contributes noticeably to a broad public awareness of the threat imposed by the apparent relative rise of the sea level. Against this background, substantial effort is being put into research in support of understanding and modelling the morphological response of the coastal zone to a rise of mean sea level. This is essential for policy design and decision making with respect to preservation of coastal zone resources as well as its socio-economic and nature values.

The present study considers the prediction of long-term to very long-term morphology and in particular the feasibility of predicting whether the morphological evolution of a tidal inlet (coastal inlet and tidal basin) can keep pace with a rising sea level. Subjects of study are, besides theoretical configurations, the inlets of the Dutch Wadden Sea, as they enjoy broad scientific and social interest and as comparatively much field data on these inlets are readily available.

To obtain a better understanding of the long-term morphological evolution of tidal inlets a literature survey is made. This survey deals with the very long-term morphological evolution of the Dutch coast since the last ice age, the long-term development of tidal inlets systems as a whole and the long-term development of distinct morphological elements present in tidal inlet systems. From the literature study it came forward that we may distinguish three morphological elements in a tidal inlet system, namely the ebb-tidal delta, the channel and the tidal flat. Further, it appears that for morphological elements that are in a state of morphological balance, relationships exists between the elements state (e.g. integrated 'wet' or 'dry' volume) and the present morphometric and hydrodynamic values.

Starting point for our long-term modelling approach is that we accept the existence of such an equilibrium state. The morphological development towards such a state of morphological equilibrium can be described in terms of need and availability of sediment, which is typical for behaviour oriented modelling. This rationale forms the basis for the model ASMITA (Aggregated Scale Morphological Interaction between a Tidal inlet system and the Adjacent coast). We use this model to analyse how a tidal inlet system responds to a rising sea level. In general, this response depends primarily on three factors:

- The availability of sediment at the seaward boundary of the system

- The sediment demand of the system

- The capability of the system to distribute the imported sediment internally

The first factor applies to the exchange of sediment between the inlet system on the one hand and the coastal and offshore areas that surround the ebb-tidal delta on the other hand. The second factor, the sediment demand needed to keep pace with the rise of the sea level, depends on the horizontal area of the morphological elements and is related to the need of sediment in the system. This need of sediment (in the geological context also referred to as a positive accommodation space) depends on the extent to which the actual morphology of the system deviates from its equilibrium state. Whether this need of sediment actually results in sedimentation of the system depends on the third factor, the capability of the system to distribute the imported sediment internally and make it available for sedimentation. This internal sediment distribution is presumed to be dominated by a diffusion-type of transport. 
When we expose a tidal inlet system to a constant sea level rise $(S L R)$, the system will be permanently in a state that deviates from the equilibrium that corresponds to a zero $S L R$. This is necessary to create a (permanent) incentive to import sediment into the system. In case the rate of sediment import matches the rate of sea level rise, a new form of morphological balance is reached. If the actual import rate is less than this, the system's morphological state will deviate increasingly from its equilibrium and become unstable. In this case the SLR has exceeded an upper boundary (named 'stability limit', denoted as SLRlimit), and the system will not be able to reach a state of morphological balance any longer and drown. For the mentioned three-element schematisation of inlet systems (ebb-tidal delta, channel and flat), it can be shown theoretically that the stability limit is determined fully by properties of the flat. This complies with what one may expect from the serial character of the system where the flat element is situated furthest from the sediment source at the seaward boundary.

With this knowledge it is interesting to test some actual inlets against their stability under the external forcing of a rising sea level. For this purpose we have selected two, area wise different, inlets of the Dutch Wadden Sea, viz. the Amelander Zeegat (also known as the Borndiep) and the Eierlandse Gat. With respect to some model parameters and element properties, these tests are based on estimates and assumed time-invariance. Against this background, we have analysed also the sensitivity of the SLRlimits of the two inlet systems to a variation in the concerned quantities. From this analysis we found that the SLRlimit of both inlets is especially sensitive to a variation of basin area, internal sediment exchange rate and availability of sediment at the seaward boundary of the system. Because estimates of the latter two variables include large uncertainties it has been chosen to assess the SLRlimit predictions probabilistically to gain quantitative insight into their reliability.

This probabilistic approach is focussed on delineating effects of uncertainties in the two parameters to which $S L R$ limit predictions are most sensitive. It concerns the availability of sediment to the system and the system's internal sediment distribution capacity. Uncertainties in the availability are estimated from an extrapolation of small-scale wave-induced longshore currents and transport to a long-term average, whereas uncertainties in the distribution capacity are derived from fitting ASMITA to field data on the evolution of the Zoutkamperlaag inlet since the closure of the Lauwers Zee in 1969. The probabilistic techniques as applied in the present study lead to a probability distribution for the stability limit of an inlet system. Application to the Amelander Zeegat indicates that there is a $32 \%$ probability of this inlet not being able to keep pace with a sea level rise of $56 \mathrm{~cm} / \mathrm{century}$ (the most likely scenario according to a recent UN study), under the present wave climate. For the worst case sea level rise scenario $(85 \mathrm{~cm} /$ century) this probability equals $62 \%$. The probability of the Eierlandse Gat not being able to keep pace with the most likely sea level rise scenario under the present wave climate is $7 \%$ and for the worst case sea level rise scenario this probability equals $24 \%$.

These probabilities comply with available fragmentary geological data, which suggests that under the influence of a sea level rise of $80 \mathrm{~cm}$ to a few meters per century, the former tidal inlets in the western region of the Netherlands were drowned. This similarity indicates that, in terms of orders of magnitude, the aggregated scale model ASMITA is capable of modelling the long-term morphological response of a tidal inlet to a rising sea level and that it is capable of predicting the maximum rise of sea level a tidal inlet system can follow. 


\section{Contents}

\section{Preface}

\section{Samenvatting (in Dutch)}

\section{Summary}

\section{List of Figures}

\section{List of Tables}

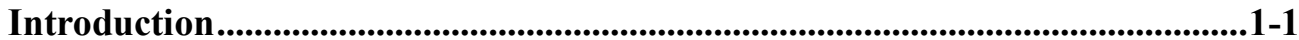

$1.1 \quad$ General

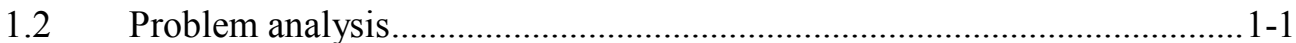

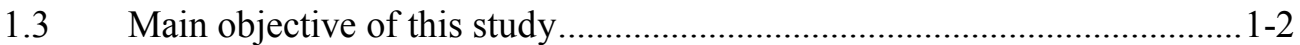

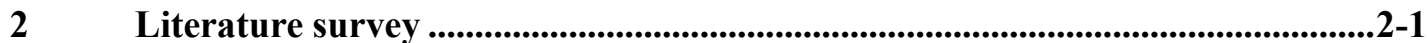

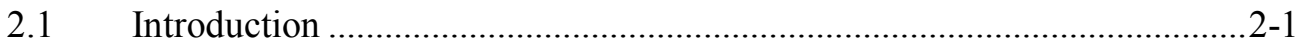

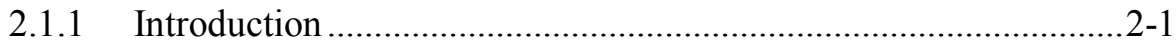

2.1.2 History of the Dutch Wadden Sea ....................................................2-1

2.1.3 Differences between West and East..................................................2-5

2.2 Development of tidal inlet systems .........................................................

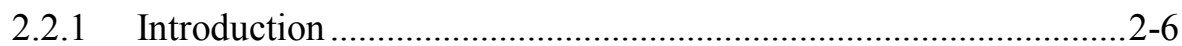

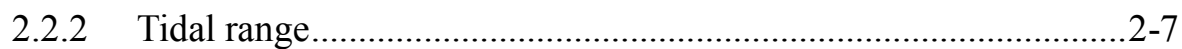

2.2.3 Seasonal Waves and Wind ..........................................................

2.2.4 Geometry of ebb-tidal delta ..........................................................2-8

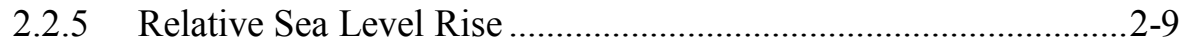

2.2.6 Sediment retention mechanism...................................................2-11

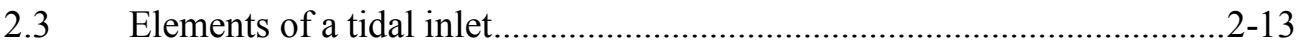

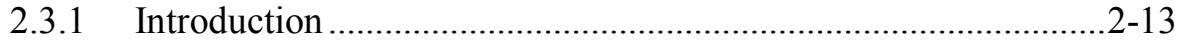

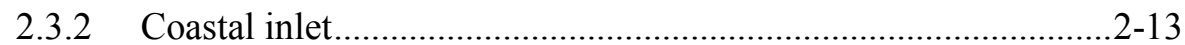

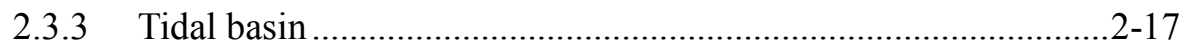

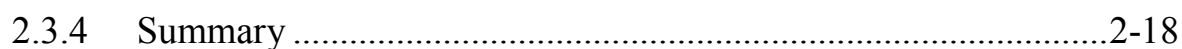

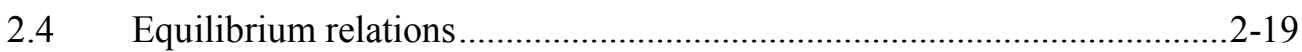

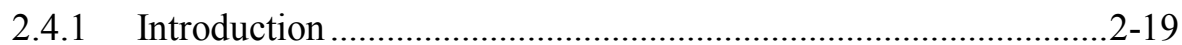

2.4.2 Empirical Equilibrium relations ..................................................2-19

2.4.3 Relationship between cross-section and tidal prism ....................2-19

2.4.4 Relationship between channel volume and tidal prism...............2-20

2.4.5 Relationship between volume of ebb-tidal delta and tidal prism 2-21

2.4.6 Relationship between volume of tidal flats and size of basin......2-22 
3.1 Introduction

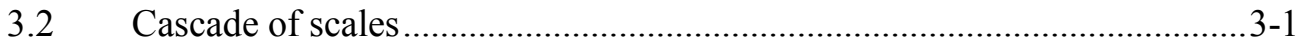

3.3 Long-term modelling..........................................................................

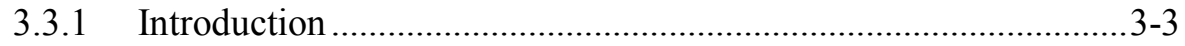

3.3.2 The ASMITA concept ...................................................................3-3

3.3.3 Model formulation ....................................................................

3.4 Stability limit analysis of modelled tidal inlet systems .............................. 3-6

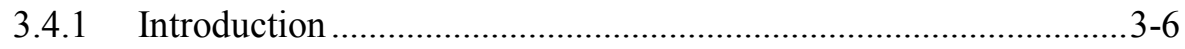

3.4.2 Single element model...................................................................

3.4.3 Two-element model.................................................................... $3-10$

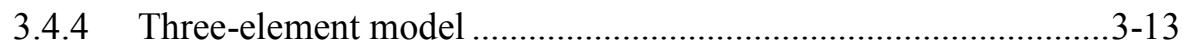

3.4.5 Main Results of Stability Limit Analysis ......................................3-16

3.5 Sensitivity analysis on the stability limit ................................................ $3-16$

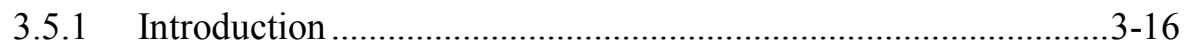

3.5.2 Input coefficients three-element model ......................................3-17

3.5.3 Sensitivity Analysis .................................................................

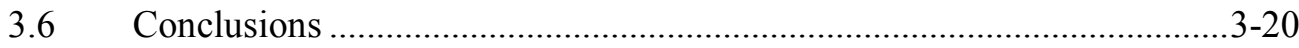

$4 \quad$ Stability of actual tidal inlets in the Dutch Wadden Sea........................................4-1

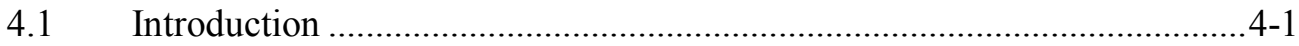

4.2 Inlet consideration for testing ...........................................................

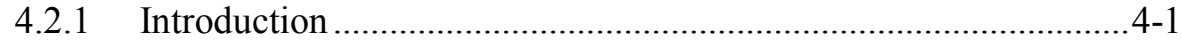

4.2.2 Available Inlets and considerations .......................................... 4-2

4.2.3 Tidal Inlets used for further testing .............................................4-2

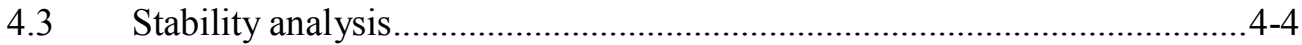

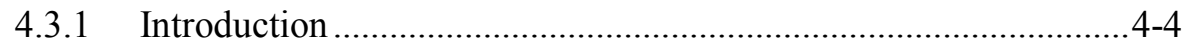

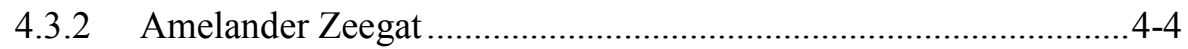

4.3.3 Eierlandse Gat ................................................................................... $4-5$

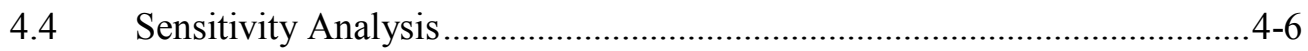

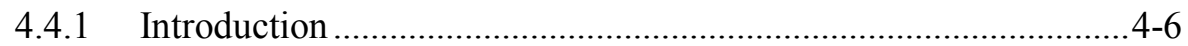

4.4.2 Sensitivity to a change of the area ...............................................

4.4.3 Sensitivity to change of horizontal exchange rate...........................4-7

4.4.4 Sensitivity to change of equilibrium concentration ........................4-8

4.4.5 Sensitivity to change in vertical exchange rate ...............................4-9

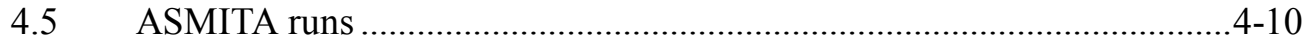

4.5.1 Introduction ..............................................................................

4.5.2 Present rate of sea level rise...................................................... 4 -10

4.5.3 Most likely scenario case ............................................................4-11

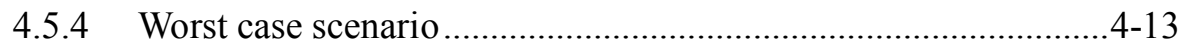


4.6 Conclusions ......................................................................................

$5 \quad$ Assessing uncertainties in the Sea Level Rise Stability Limit ...............................5-1

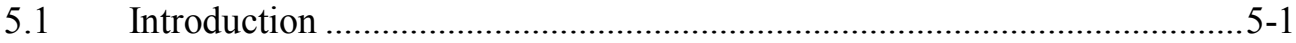

5.2 Assessing the uncertainty in 'outside world' equilibrium concentration ...5-1

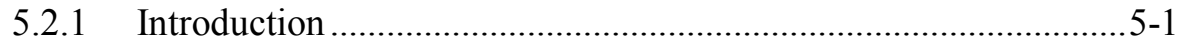

5.2.2 Physical concept of 'outside world' equilibrium concentration ....5-1

5.2.3 Estimates for 'outside world' equilibrium concentration ..............5-5

5.3 Assessing the uncertainty in horizontal exchange rate.................................5-9

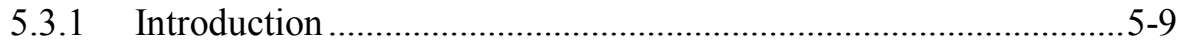

5.3.2 Development of the Zoutkamperlaag inlet......................................5-9

5.3.3 Mean values of horizontal exchange rate ......................................5-11

5.3.4 Standard deviation of horizontal exchange rates ..........................5-13

5.4 Probability of Sea Level Rise Stability Limit............................................5-14

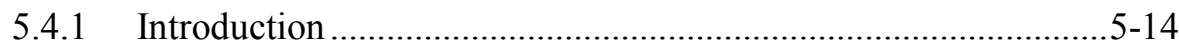

5.4.2 The probability that the $S L R$ exceeds the $S L R$ limit......................5-15

5.5 Consideration with respect to $S L R$ limit probability …..............................5-17

$6 \quad$ Conclusions and Recommendations ...............................................................6-1

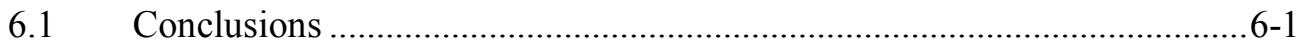

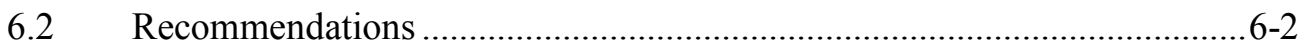

\section{References}

\section{Appendices}




\section{List of Figures}

Figure 1.1 Satellite view of the barrier islands along the Dutch and German coast

Figure 2.1

Figure 2.2

Figure 2.3

Figure 2.4

Figure 2.5

Figure 2.6

Figure 2.7

Figure 2.8

Barrier islands of the Dutch and German Wadden Sea

9,200-5,800 BC; Rapid Sea Level Rise causing coast to erode and recede

$5,800-3,780 \mathrm{BC}$; Forming of a fairly stable coastline

3,780-2,100 BC; Deceleration of Sea Level Rise and extension of coast

3,700 (C14)-Middle Ages; Formation of the present wadden environment

The interaction of inlet tidal currents with offshore tidal currents at mid-flood and mid-ebb stage

Figure 2.9

Development of Sea Level Rise from 6,000 BC to 2,000 AD

Figure 2.10

Estimates for accelerated rate of Sea Level Rise

Figure 2.11

Relative Sea Level Rise; also influenced by sea floor subsidence

Tidal inlet system adapting to accelerated Relative Sea Level Rise and regaining a new state of dynamic equilibrium.

Figure 2.12 Tidal inlet system unable to adapt to accelerated Sea Level Rise and not able to regaining a new state of dynamic equilibrium.

Figure 2.13

Figure 2.14 Layout of a typical ebb-tidal delta

Figure 2.15 Cross-section of ebb-tidal delta, indicating the cross-shore boundaries by the no-inlet bathymetry

Figure 2.16 Channel volume - characteristic tidal volume relationship

Figure 2.17 Sand volume outer deltas in USA and Dutch Wadden Sea in relation to the mean tidal prism and wave climate of the inlet

Figure 2.18 Relative area of the intertidal zones in the Dutch Wadden Sea against the tidal basin area

Figure 3.1 Cascade of model scales

Figure 3.2

Figure 3.3

Elements used in ASMITA concept

Figure 3.4

Single element model

Dynamic equilibrium volume channel element as function of a constant external forcing; the accelerated rate of sea level rise

Figure 3.5 Two-element model

Figure 3.6 Phase plane of dynamic equilibrium states for two-element model under the external forcing of $0 \mathrm{~mm} /$ year $S L R$

Figure 3.7 Phase plane of dynamic equilibrium states for two-element model under the external forcing of $10 \mathrm{~mm} /$ year $S L R$

Figure 3.8 Phase plane of dynamic equilibrium states for two-element model under the external forcing of $25 \mathrm{~mm} /$ year $S L R$

Figure 3.9 Phase plane of dynamic equilibrium states for two-element model under the external forcing of $40 \mathrm{~mm} /$ year $S L R$

Figure 3.10 Three-element model

Figure 3.11 Dynamic equilibrium volumes of a fictitious three-element model as a function of rate of sea level rise

Figure 3.12 Cross-sections of phase space at dynamic equilibrium states of three-element model, no sea level rise

Figure 3.13 Sensitivty of the SLRlimit to change of element area.

Figure 3.14 Sensitivty of the SLR limit to change of horizontal exchange rates

Figure 3.15 Sensitivty of the SLRlimit to change of 'outside world' equilibrium concentration

Figure 3.16 Sensitivty of the SLRlimit to change of vertical exchange rate 
Figure 4.1 Satellite view and depth sounding of the Amelander Zeegat inlet

Figure 4.2 Satellite view and depth sounding of the Eierlandse Gat inlet

Figure 4.3 Dynamic equilibrium volumes of Amelander Zeegat inlet as function of a constant external forcing; the accelerated rate of sea level rise

Figure 4.4 Dynamic equilibrium volumes of Eierlandse Gat inlet as function of a constant external forcing; the accelerated rate of sea level rise

Figure 4.5 Sensitivty of SLRlimit to change of element area for Amelander Zeegat

Figure 4.6 Sensitivty of SLRlimit to change of element area for Eierlandse Gat

Figure 4.7 Sensitivty of SLRlimit to change of horizontal exchange rate for Amelander Zeegat

Figure 4.8 Sensitivty of SLRlimit to change of horizontal exchange rate for Eierlandse Gat

Figure 4.9 Sensitivty of SLRlimit to change of 'outside world' equilibrium concentration for Amelander Zeegat

Figure 4.10 Sensitivty of SLRlimit to change of 'outside world' equilibrium concentration for Eierlandse Gat

Figure 4.11 Sensitivty of SLRlimit to change of vertical exchange rate for Amelander Zeegat

Figure 4.12 Sensitivty of SLRlimit to change of vertical exchange rate for Amelander Zeegat

Figure 4.13 Volume development for the Amelander Zeegat for the present sea level rise

Figure 4.14 Volume development for the Eierlandse Gat for the present sea level rise

Figure 4.15 Volume development for the Amelander Zeegat for an accelerating rate of sea level rise up to $56 \mathrm{~cm} /$ century in 2100

Figure 4.16 Volume development for the Eierlandse Gat for an accelerating rate of sea level rise up to $56 \mathrm{~cm} /$ century in 2100

Figure 4.17 Volume development for the Amelander Zeegat for an accelerating rate of sea level rise up to $85 \mathrm{~cm} /$ century in 2100

Figure 4.18 Volume development for the Eierlandse Gat for an accelerating rate of sea level rise up to $85 \mathrm{~cm} /$ century in 2100

Figure 5.1 Longshore transport $S$ and discharge $Q$ for low and high wave conditions

Figure 5.2 Longshore current velocity profile in surf zone

Figure 5.3 CERC design curve for longshore sediment transport $Q$ versus energy flux factor (wave height related) with dashed lines representing $1.5 \cdot Q$ and $0.5 \cdot Q$

Figure 5.4 The Friesche Zeegat, with in the Pinkegat inlet and the Zoutkamperlaag inlet separated by the Engelsmanplaat

Figure 5.5 Simulation of volume development of Zoutkamperlaag inlet after closure Lauwerszee (1969)

Figure 5.6 Probability distribution of Amelander Zeegat for present and changed wave climate scenarios

Figure 5.7 Probability distribution of Eierlandse Gat for present and changed wave climate scenarios 


\section{List of Tables}

Table 2.1

Table 2.2

Table 3.1

Table 3.2

Table 3.3

Table 3.4

Table 4.1

Table 4.2

Table 4.3

Table 4.4

Table 4.5

Table 4.6

Table 4.7

Table 4.8

Table 4.9

Table 4.10

Table 4.11

Table 5.1

Table 5.2

Table 5.3

Table 5.4

Table 5.5

Table 5.6

Table 5.7

Table 5.8

\section{Tidal Classification}

Wave Classification

Element characteristics fictitious single-element system

Element characteristics fictitious two-element model

Element characteristics fictitious three-element model

Variables viable for sensitivity analysis

Tidal inlets of the Dutch Wadden Sea and their main characteristics

Element characteristics Amelander Zeegat

Element characteristics Eierlandse Gat

Equilibrium sediment transports between elements; $S L R 17 \mathrm{~cm} /$ century

Equilibrium sediment demand/ accretion in elements; $S L R 17 \mathrm{~cm} /$ century

Equilibrium sediment transports between elements; $S L R 56 \mathrm{~cm} /$ century

Equilibrium sediment demand/accretion in elements; $S L R 56 \mathrm{~cm} /$ century

Equilibrium sediment transports between elements; $S L R 85 \mathrm{~cm} /$ century

Equilibrium sediment demand/ accretion in elements; $S L R 85 \mathrm{~cm} /$ century

Equilibrium levels as a function of $S L R$

Equilibrium levels as a function of $S L R$

Representative reference wave conditions

Long-term averaged 'outside world' equilibrium concentration $c_{E}$

Wave climate scenarios

Volume development of the elements of the Zoutkamperlaag inlet due to the closure of the Lauwerszee

System variables Zoutkamperlaag inlet

Optimised horizontal exchange rates

Resulting means and standard deviation of horizontal exchange rates

Probability $S L R>S L R$ limit for given $S L R$ scenarios and wave climates 


\section{Introduction}

\section{I.I General}

A major part of the Netherlands is situated below or around mean sea level. This contributes noticeably to a broad public awareness of the threat imposed by the apparent relative rise of the sea level. Against this background, substantial effort is being put into research in support of understanding and modelling the morphological response of the coastal zone to a rise of mean sea level. This is essential for policy design and decision making with respect to preservation of coastal zone resources as well as its socio-economic and nature values.

The present report contributes to this research. It is focussed on the morphological evolution of a tidal inlet and its direct environment under a persistently rising sea level. In particular, the potential is investigated of an aggregated-scale modelling approach for predicting under which conditions the evolution of an inlet can keep pace with a sea level rise.

\section{I.2 Problem analysis}

If we want to create a perception of the morphological response of a shoreline to a relative rise of the sea level, we need to concentrate on the accompanying time-scale. With respect to modelling at this scale, two approaches can be distinguished. First there is the option of describing the morphological behaviour on a relative small time-scale (inter-tidal) and integrating this to form a statement of the long-term behaviour. The advantage of this method is that use of available knowledge concerning small morphological processes is made. However, in the quantitative prediction for long-term developments the integration of smallscale knowledge can cause an accumulating error that brings significant uncertainties to our predictions.

The other approach describes large-scale behaviour of the shoreline directly. It is based on the assumption that morphological developments tend to a (dynamic) equilibrium, governed by relatively slow changing boundary conditions. This approach is far less affected by an accumulation of error but it requires quantitative insight into the parameters of the underlying large-scale morphological processes. These parameters can only be determined from field data and with a limited reliability because of the relatively small time span of measurements. This method aims at gross predictions for the long to very long-term.

Both methods suffer of decreasing reliability with increasing prediction term. Against this background it seems useful to accompany model results with quantitative estimates of the corresponding reliability. A probabilistic approach might provide this estimate. 


\section{I.3 Main objective of this study}

The present study considers the prediction of long-term to very long-term morphology and in particular the feasibility of predicting whether the morphological evolution of a tidal inlet can keep pace with an accelerated rise in relative sea level.

Subjects of study are, besides theoretical configurations, the inlets of the Dutch Wadden Sea, as they enjoy broad scientific and social interest and as comparatively much field data on these inlets are readily available.

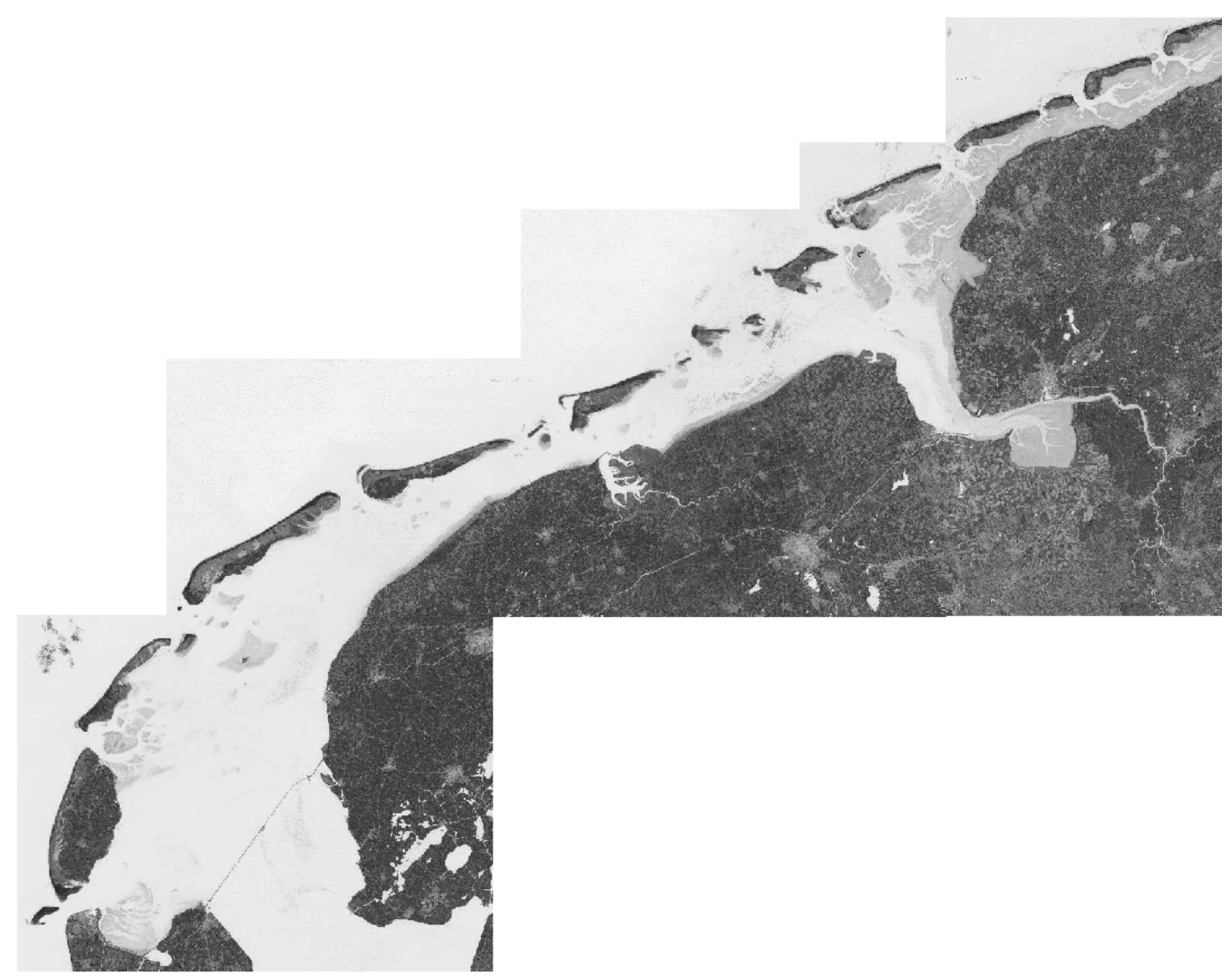

Figure 1.1: Satellite view of the barrier islands along the Dutch and German coast 


\section{Literature survey}

\section{I Introduction}

To obtain a better understanding of the long-term morphological evolution of coastal inlets and tidal basins a literature survey is made. This literature survey deals with morphological behaviour and characteristics of coastal inlets and tidal basins, which have been the subject of numerous studies and research projects. Hereafter an overview is given of the results of a number of studies, most of them related to the Wadden Sea, the barrier coast in the north of the Netherlands. The coastal inlets and tidal basins, which are subject of the present study, are part of this coastal system.

For the present chapter it has been chosen to describe the Wadden Sea starting from comparatively large time- and space-scales towards ever smaller scales, down to the sonamed meso-scale level (length-scales of meters to kilometres and time-scales of months to years).

\section{I.I Introduction}

The Dutch Wadden Sea consists of a system of barrier islands, coastal inlets and tidal basins (see Figure 2.1). History teaches us that the morphology of such a system is highly dynamic and, to a certain extent, is able to adapt itself to external forcings e.g. land reclamation and a rise in sea level. How the system has adapted itself to these forcings from the last ice age to present day is described in Section 2.1.2.

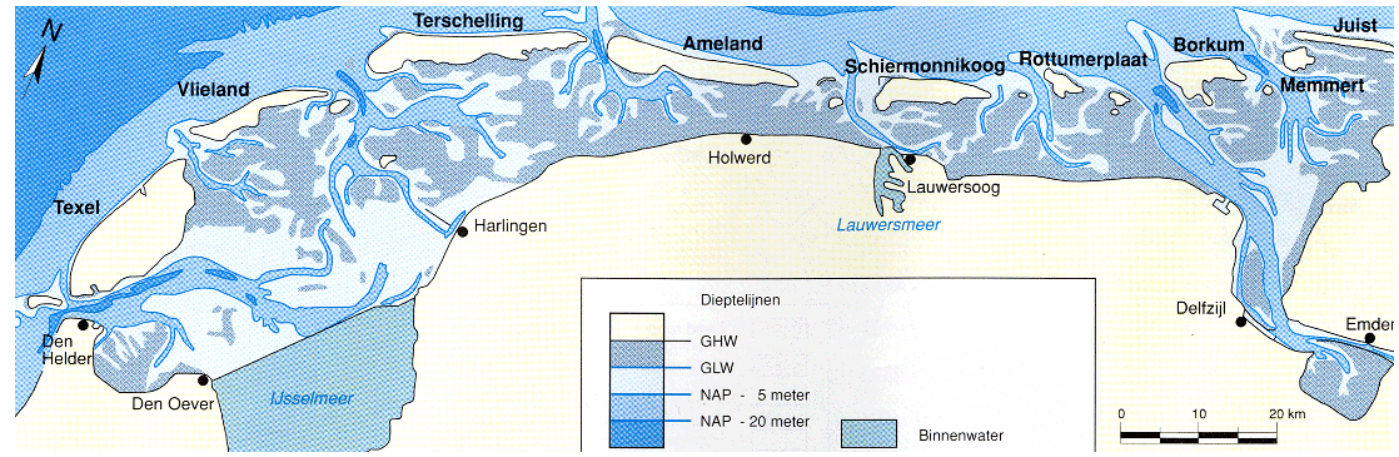

Figure 2.1: $\quad$ Barrier islands of the Dutch and German Wadden Sea

\subsubsection{History of the Dutch Wadden Sea}

To understand more of the long-term morphological processes that take place in the Wadden Sea it is important to know the geological developments that formed it to its present shape. In its relatively short geological existence, the Wadden Sea has already gone through some turbulent developments. According to Zagwijn (1986) and Van der Spek (1994), part of the Wadden Sea system has shifted eastward and landward under the influence of the preceding rise of the sea level. Historical geological findings also show that in the course of time the system has become considerably smaller. The historical developments of the Wadden Sea 
since some 100,000 years ago can be described as follows (Zagwijn, 1986 and Van der Spek, 1994):

\section{Melting of the ice caps and the sea level starting to rise}

\section{0,000 to $10,000(\mathrm{C} 14)$ years ago}

During the last ice age, the North European ice-cap did not reach what is now the Netherlands. Instead a thick layer of sand was deposited on the irregularly shaped Pleistocene landscape. Approximately 15,000 years ago, when the sea level was 120 to 140 meters lower than it is presently, the melting of the North American ice-caps caused the sea level to start rising at a rate of several meters per century. At that time, the Wadden Sea did not exist yet. It was formed in the course of coastal evolution under the influence of a persistently rising sea level. As such, the Wadden Sea is just like the Dutch dunes, a geologically young landscape, which did not take on its current form until the warm period after the last ice age.

\section{Rapid Sea Level Rise causing coast to erode and recede}

\section{0,000 to 7,000 (C14) years ago $(9,200-5,800 \mathrm{BC})$}

Available fragmentary geological data suggests that under the influence of a rapid relative sea level rise of at least $80 \mathrm{~cm}$ to a few meters per century, the Dutch coast shifted landward. In the western region of the Netherlands, a brackish to saltwater lagoon was formed (see Figure 2.2). At that time, the area now known as the Wadden Sea, consisted of estuaries with lagoons and tidal flats, formed by flooding by the sea of the river valleys that had formed in the Pleistocene. In an arch enclosing this sea, there was a series of islands with tidal inlets and channels between them. It is not clear how far seaward this former wadden area extended. The area as a whole gradually became subjected to ever increasing marine influence and was unable to keep pace with the rapid rise of the sea level, causing the coast to erode and recede. It seems that the supply of alluvial sediment to the area was to slow at that time to cause accretion of the large wadden area. This is interesting, as the predicted rate of sea level rise for the coming centuries (2100-2300) might equal the rate of sea level rise in the latter period.

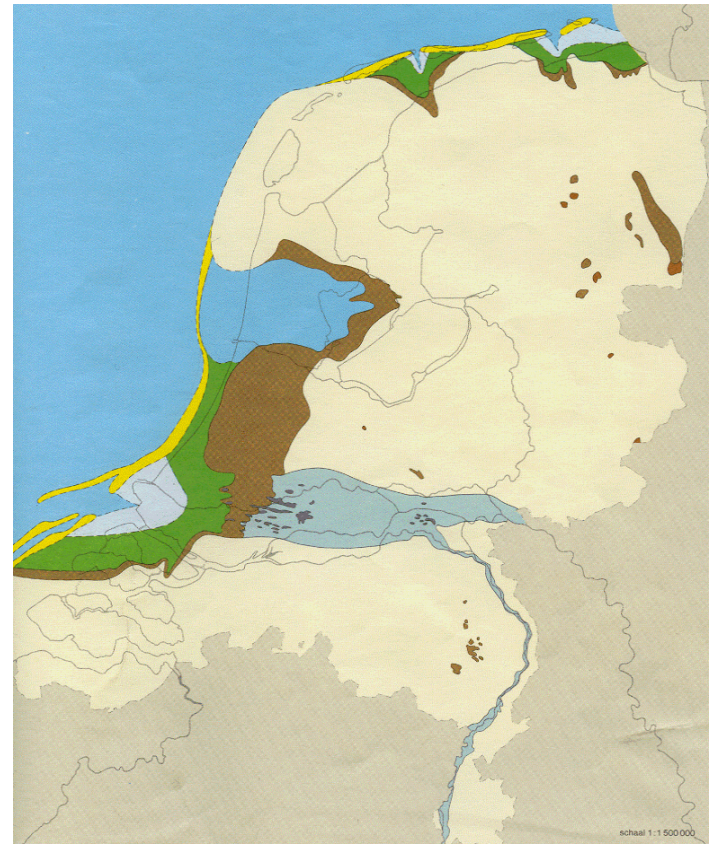

Figure 2.2: $\quad 9,200-5,800$ BC; Rapid Sea Level Rise causing coast to erode and recede, Zagwijn (1986). 


\section{Forming of a fairly stable coastline}

\section{$\mathbf{7 , 0 0 0}$ to 5,000 (C14) years ago $(5,800-3,780 \mathrm{BC})$}

In this period the sea level rise amounted to some 80 to $40 \mathrm{~cm}$ per century. The tidal flats area still shifted landward and the Pleistocene Heights near Texel underwent severe erosion. The area started to bear more resemblance to the present-day wadden area (see Figure 2.3). Due to the gradually developing barrier bars and dunes, a fairly stable coastline with tidal inlets and channels was formed in what are now the Noord-Holland and Zuid-Holland provinces. Behind it, tidal flats and salt marshes developed and the higher boggy areas became covered with a layer of peat. It can be deduced that under these conditions, sediment was deposited at the same rate that the sea level rises. This teaches us that if the supply of material is sufficiently large, a rising sea level does not necessarily mean loss of land or the formation of an inland sea.

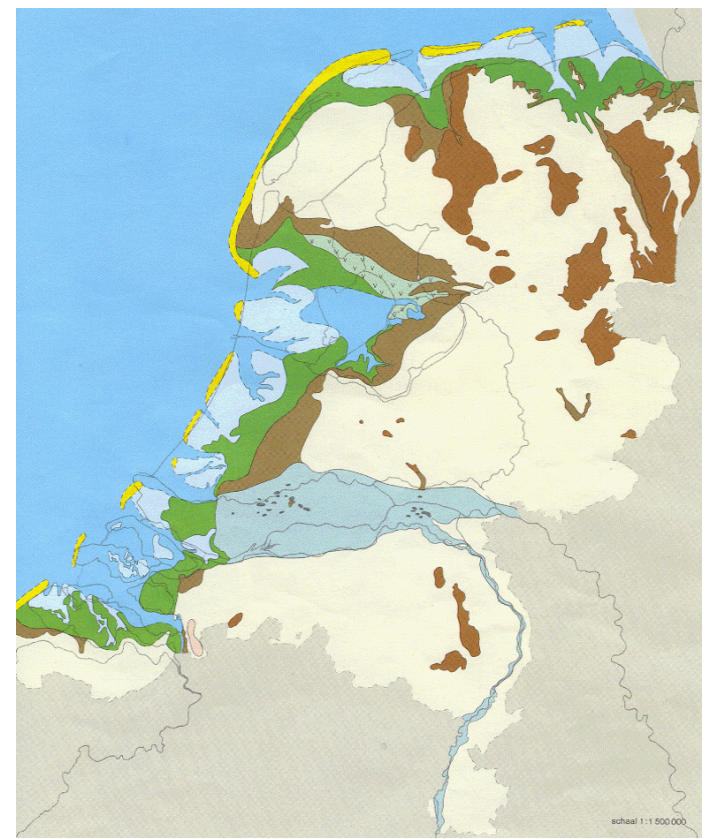

Figure 2.3: $\quad 5,800-3,780 \mathrm{BC}$; Forming of a fairly stable coastline, Zagwijn (1986)

\section{Deceleration of Sea Level Rise and extension of coast}

\section{5,000 to $3,700(\mathrm{C} 14)$ years ago $(3,780-2,100 \mathrm{BC})$}

The sea level rise in this period decelerated to a rate between 40 and $20 \mathrm{~cm}$ per century. In the delta area, which stretches across the entire west coast of the Netherlands, enough sediment was deposited to catch up with the sea level rise and allow the coast to expand in a seaward direction (first in the south, later in the north). The sediment originally came from erosion of the receding capes (Zeeland delta area and Texel Heights) and the former outer deltas and was transported by the North Sea and rivers. The area north of Bergen continued to erode, as did the coast of the area now known as the Wadden Sea, which progressively receded, making sand available for the wadden area. Parts of the elevated flats in the wadden were transformed into salt marshes or even became dry land. The Zuider Sea was not yet a sea but a freshwater lake (Lake Flevo) in which rivers from the south drained (see Figure 2.4). 


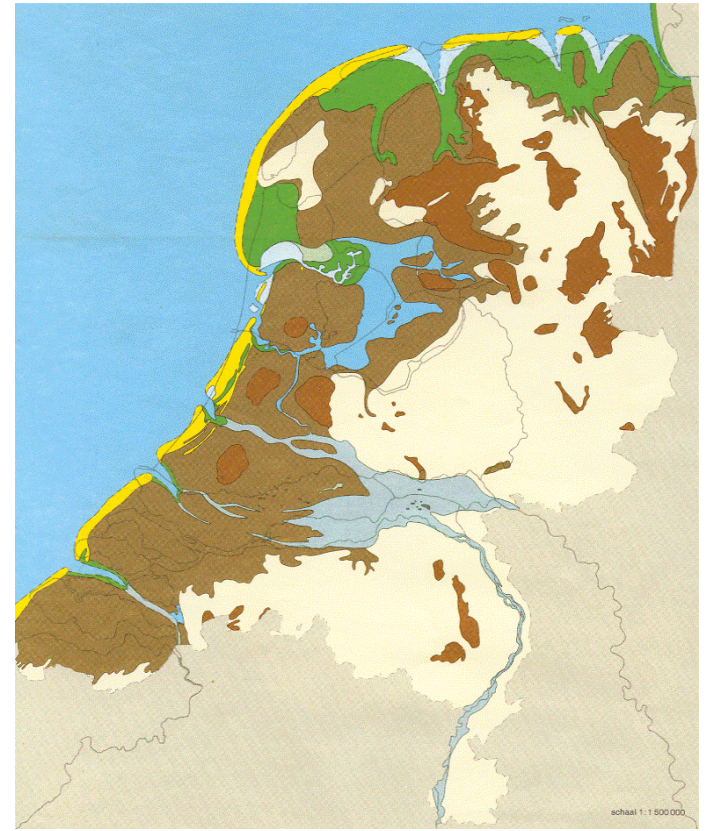

Figure 2.4: $\quad 3,780-2,100$ BC; Deceleration of Sea Level Rise and extension of coast, Zagwijn (1986)

\section{Formation of the present wadden environment}

\section{3,700(C14) years ago until the Middle Ages}

Until about 3,700 (C14) years ago, the area that is now the western Wadden Sea developed in more or less the same way as the western region of the Netherlands. After that, the area flooded and transformed into tidal flats. The pattern of peat bog formation and flooding dominated everywhere except at the higher-lying areas of Texel to about Harlingen. At the end of the Middle Ages, here too, an area of shallow tidal flats developed into intertidal flats we know from the time before the Zuider Sea (former IJsselmeer) was closed off. The highlying areas in the eastern Wadden Sea flooded some 3,000 years ago, bringing about the eastern extension of the wadden area.

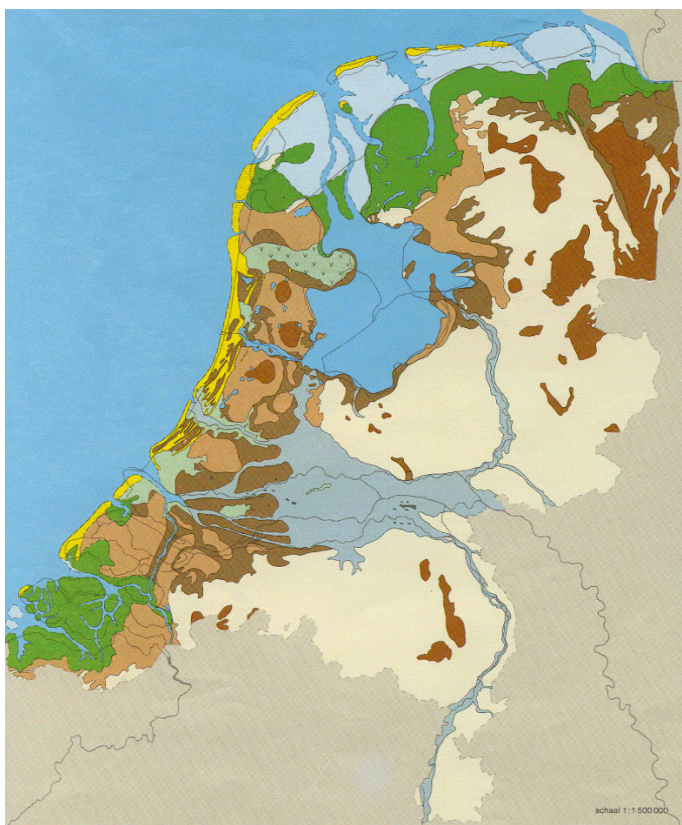

Figure 2.5: $\quad 3,700$ (C14)-Middle Ages; Formation of the present wadden environment, Zagwijn (1986) 


\section{Mankind intervenes}

\section{Post-Middle Ages until present}

Until the Middle Ages nature was the predominant forcing on the development of the Wadden Sea. After this period mankind steps in and introduces a new force on the system: human intervention in natural processes. Acts of intervention include dike construction, reclamation of land from the sea, peat-cutting, damming up of channels and parts of tidal basins. Also reinforcing existing dunes to serve as dikes, constructing jetties and large-scale activities as closing of the Zuider Sea (1932) and the Lauwers Sea (1969) have had a major influence on the development of the wadden system. Despite these interventions the Wadden Sea is far from 'fixed'. The system of deltas, channels, flats and island shoreline is still a highly dynamic one as is demonstrated by the shifting position of islands, island headlands and tidal channels.

\section{I.3 Differences between West and East}

Although the previous sections describe the historical development of Wadden Sea area as a whole, a distinct difference in development of the western and eastern part op the Wadden Sea exists. A major portion of the western Wadden Sea was created by human intervention combined with relative sea level rise. The eastern area (east of the Vliestroom Channel) developed into an intertidal area earlier due to the lower elevation of the Pleistocene surface, causing this area to be influenced by the sea sooner.

\section{Western Wadden Sea}

The early inhabitants of the western wadden dug ditches and channels to drain and empolder the lowlands and to cut peat for salt extraction and fuel. These human activities made the marshy area vulnerable to flooding and around 1,000 AD the sea penetrated this area and transformed it into tidal flats. The tidal basin increased in volume and the old peat in the wadden area was washed away, while the coasts of Noord-Holland, Texel, Eijerland and Vlieland were subjected to intense coastal erosion due to the inherent enlargement of the tidal basin. The erosion of old peat in the wadden area created a link between the intertidal wadden area with the inland fresh water lake (the Flevo) and finally resulted into the saltwater basin Zuider Sea. It took several centuries for man to regain land from the sea and to empolder parts of the western Wadden Sea and the Zuider Sea. This was done by constructing dikes along the northern coasts of what is presently known as Friesland and Groningen and it reached its climax with the closure of the Zuider Sea by the Afsluitdijk. To this day, the artificial interventions have had a major influence on the sediment management and the hydrodynamics of the western Wadden Sea.

\section{Eastern Wadden Sea}

Influenced by the rise of the sea level, the eastern Wadden Islands and the inlets have been moving landward for the past 5,000 years. Study of remainders of ancient outer deltas and filled-up channels of former tidal inlets has revealed that about 5,000 to 6,000(C14) years ago, the position of the coastlines of the islands of Ameland and Schiermonnikoog used to be further north by 11 to 15 kilometres. From the beginning of the Middle Ages the inhabitants started to protect the land from flooding and to empolder parts of the Wadden Sea. Later on 
parts of the Lauwers Sea and the Dollard estuary were empoldered, reducing the size of the sediment retention area. In response, the inlets and channels became shallower and together with the eroding island coasts, they shifted east and simultaneously towards the main land coast. Due to dune vegetation the rate at which the Wadden Islands migrated towards the coast slowed down in the second half of the Middle Ages. This dune vegetation considerably reduced the formation of new wash-overs and dune erosion. In spite of major changes caused by island migration and extensive empoldering, the shape of the eastern wadden system remained almost the same.

\subsection{Development of tidal inlet systems}

\subsection{Introduction}

In Section 2.1 we discussed the historical evolution of the area now know as the Wadden Sea on very large time- (centuries to millennia) and space-scales (development of entire coastal stretch). The large-scale development of a specific tidal inlet system can be described on a somewhat smaller scale, with time-scales of decades to centuries and space-scales covering the tidal inlet system as a whole.

According to Hayes(1979), the morphological state of an arbitrary tidal inlet system can be classified based on tidal range and wave energy. Hayes(1979) made a hydrodynamic classification in which he distinguishes five classes of tidal inlets with respect to tidal/wave dominance:

- Wave dominated inlets

- Mixed energy-wave dominated

- Mixed energy-tide dominated

- Low-tide dominated

- High-tide dominated

Wave dominated inlets have long continuous barriers, with only few tidal inlets and a lot of washovers. Mixed energy inlets (wave dominant) have a large number of inlets and a smaller number of washovers. The size of the ebb-tidal delta will become somewhat larger. Mixed energy inlets (tide dominant) have abundant tidal inlets and larger ebb-tidal deltas. Tide dominated inlets are characterised by predominant tidal current ridges, extensive salt marshes and tidal flats. Inlets of this type often have large ebb-tidal deltas and very deep inlet gorges.

Analogously, Eysink (1993) concluded that much of the large-scale tidal inlet morphology in the Wadden Sea depends on:

- Tidal range (Section 2.2.2)

- Seasonal waves and winds (Section 2.2.3)

- Geometry of the ebb-tidal delta (Section 2.2.4)

- Relative sea level rise (Section 2.2.5)

- Sediment retention and demand (Section 2.2.6)

This dependency hardly shows on a small time-scale (days to years), but manifests itself in changes in the wadden landscape that become significant over a time span of decades up to centuries. As such, the mentioned factors steer the large-scale morphological changes in the 
Wadden Sea tidal inlets. In the next sections an overview will be given of the most significant processes.

\subsubsection{Tidal range}

The tidal range determines most of the large-scale morphological behaviour of the wadden area. Outside the wadden area, the tidal range depends primarily on the ocean tides and their interaction with the continental shelf. The tidal motion at the North Sea is determined by the tide at the Atlantic Ocean. Along the Dutch coast, the tidal wave propagates from south to north and it enters the Wadden Sea through the tidal inlets, where the wave is reflected against the mainland coast. The tidal range has a minimum near Den Helder and increases towards the mouth of the River Elbe. Due to the limited depth in the tidal basins the tidal energy and celerity decreases. This results in the Wadden Sea in a complex interaction pattern of incoming and reflecting tidal wave components. In the relatively short tidal basins of the Wadden Sea (relative to the tidal wave length), the tidal wave is reflected and it has a more or less standing character.

The propagation of the tidal wave into the tidal basin means that a substantial water volume needs to pass the inlets each tidal cycle. This water volume, also known as the tidal volume, may be estimated by measuring the basin area up to the tidal limit and multiply it by its the tidal range. This gives us the tidal prism, which equals approximately half the tidal volume. The tidal volume causes high flow velocities at the inlet and negligible flow at the watershed behind the islands were the flood flows meet. Because of the low flow velocities at these watersheds the conditions for sedimentation are favourable and can be recognised as a relatively high ridge, which separates adjacent tidal basins.

To identify the effect of the tidal range (and thus the tidal volume) on the morphology of a tidal inlet system in general, Hayes (1979) made five tidal classifications, shown in Table 2.1.

Table 2.1: Tidal Classification

\begin{tabular}{lc}
\hline Classification & Tidal Range $(\mathrm{m})$ \\
\hline Microtidal & $<1.0$ \\
Low mesotidal & $1.0 \mathrm{~m}-2.0$ \\
High mesotidal & $2.0 \mathrm{~m}-3.5$ \\
Low macrotidal & $3.5 \mathrm{~m}-5.5$ \\
High macrotidal & $>5.5$ \\
\hline
\end{tabular}

A microtidal range is commonly found in combination with relatively small tidal inlets in between barrier islands. The deltas in offshore direction of these inlets do not become very large. A mesotidal range is favourable for the maintenance of smaller barrier islands, large inlets and large ebb-tidal deltas, for example the barrier coast of the Dutch Wadden Sea. An inverse relation between tidal range and length of a barrier island seems to exist: ever-larger tidal ranges apparently result in ever-shorter barrier islands. A mesotidal range seems to encourage the formation of tidal flats and salt marshes to a larger extent. A macrotidal range induces a coastline of tidal flats and flat marshes, in which barrier islands and ebb-tidal deltas are absent, for example the German Bight. 


\subsubsection{Seasonal Waves and Wind}

Beside the considerable influence of the tidal range / tidal volume on the morphology of the tidal inlets in the Wadden Sea, seasonal waves and wind have their own distinct impact on the morphological development of the inlets.

\section{Waves}

Generally, wave action is considered to act as a bulldozer on the seaward tidal inlet morphology (Hageman, 1969). The wave-generated longshore currents transport the sediment of the seaward extending ebb-tidal delta onshore and so limit the area over which the ebbtidal delta can spread. Because waves generally break at a water depth of about twice their height, only a very limited amount of wave energy can pass the shoals of the ebb-tidal delta and enter the basin (Eysink and Biegel, 1992).

As for the tidal range, a general classification for the effect of waves on the tidal inlet morphology can be made, characterised by the yearly mean significant wave height $\mathrm{H}_{\mathrm{s}}$, see Table 2.2. Hayes (1979) used this wave classification for his hydrodynamic classification of tidal inlets with respect to tidal/wave dominance (see Section 2.2.1).

Table 2.2: Wave Classification

\begin{tabular}{lc}
\hline Classification & Wave Height $\mathrm{H}_{\mathrm{s}}(\mathrm{m})$ \\
\hline Low wave energy & $<0.6$ \\
Medium wave energy & $0.6-1.5$ \\
High wave energy & $>1.5$ \\
\hline
\end{tabular}

For the Wadden Sea inlets (medium wave energy), Eysink (1993) found that the effect of sea waves and swell from the North Sea remains limited to the area near the inlets. Inside the Wadden Sea waves are primarily generated by local winds. Only during a severe storm surge, part of the North Sea waves and swell will penetrate the Wadden Sea and break on the first tidal flats inside the basin.

\section{Wind}

Wind may have an important effect on the water motion in the Wadden Sea. It generates a shear stress at the water surface which causes drift currents and wind waves. If a drift current is directed to or from a coast, the flow component perpendicular to the coast ultimately is compensated by a 'return flow' generated by a slope in the water surface. The net result is a vertical circulation where the flow at the bed opposes the cross-shore wind component. Towards the coast, this slope results in a wind set-up or set-down. In a complex geometry with flats and channels, like a tidal basin, the 'return flow' is likely to concentrate in the relatively deep areas. This creates a complicated flow pattern of tidal flow with wind-induced drift currents and return flow. In the general the tidal flow will dominate but on the tidal flats and at the watersheds the opposite may occur during conditions with strong winds.

\subsubsection{Geometry of ebb-tidal delta}

A third feature, influencing the large-scale morphology of a tidal inlet system, is the geometry of the ebb-tidal delta. The large-scale orientation (direction) of the ebb-tidal delta (which consists of ebb and flood channels, marginal bars and swash platforms) largely depends on 
the offshore wave climate and the characteristics of the tidal regime. This is described by Van den Berg and Sha (1993), who used tidal inlets in the south-western part of the Netherlands and those at the western Wadden Sea as study material. According to Van den Berg and Sha the phase difference between the horizontal and the vertical tide can have significant influence on the orientation of the delta and of the ebb- and flood-channels.

For the ebb-tidal deltas in the western Wadden Sea, where there is no phase difference between the horizontal and vertical tide, the tidal currents reach their maximum value around the mid-tide water level. At the same time the tidal discharge through the inlet is maximal. The tidal slack waters (for high and low water) occur almost simultaneously within the inlet throat and the adjacent offshore area.

Mid-flood

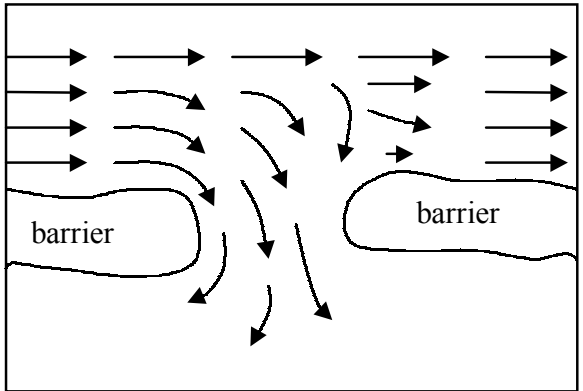

Mid-ebb

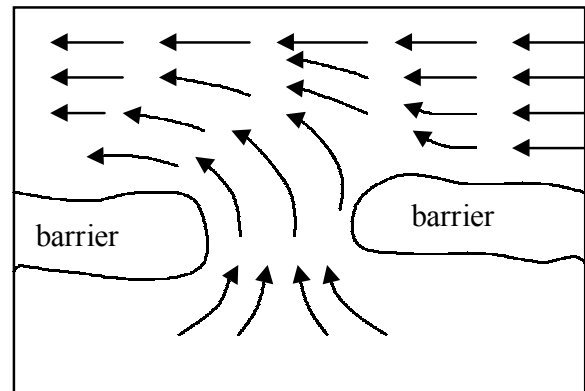

Figure 2.6: The interaction of inlet tidal currents with offshore tidal currents at mid-flood and mid-ebb stage; the tidal wave propagates from the left (west) to the right (east).

The interaction between inlet tidal currents and offshore tidal currents at flood and at ebb under such a tidal regime is illustrated in Figure 2.6. At flood, tidal currents approach the inlet from the left side of the inlet; at ebb, tidal currents are also concentrated on the left part of the ebb-tidal delta. This is the main reason that the main ebb channels in the ebb-tidal deltas of the Marsdiep, the Vlie and the Amelander Zeegat are directed to the west. For the same reason, the seaward end of the deltas generally bends to the west.

\subsubsection{Relative Sea Level Rise}

The fourth process influencing the large-scale morphological evolution of the tidal inlet systems in the Wadden Sea is the persistently rise of the sea level. According to Louters and Gerritsen (1994), the mean sea level has been rising for more than a hundred centuries. In the last Ice Age (which ended about 10,000 years ago), when the area of the Netherlands remained free of ice, most of the North Sea was dry. As the climate became warmer, the North European ice-cap thawed and the sea level rose by 120 to 140 metres. This rise in sea level was very rapid at first; later, the rate gradually decreased. In general, the sea level has gradually risen in the past thousand years. The sea level only dropped in the Late Middle Ages (the 'little' Ice Age). Circa 1850, the average temperature began rising again, mountain glaciers shrank and the sea level along the Dutch coast rose by some twenty to thirty centimetres, regaining the level of the Early Middle Ages. According to Rakhorst (2000), measurements of the mean sea level along the northern Dutch coast over the past 150 years reveal a fairly constant increase of $14-17 \mathrm{~cm}$ per century. This rise in sea level is probably still the ongoing effect of the last Ice Age (see Figure 2.7). 


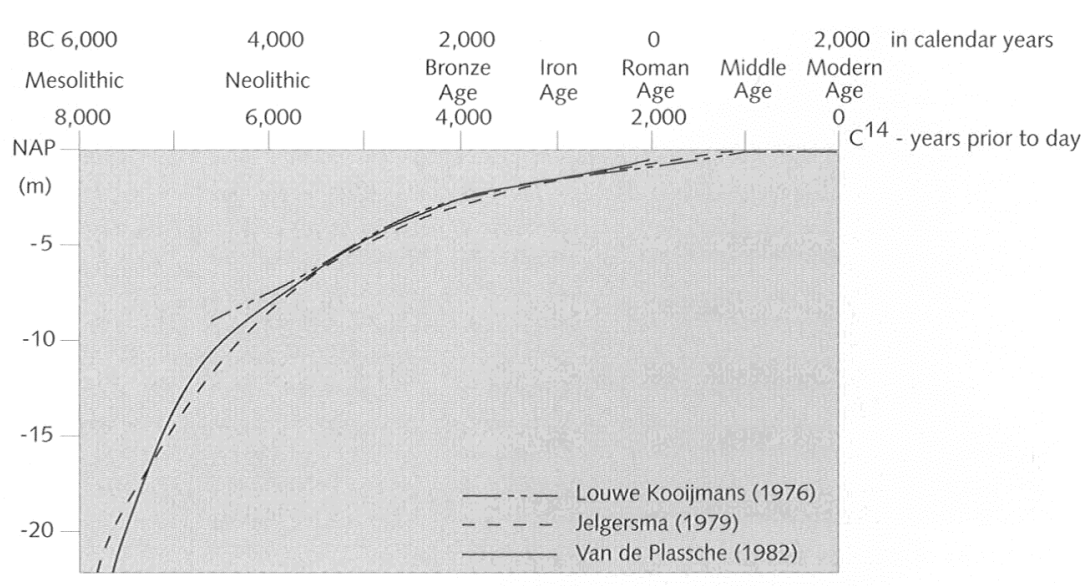

Figure 2.7: Development of Sea Level Rise from 6,000 BC to 2,000 AD

However, recent studies by the KNMI (Royal Netherlands Meteorological Institute) and the IPCC (Intergovernmental Panel on Climate Change), indicate that a dramatic change in global climate is to be expected. According to the IPPC, there is no scientific doubt that the atmospheric concentrations of a number of 'greenhouse gases' capable of global warming have increased due to human activities (IPCC 2001). It is generally accepted within the scientific community that the continuing increase in greenhouse gas concentrations will result in substantial global warming. There is, however, uncertainty about the magnitude and timing of the warming.

Predictions of climate change depend on the validity of the climate models and the accuracy with which trends in the greenhouse gas emissions and atmospheric concentrations are simulated. Despite the uncertainties in this data, the best models available today are consistent with one another in indicating a rise of global mean temperature. There is also a general consensus that global warming will be accompanied by a rise in global mean sea level. The predicted rise is mainly caused by thermal expansion of ocean water, melting of ice sheets and glaciers make a smaller contribution, while the projected increase in snowfall on Greenland and Antarctica has an opposite contribution. In the long-term (centuries) this opposite contribution will diminish while the probability of a decrease in ice volume will grow.

The best estimate for the policy scenario 'Business As Usual' is that the sea level rise will amount between about 8 and $29 \mathrm{~cm}$ by 2030, and between 31 and $110 \mathrm{~cm}$ by 2100 (Vellinga, 2000), with $56 \mathrm{~cm}$ as the best estimate of the average rise by 2100 . For the Netherlands, the sea level could, in the worst, realistic, scenario rise by some $85 \mathrm{~cm}$ in 2100 (see Figure 2.8).

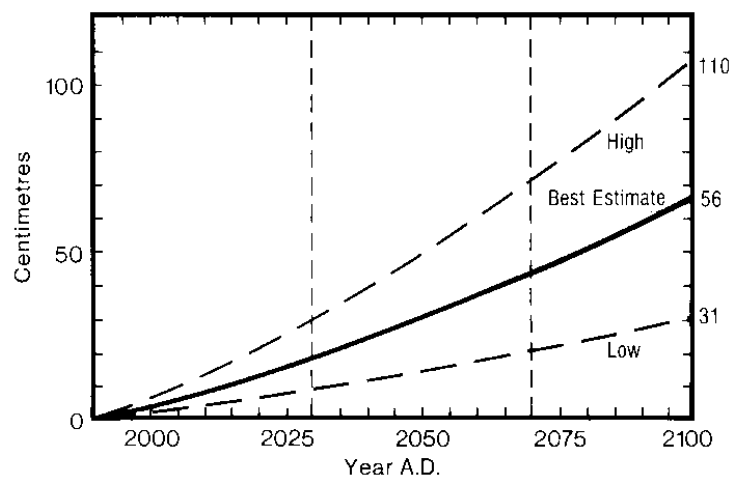

Figure 2.8: Estimates for accelerated rate of Sea Level Rise (Vellinga,2000) 
Climate models predict the sea level to rise continuously over many centuries, even after stabilisation of the concentration of greenhouse gases. This leads to sea level rise projections for 2300 that are a factor 2 to 4 greater than the 2100 projections, resulting in a best estimate sea level rise of $0.5 \mathrm{~m}$ to $2.0 \mathrm{~m}$ by 2300 .

\section{Relative Sea Level Rise: also influenced by sea floor subsidence}

The distance between the sea surface and floor along the Dutch coast is increasing not only as a result of the sea level rise, but also because the seabed is subsiding. This combined action is what we call relative sea level rise (see Figure 2.9).

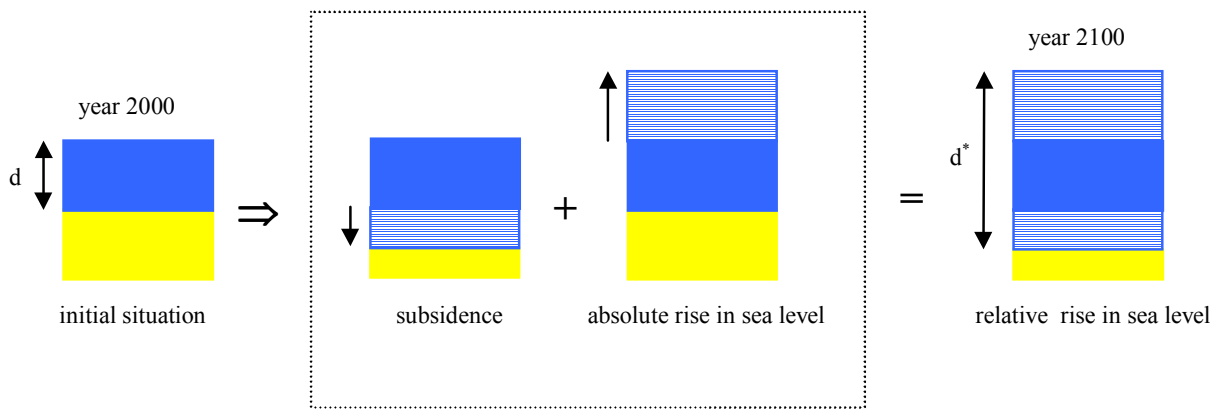

Figure 2.9: Relative Sea Level Rise; also influenced by sea floor subsidence

A recent study carried out in connection with the Normal Amsterdam Level (NAP) proved that the level of deep substratum of the coast changes. A natural process of sea floor subsidence has been discovered, which varies from 4 to $8 \mathrm{~cm}$ per century along the Dutch coast. This natural shift in ground level has been evenly and is related to known geological structures in the substrata. Since the downward movement is the result of large-scale geological processes, we can draw the tentative conclusion that comparable ground shifts will occur in the century to come.

In addition to the natural subsidence, a smaller-scale process of accelerated subsidence is caused by human activity. This human activity can been seen on different spatial scales. On the local scale the subsidence can be due to the result of sand mining. On a regional scale the sea bed subsidence can be caused by the extraction of gas.

\subsubsection{Sediment retention mechanism}

Under the present forcing of steady relative sea level rise, we presume the system of coastal inlet and tidal basin (also referred to as tidal inlet) in a dynamic equilibrium. This means that the depth increase by the present sea level rise is compensated by a similar depth decrease by sediment entrapment in the basin. However, when the rate at which the sea level rises accelerates, the tidal inlet system is slightly thrown off its dynamic equilibrium balance and becomes somewhat deeper and develops and increased need of sediment.

The need of sediment (which in geological context is considered as a positive accommodation space) can be explained by the slight depth increase of the system, which causes a slight reduction in the average current speeds in the channels and over the flats. As there is a quadratic relation between sediment transport and current velocity, the transport capacity will drop much more than the current velocity. The flood stream carrying a sediment load can then deposit sediment in the tidal basin. The ebb stream does not have enough force to remove the 
total quantity of sediment brought in. Thus, over a long period, the quantity of sediment that is being transported into the basin is on the average larger than the quantity that is being transported out.

This process is called the sediment retention mechanism of a deepened basin. In the beginning of this process, the sediment retention capacity of the deepened basin gradually increases. The more the sea level rises, the greater the increase in retention capacity, until a 'new' dynamic equilibrium is reached (see Figure 2.10). The system's response to the rise is delayed and the average basin level thereby becomes slightly lower in relation to the sea level ( $\Delta \mathrm{d}$ in Figure 2.10). The development of the system into a 'new' state of dynamic equilibrium is contingent upon the degree of rise in sea level and the supply of sediment from the adjacent coasts and offshore region. When the system has reached a 'new' state of dynamic equilibrium, the depth increase $\Delta \mathrm{d}$ does not increase with time.

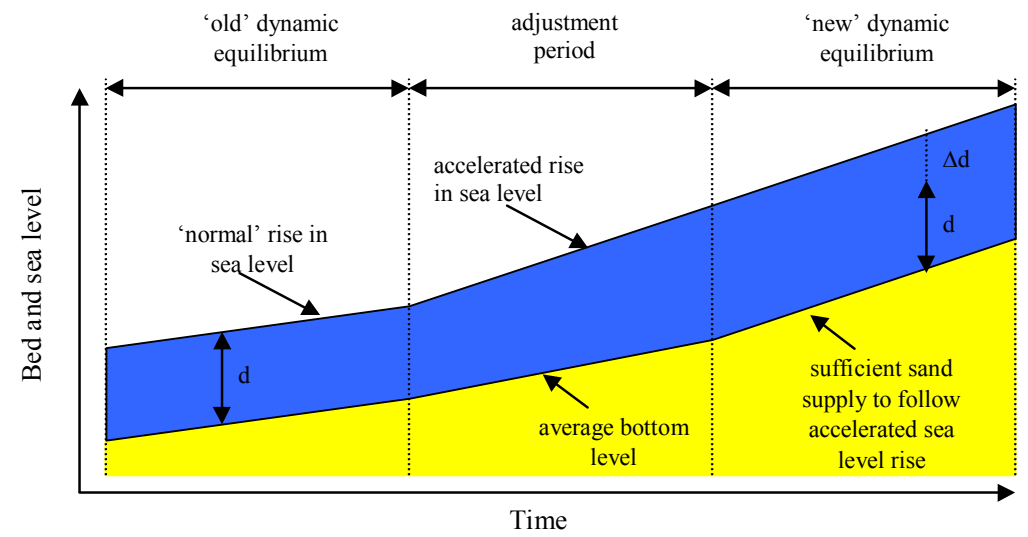

Figure 2.10: Tidal inlet system adapting to accelerated Relative Sea Level Rise and regaining a new state of dynamic equilibrium.

If the supply or the rate of the supply of sediment is not sufficient to allow the tidal area to keep pace with the sea level rise, a new dynamic equilibrium cannot be reached (see Figure $2.11, \Delta \mathrm{d}$ increases continuously with time). In that case, the wadden area will gradually and persistently lag behind the rise of the sea level, eventually brining about the drowning of the system.

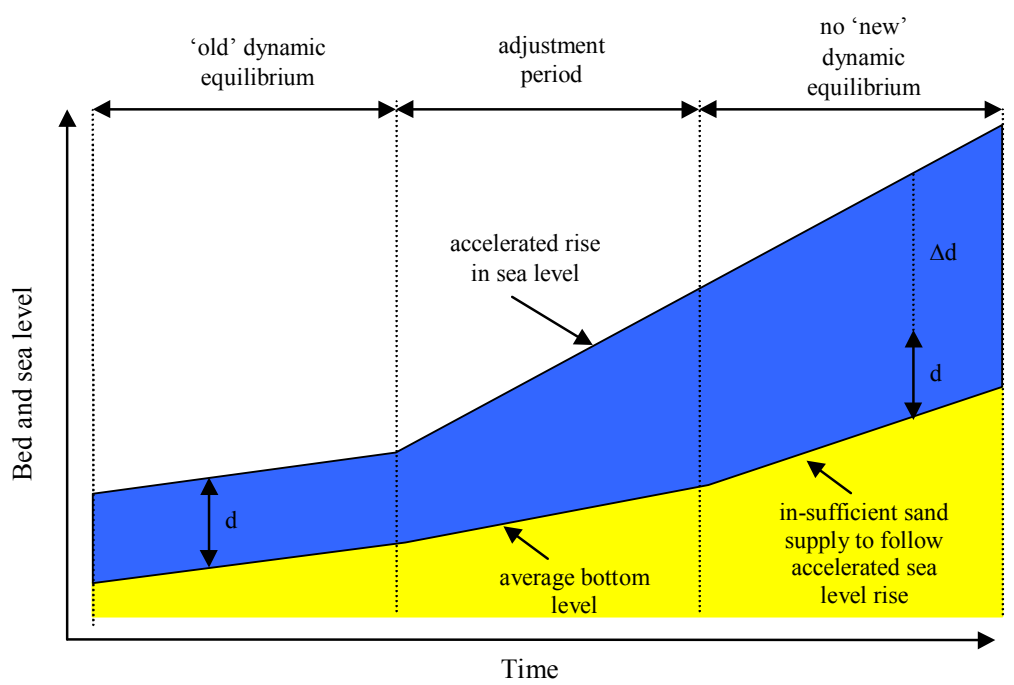

Figure 2.11: Tidal inlet system unable to adapt to accelerated Sea Level Rise and not able to regaining a new state of dynamic equilibrium. 


\subsection{Elements of a tidal inlet}

\subsection{Introduction}

In Section 2.2 we discussed the morphological processes determinative for the morphological development of a tidal inlet system with a time-scale in the order of centuries and spacescales covering the tidal inlet system as a whole. Because our modelling scale of interest (see Chapter 3) applies to time-scales of decades to centuries and space-scales covering distinct morphological elements of the tidal inlet system, we have to take one step further in defining morphological elements and processes.

To distinguish distinct morphological elements and their accompanying morphological processes we may identify two areas in the tidal inlet system, namely the coastal inlet and tidal basin area. In coastal inlet area we may distinguish the morphological elements ebb-tidal delta and adjacent coastal stretch. The morphological development of this area is mainly related to the hydrodynamic forcing of tidal prism and offshore waves. In tidal basin area we may distinguish the morphological elements channels and tidal flats which are bounded by the watersheds. The morphological development in the tidal basin is mainly related to the tidal range and the horizontal area of the basin.

In the following sections a description is given of both areas and their accompanying morphological elements.

\subsubsection{Coastal inlet}

Generally, coastal inlets have a variety of forms. Many inlets are associated with barrier islands, where the inlets connect the ocean to the tidal basins containing marshes and tidal flats. Due to the influence of waves and tidal prism, sediment is transported into and out of the coastal inlet where it can be deposited in the form of a flood tidal delta in the tidal basin area and, respectively, in the form of an ebb-tidal delta seaward in the coastal inlet area. In the inlets of the Dutch Wadden Sea both forms of deltas are present. In the tidal basin area the flood delta has grown to such an extend that it covers the whole inter tidal flat area. In the coastal inlet area we may distinguish an ebb-tidal delta. The ebb-tidal delta forms a distinct morphological element in the coastal inlet area. The processes influencing the morphological development of the ebb-tidal delta are discussed in the following paragraphs.

\section{Ebb-tidal delta}

As briefly described in Section 2.2.1, three general types of inlets can be distinguished; tidedominated, mixed energy, and wave dominated inlets. This means for the ebb-tidal delta we have tide dominated deltas which tend to protrude into the sea at essentially right angels relative to the shoreline and have well-developed sandbars along their margins. Mixed-energy deltas generally have a smooth and curved outer sandbar (due to wave influence), whereas wave-dominated deltas are small and have very little accumulated sediment. In the Dutch Wadden Sea we find mixed energy-tide dominated ebb-tidal deltas which generally have the form as presented in Figure 2.12. 


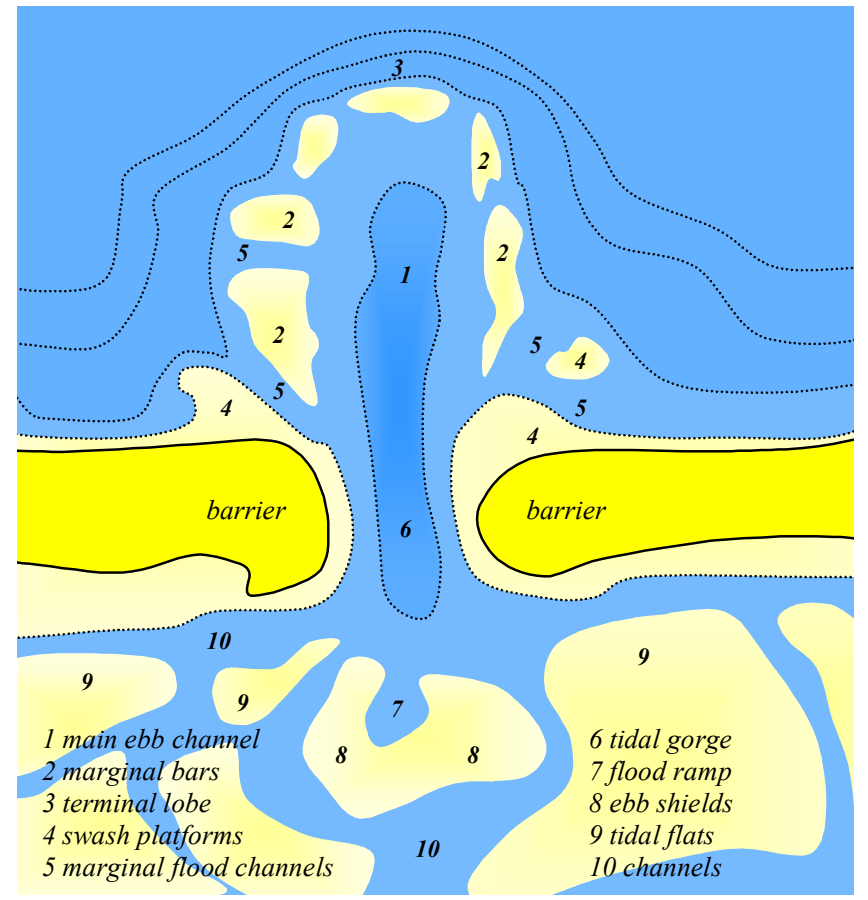

Figure 2.12: Layout of a typical ebb-tidal delta

A typical mixed energy-tide dominated ebb-tidal delta includes a main ebb channel (1), channel margin linear bars (2), a terminal lobe (3), swash platforms and bars (4) and marginal flood channels (5).

The channel margin linear bars flank the ebb-tidal channel and are deposits built up by the interaction between flood, ebb and wave generated currents (see Figure 2.15). In the Dutch inlets these distinct bars are not recognisable, in stead, there are wide flats On these wide flats, which act as swash platforms, isolated swash bars can be recognised, built up by action of waves. Marginal flood channels usually occur between the barrier island coast and the swash platforms. The terminal lobe is a rather steep seaward-sloping body of sand, which forms the outer end of the ebb-tidal delta.

Considering the ebb-tidal delta as an element of the tidal inlet, we may define the volume of the ebb-tidal delta via the no-inlet bathymetry (Dean and Walton, 1975). In the no-inlet bathymetry the coastal slope is assumed undisturbed by the coastal inlet and therefore assumed equal to the bathymetry of the adjacent barrier coast. Where the difference in bed level between the actual and no-inlet bathymetry is nil results in morphological boundary of the ebb-tidal delta. The volume of sediment above this no-inlet bathymetry is considered as the ebb-tidal delta sediment volume, representing its morphological state (see Figure 2.13).

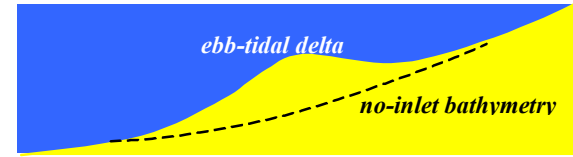

Figure 2.13: Cross-section of ebb-tidal delta, indicating the cross-shore boundaries by the no-inlet bathymetry 
The tide and wave-generated currents transport sediment from and into the inlet. The strong ebb jet blasts sand out of the inlet, waves and flood currents bring the sand back into the inlet (see Figure 2.14). Dean and Walton (1975) concluded that the strong ebb jet entrains adjacent water, which flows inward through the marginal flood channels and then outward through the main ebb channel. According to Hayes et al. (1970) a persistent current inward the delta can also result from strong wave refraction over the ebb-tidal delta shoals. This drift promotes sedimentation of sand on the down-drift barrier (relative to the wave-generated current), resulting in a down-drift offset of the beach (see accretional area in Figure 2.14). On the updrift side of the inlet the longshore current combines with the flood tides to carry sand into the inlet. However, during strong ebb tides the longshore current is pushed seaward towards the ebb-delta shoals.

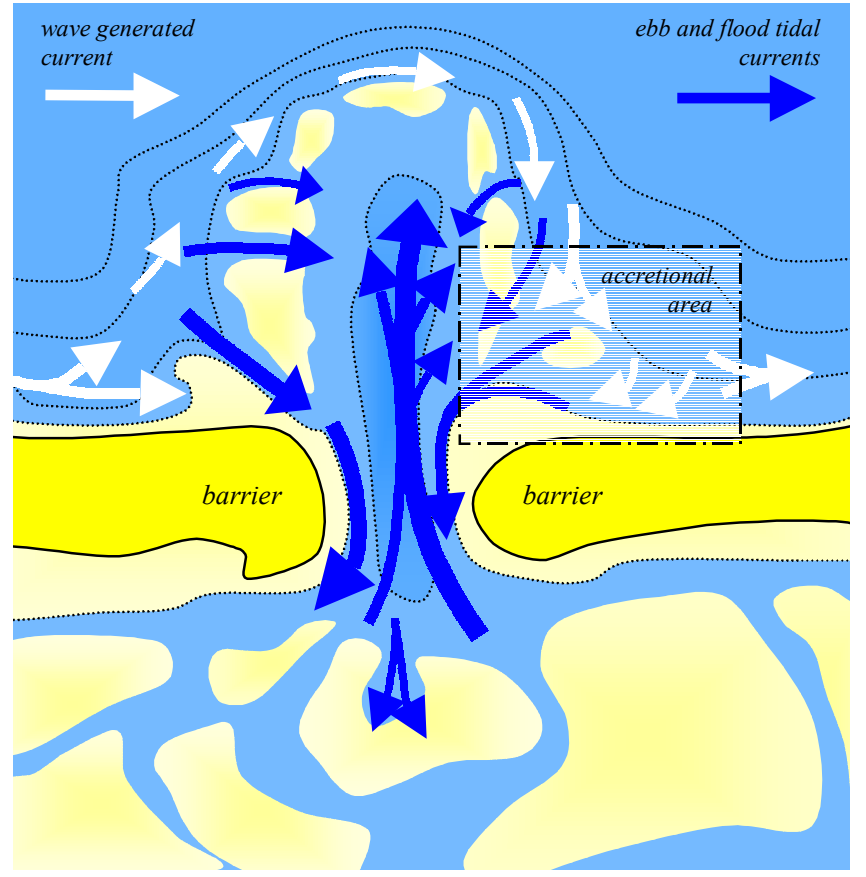

Figure 2.14: Tidal and Wave driven currents in ebb-tidal delta

In contrast, along the down-drift side of the inlet, which is partly sheltered from the waves by offshore shoals, even during ebb tides there is an inward flowing current that joins the seaward ebb flow concentrated within the main channel. The net motion carries sand into the area of the down-drift shore (sediment bypassing), where it is deposited, resulting in a accretional down-drift shore and possible up-drift migration of the inlet (see Figure 2.14).

From the description of the ebb-tidal delta we may derive another morphological element presenting itself in the coastal inlet area, namely the coastal stretch adjacent to the ebb-tidal delta. In next paragraph a brief description of the interaction between the ebb-tidal delta and the adjacent coastal stretch is given, followed by a description of the inlet stability and sediment bypassing processes which mainly determine the morphological development of the coastal inlet area as a whole.

\section{Adjacent coastal stretch}

According to FitzGerald (1996), ebb-tidal deltas are important permanent and temporary sand reservoirs. They have strong influence on the distribution of wave energy along the inlet 
shoreline and dictate where sand is added to the down-drift beach in the processes of sediment bypassing. Fenster and Dolan (1996) investigated the impact of tidal inlets on adjacent shorelines for the wave dominated Outer Banks of North Carolina and the mixed-energywave dominated Virginia Barrier Islands. They determined that the maximum distance of inlet influence extends to $6.8 \mathrm{~km}$ up-drift and $5.4 \mathrm{~km}$ down-drift of the tide dominated inlets along the Virginia barrier islands. For the wave dominated Outer Bank barrier the influence of the inlet reached $6.1 \mathrm{~km}$ for the up-drift and $13.0 \mathrm{~km}$ for the down-drift inlet shorelines. According to Fenster and Dolan, sand-bypassing processes exert greater influence on mixedenergy, short barrier island shorelines than on wave-dominated, long linear barrier island shorelines.

\section{Inlet stability and sediment bypassing}

In general, many processes affect the stability of an inlet; important ones are the tidal currents, tidal prism, littoral sediment transport and storms. According to Bruun and Gerritsen (1959) and to FitzGerald (1988), three explanatory models for inlet stability and sediment bypassing along mixed energy coasts exists.

If the littoral (longshore) sediment transport is the predominant process, it can cause constriction of the inlet throat. The decrease in cross-sectional area will result in greater scouring capacities in the inlet, which will cause erosion of the down-drift barrier beaches. The rate of migration is dependent on sediment supply, wave energy, tidal currents and the composition of the ebb and flood channel banks. When after a storm, a short cut through the up-drift coastal stretch has been created, the new channel will take over from the old one. This process can be classified as inlet migration and split branching.

When inlets have a stable throat position and a non-migrating main ebb channel, sediment bypassing at the inlets occurs through the formation of bars that migrate and attach to the down-drift coast (bypassing via offshore bars). These large bars have been formed by stacking and coalescing of wave built accumulations of swash bars on the ebb-tidal delta platform. Due to flood dominance at these parts of the ebb-tidal delta in combination with breaking and shoaling waves, the swash bars move onshore.

Tidal inlets that bypass sediments by ebb-tidal delta breaching have a stable inlet throat position, but a variable position of the main ebb-tidal channel. The main ebb channel will be pushed towards the down-drift coast by the predominant littoral drift. The flow efficiency of this elongated channel decreases and hydraulic gradients over the bars steadily increase. The inlet will divert its flow to a more seaward direction via so-called spillover lobe channels. Consequently, the discharge through the degenerated ebb channel decreases and as a result a large portion of the ebb-tidal delta sand body is bypassed (bypassing by tidal flow action).

According to FitzGerald (1988) in actual tidal inlets all three-bypass processes can occur simultaneously or may dominate alternately. The movement of sand along the terminal lobe by wave action is almost always present at mixed-energy coasts. 


\subsubsection{Tidal basin}

The characteristic morphology of tidal basins area (see Figure 2.15) is that of a meandering, braided and/or branched channel system, ebb- and flood chutes, inter-tidal sand and mud flats and marshes.

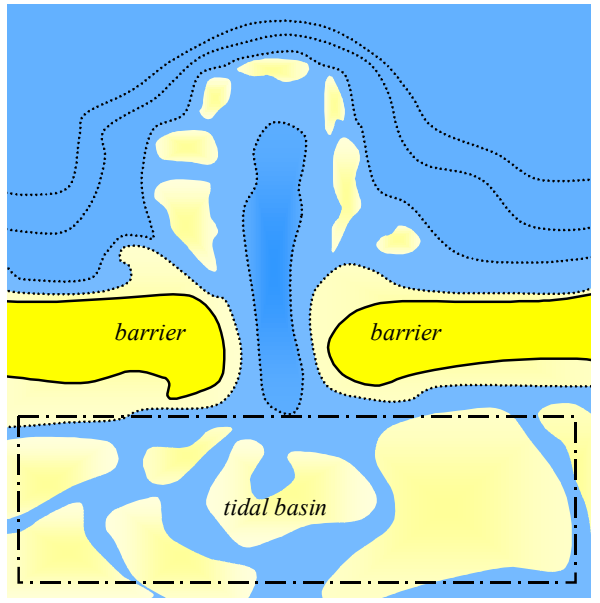

Figure 2.15: Location of tidal basin

Along barrier island coasts of the Dutch Wadden Sea, the basins are often rectangular or near square and the channel structure is often more branched than braided. In the tidal basin a distinction can be made between two morphological elements: tidal flats and channels.

We may define the channels as water volumes between the Mean Low Water (MLW) and the bed level. The flats can be defined as sediment volumes above MLW. Although it is easy to schematise the morphological elements channel and flat this way, one must keep in mind that they form one system in which the flat and channel influence each other. In the following paragraphs we review both morphological elements with their determinative morphological processes.

\section{Channels}

The channels in the tidal basin are the veins of the system; sediment is transported through these channels both from and to the tidal flats. If one considers the shape of the channels (for example of the Wadden Sea) one will see that all channel systems seem to have similar branching pattern (Cleveringa, Oost and De Boer, 1997). The pattern has the same characteristic as a four-time branching net work. Below the one-kilometre scale the branching does not continue, which can be explained with the fact that each of the smallest branches has a minimum drainage area. Near the inlet, the depth and width of the channels is largest. Away from the inlet, into the basin, the channels get smaller.

According to Eysink (1994), a rather firm relation exists between the cross-sectional area of tidal channels and the tidal volume when the tidal inlet system is in a state morphological equilibrium. This makes it likely that the volume of the channel behind a certain cross-section (of the channel) is related to the tidal volume at that cross-section. For basins of the Wadden Sea and the Dutch Delta area, such relations have been proven to exist (Renger and Paternscky, 1974, 1980; Renger, 1976; Eysink, 1979, 1990, 1991; Dieckmann, 1985; Dieckmann and Paternscky, 1986). For the mentioned relations we refer to Section 2.4. 
From these relations it can be concluded that the channel volume will change if the tidal volume / tidal prism is changed by man or by natural causes. This is clearly confirmed by field observations, e.g. in the basin of the Zoutkamperlaag after closure of the Lauwers Sea in 1969 (Eysink, 1990).

\section{Tidal Flats}

The tidal flat area or the intertidal zone is the area that normally inundates and dries during the tidal cycle. It is of great importance as feeding ground for many birds and it can be a resting-place for seals.

Eysink (1993) found that, according to general classifications of coastal features, the presence of tidal flats mainly depends on the tidal range, basin area, shape of the basin and the orientation of the basin relative to the dominating wind direction. Large tidal basins, especially long basins orientated in the direction of the dominant wind, allow significant wave action around High Water (HW) because of to the considerable fetch lengths. This very likely prevents the growth of extensive areas of tidal flats to a height above MLW in these tidal basins.

According to Eysink(1993), tidal flats grow out of emerging shoals and range from small or relatively narrow low flats in or along large tidal channels to wide and high tidal flats. In the Dutch Wadden Sea the crest levels of most of the flats range between MSL and MHW-0.3 m. The crest of the flats is located at the local watershed between two channels and generally the level seems more or less related to the width of the flat. A second factor governing the crest height of the flat seems to be the stability of the watershed. If it is rather stable in the sense that its position hardly varies between high and low tide for one tidal cycle to another, the crest level will be relatively high. Therefore we may summarise that the height of the tidal flats is related to the tidal range (especially MHW), basin area and the local flow and wave conditions.

\subsubsection{Summary}

In the foregoing sections we have distinguished several morphological elements in a tidal inlet system, which correspond with the time- and space-scale of our interest. The distinguished morphological elements are the ebb-tidal delta and adjacent coastal stretch in the coastal inlet area and the channel and tidal flat in the tidal basin area.

Furthermore we derived that the morphological processes in an element are mainly related to the hydrodynamic (e.g. tidal volume/prism and the offshore wave climate) and morphometric (e.g. tidal basin area) values present in the element. Therefore we may tentatively assume that the morphological equilibrium state (e.g. volume) of an element is related to these hydrodynamic and morphometric values. A summary of empirical relations describing the relationship between the morphological equilibrium state (volume) of an element and the present hydrodynamic and morphometric values is given in Section 2.4. 


\subsection{Equilibrium relations}

\subsection{Introduction}

When in a state of morphological balance, relationships exist between the element equilibrium state (volume) and the present morphometric and hydrodynamic values. These relationships enable us to predict new morphological equilibrium states of the element if changes occur in morphometric or hydrodynamic values present, whether caused by human intervention or natural processes.

In the following sections a description is given for a number of empirical relations between the morphometric and hydrodynamics values, on the one hand, and equilibrium states (volumes) of the morphological elements (as derived in Section 2.3), on the other.

\subsubsection{Empirical Equilibrium relations}

One of the key forces behind morphological changes in a tidal area is the tidal volume. A great deal of research has been done to determine the relationship between the morphological balance of the tidal inlets and the tidal volume. The basics for these relations are founded in the United States by O'Brien (1931,1967), Jarret (1976) and Walton and Adams (1976). For the Dutch deltas adaptations where made by Gerritsen and De Jong $(1983,1984)$ and Gerritsen (1990). Broad literature surveys of these empirical relations for both Dutch and foreign inlets are given by for instance Biegel (1991), Van Kleef (1991) and Eysink and Biegel (1992).

First two basic definitions are given regarding the tidal volume and the tidal prism:

The tidal volume is the volume of water entering the tidal basin during flood (flood volume) plus the volume of water that is flushed out of the tidal basin during ebb (ebb volume). It is based on discharge measurements in the tidal basin.

The mean tidal prism is equal to the water volume between Mean Low Water (MLW) and Mean High Water (MHW) in the tidal basin. It is based usually on systematic bathymetric surveys of the tidal basin. In relatively short basins (relative to the length of the tidal wave) the tidal motion is that of a standing wave which results in a tidal volume of about twice the tidal prism. Eysink uses in his studies the term characteristic tidal volume, which is equal to the tidal prism.

In this report we will mainly use the tidal prism as characteristic parameter for the hydrodynamic forcing in the tidal inlet.

\subsubsection{Relationship between cross-section and tidal prism}

A typical unit of measure for an inlet is the narrowest cross-section at the opening between two barrier islands. A clear connection has been established between the size of this crosssection and the tidal prism. Empirical study has shown that the cross-section of an inlet increases almost linearly with the tidal prism. According to Van Kleef (1991) this is one of the best-investigated empirical relationships between hydraulic and morphological parameters. 
In 1985 Gerritsen and De Jong found for the western part of the Wadden Sea the following relation:

$$
T V_{\text {throat }}=3.3 \cdot 10^{4}[\mathrm{~m}] \cdot A_{\text {channel, throat }}-79.2 \cdot 10^{6}\left[\mathrm{~m}^{3}\right]
$$

where:

$$
\begin{array}{ll}
A_{\text {chamel, } \text {,troat }} & \text { Cross-sectional area at the throat of the inlet }\left[\mathrm{m}^{2}\right] \\
\left.T V_{\text {chamel }}\right] \text {, throat } & \text { Tidal volume at the throat }\left[\mathrm{m}^{3}\right]
\end{array}
$$

Misdorp et al. (1990) found for the western Wadden Sea inlets almost the same relationship as Gerritsen and De Jong did:

$$
T V_{\text {throat }}=3.6 \cdot 10^{4}[\mathrm{~m}] \cdot A_{\text {channel, throat }}-152 \cdot 10^{6}\left[\mathrm{~m}^{3}\right]
$$

Eysink (1990) stated that for 'throat area - tidal prism' relationship a fairly good description is presented by:

$$
A_{M S L}=\alpha_{A} \cdot V_{c t v}
$$

where:
$A_{\text {MSL }} \quad$ Flow area below MSL (Mean Sea Level) $\left[\mathrm{m}^{2}\right]$
$\alpha_{A} \quad$ Empirical coefficient for the equilibrium flow area $\left[\mathrm{m}^{-1}\right]$
$V_{c t v} \quad$ Characteristic tidal volume / mean tidal prism $\left[\mathrm{m}^{3}\right]$

For the Wadden Sea $\alpha_{A}$ is equal to $70 \cdot 10^{-6}\left[\mathrm{~m}^{-1}\right]$ (relative to MLW), for the Western Scheldt $\alpha_{A}$ is equal to $80 \cdot 10^{-6}\left[\mathrm{~m}^{-1}\right]$ (relative to MSL) and for tidal inlets on the East Coast of the United States $\alpha_{A}$ is equal to $85 \cdot 10^{-6}\left[\mathrm{~m}^{-1}\right]$ (relative to MSL).

\subsubsection{Relationship between channel volume and tidal prism}

The rather firm relation between the size of a tidal channel and the tidal prism makes it likely that also the volume of the channel system behind a certain channel cross-section is related to the tidal prism at that cross-section (Eysink, 1990). Plotting data of the channel volumes of the different tidal basins of the Wadden Sea versus their tidal volumes shows such a relation (See Figure 2.16).

The following relation is valid for the channel volume of a tidal basin with minor upland discharge (meaning channels that are getting narrower farther from the inlet away):

$$
V_{\text {channel }}=\alpha_{c} \cdot V_{c t v}^{1.5}
$$

where:

$V_{\text {channel }}$ Channel (water) volume below MSL $\left[\mathrm{m}^{3}\right]$

$\alpha_{c} \quad$ Empirical coefficient for the equilibrium volume $\left[\mathrm{m}^{-1.5}\right]$

$V_{c v v} \quad$ Characteristic tidal volume / mean tidal prism $\left[\mathrm{m}^{3}\right]$ 
Eysink and Biegel (1992) also found a relation between the tidal prism and the channel volume below MLW:

$$
V_{\text {chamel }}=16 \cdot 10^{-6}\left[m^{-1.55}\right] \cdot P^{1.55}
$$

where:

$$
\begin{array}{ll}
V_{\text {chamel }} & \text { Channel (water) volume below MSL }\left[\mathrm{m}^{3}\right] \\
P & \text { Tidal Prism }\left[\mathrm{m}^{3}\right]
\end{array}
$$

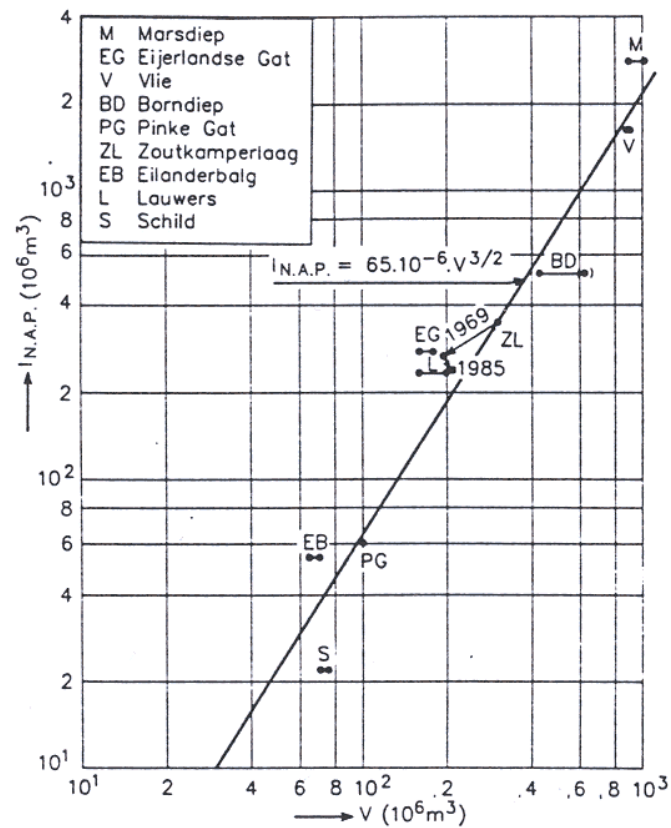

Figure 2.16: Channel volume - characteristic tidal volume relationship by Eysink (1990)

\subsubsection{Relationship between volume of ebb-tidal delta and tidal prism}

The ebb-tidal delta is a 'storehouse' for a large quantity of sediment. Walton and Adams (1976) found that the volume of the ebb-tidal delta depends on the tidal prism and on the total wave energy available for the transport processes. They derived their relations for inlets on sandy coasts in the United States.

Walton and Adams defined the sand volume of the ebb-tidal delta as the volume above the bed level, which would be there if there were no tidal inlet and thus no ebb-tidal delta (see Figure 2.14). They identified three classes of wave energy: low, moderate and high (see also Section 2.2.3) and found that:

$$
V_{\text {della }}=\alpha_{W A} \cdot P^{1.23}
$$

with:

$$
\begin{array}{ll}
V_{\text {delta }} & \text { Ebb-tidal delta (sand) volume }\left[\mathrm{m}^{3}\right] \\
P & \text { Tidal Prism }\left[\mathrm{m}^{3}\right]
\end{array}
$$


and $\alpha_{w a}$ is a proportional constant with dimension $\left[\mathrm{m}^{-1.23}\right]$. Its value varies with the local wave conditions. To describe this, Walton and Adams(1976) identified three classes of wave energy:

- low wave energy coasts:

$\alpha_{W A}=8.46 \cdot 10^{-3}$

- moderate wave energy coast:

$\alpha_{W A}=6.44 \cdot 10^{-3}$

- high wave energy coast:

$\alpha_{W A}=5.33 \cdot 10^{-3}$

Figure 2.17 shows the relation of sand volume in the outer delta in relation to the mean tidal prism of the inlet.

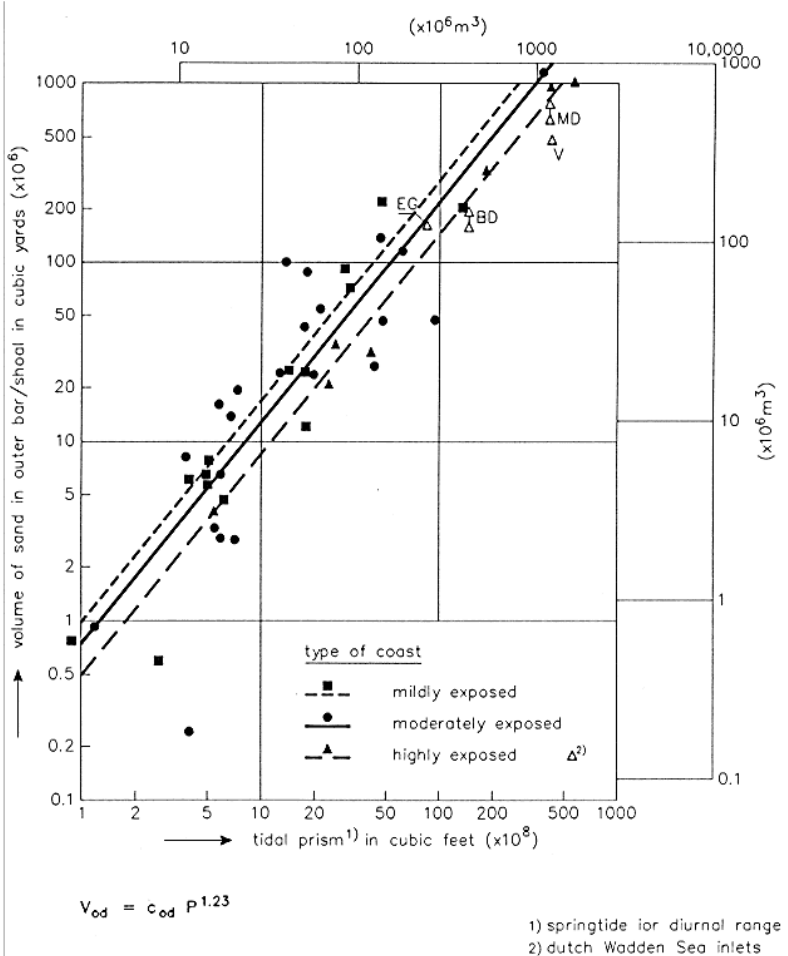

Figure 2.17: Sand volume outer deltas in USA and Dutch Wadden Sea in relation to the mean tidal prism and wave climate of the inlet according to Walton and Adams.

Eysink (1990) found that this relationship is also valid for the Wadden Sea inlets:

$$
V_{\text {dela }}=6.57 \cdot 10^{-3}\left[m^{-1.23}\right] \cdot V_{c t v}^{1.23}
$$

with

$$
V_{c v} \quad \text { Characteristic tidal volume }\left[\mathrm{m}^{3}\right]
$$

\subsubsection{Relationship between volume of tidal flats and size of basin}

The relative flat area $\left(A_{\text {flat }} / A_{\text {basin }}\right)$ depends on the size of the basin and - less importantly - on the tidal range H. According to Eysink (1991) the relative flat area for the Wadden Sea with its mesotidal range, appears to be distinctly dependent on the size of the basin (see Figure 2.18). Renger and Partensky found for the German Bight the following relation:

$$
\frac{A_{\text {flat }}}{A_{\text {basin }}}=1-2.5 \cdot A_{\text {basin }}^{0.5}
$$


Eysink (1991) stated that the relative tidal flat area affects the tidal prism:

$$
P=A_{\text {basin }} \cdot H-\alpha_{f e} \cdot\left(\frac{A_{\text {flat }}}{A_{\text {basin }}}\right) \cdot A_{\text {basin }} \cdot H
$$

with:

$$
\begin{array}{ll}
P & \text { The tidal prism }\left[\mathrm{m}^{3}\right] \\
A_{\text {basin }} & \text { Area of tidal basin measured at MHW }\left[\mathrm{m}^{2}\right] \\
A_{\text {flat }} & \text { Area of tidal flats measured at MLW }\left[\mathrm{m}^{2}\right] \\
H & \text { Mean tidal range [m] } \\
\alpha_{f e} & \text { Empirical coefficient for the average tidal flat level [-] }
\end{array}
$$

The height of the tidal flats is related to the tidal range: the average height of the flats relative to MLW is $\alpha_{f e} \cdot H$. Eysink derived an empirical relation between the basin area and the dimensionless coefficient $\alpha_{f e}$, which can be used for the Wadden Sea tidal basins:

$$
\alpha_{f e}=0.41[-]-0.24 \cdot 10^{-9}\left[m^{-2}\right] \cdot A_{\text {basin }}
$$

The area of the flats $\left(A_{\text {flats }}\right)$ depends on the basin area $\left(A_{\text {basin }}\right)$, so the volume of the tidal flats depends on the tidal range and on the basin area. The value of the volume of the tidal flats can be formulated as follows:

$$
V_{\text {flat }}=\alpha_{f e} \cdot\left(\frac{A_{\text {flat }}}{A_{\text {basin }}}\right) \cdot A_{\text {basin }} \cdot H
$$

with

$V_{\text {fat }} \quad$ Volume of tidal flats above MLW $\left[\mathrm{m}^{3}\right]$

$A_{\text {basin }} \quad$ Area of tidal basin measured at MHW $\left[\mathrm{m}^{2}\right]$

$A_{\text {flat }} \quad$ Area of tidal flats measured at MLW $\left[\mathrm{m}^{2}\right]$

$H \quad$ Mean tidal range [m]

$\alpha_{f e} \quad$ Empirical coefficient for the average tidal flat level [-]

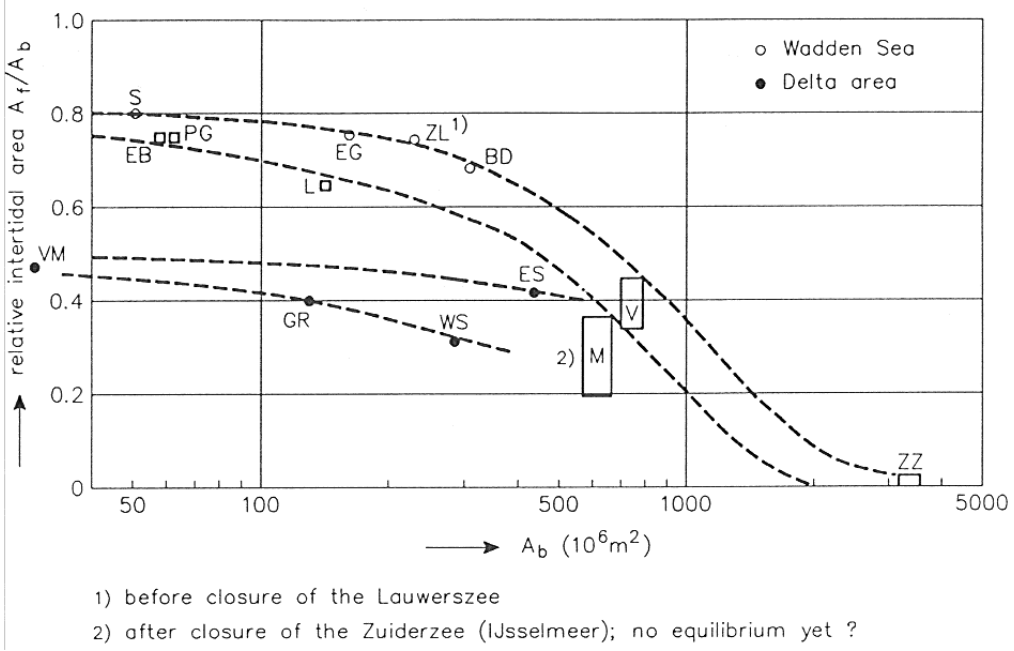

Figure 2.18: Relative area of the intertidal zones in the Dutch Wadden Sea against the tidal basin area. 


\section{Long-term morphological modelling of coastal inlets and tidal basins}

\section{I Introduction}

The morphological evolution of coastal inlets and tidal basins is governed by a complex of mutually interacting processes, each of which acts on its own characteristic time- and spacescales. The forcing of these processes may be either deterministic (like the tide) or of a predominating random nature (like wave conditions). This mixture of scales and types of forcing substantially complicates modelling and predicting the inlet morphodynamics. This implies that large-scale behaviour cannot be derived in a deterministic way from small-scale processes. Therefore, in the following sections an attempt is made to model the large-scale morphological behaviour of tidal inlets under the external forcing of a rising sea level on an aggregated scale.

To start with, in Section 3.2, a description is given of different modelling levels (space- and time-scale) available to us. In Section 3.3 we determine which modelling level suits the longterm modelling of the morphological response to a rise of the sea level. Subsequently the ASMITA modelling concept is discussed. In Section 3.4, a stability limit for a modelled tidal inlet system is derived, in which the system is subjected to a certain rate of Sea Level Rise (also referred to as $S L R$ ) and has to adapt itself to a 'new' dynamic equilibrium. In Section 3.5 we perform a sensitivity analysis on the latter derived stability limit of the tidal inlet system.

Section 3.2 is based on the De Vriend (1998), the description of the ASMITA concepts (Section 3.3) is based on the ASMITA model description of Stive et al. (1998).

\subsection{Cascade of scales}

In order to tackle the problem of mixture of scales and types of forcing, complicating the modelling and predicting of large-scale morphological behaviour of tidal inlet systems, De Vriend (1998) introduced the concept of dealing with our interest on a cascade of scales. With the purpose of dealing with time- and space-scales from large scale to small-scale level (like in Chapter 2), the following cascade of scales is derived by De Vriend (1998):

The mega-scale level, representing the level at which the principal elements of the entire system (barrier islands, outer deltas, inlets) evolve and interact, involves many kilometres in space and centuries in time. The principal forcing are mean sea level rise, climate change, long-term tidal variations, subsidence, etc.

The macro-scale level, representing the level at which the (one order smaller) meso-scale features interact. This level is associated with space-scales that comprise meso-scale features as a whole (e.g. outer delta) and time-scales of decades. The principal forcings are the longterm cycles in the tide (e.g. the 18,6 year lunar-related cycle), long-term variations in the wave climate and long-term human interference (like the construction of dykes and land reclamation). 
The meso-scale level, which represents the level of the principal morphological features, such as channels and shoals. At this level, developments have a time-scale of years and a spacescale of hundreds of metres. The principal forcings are seasonal and inter annual variations in the tide and the weather conditions. Also human activities and extreme events have their impact on this scale.

The micro-scale level, which represents the level of the smallest scale (time and space) of morphological processes (e.g. ripple and dune formation). The principal forcings are the tide and the day to day weather and wave conditions.

The highly dynamic nature of the non-linear, stochastically forced systems we are dealing with makes it not very likely that one single model will be able to cover all these scale levels at one time. According to the De Vriend (1998), one must expect to run into intrinsic or practical limits of predictability when ascending from small-scale (relatively well known) processes to large-scale (relatively unknown) processes, see Figure 3.1. This means that brute-force computing with process based models is probably not a viable approach for predicting the macro- and mega-scale behaviour of the system.

In general, predictability limits can be overcome by aggregation. Based on what is known of the systems behaviour at scales below and above this limit, an aggregated scale model is formulated at the higher scale level without attempting to describe every detail of what happens at the lower scale level. Hence, we should aim at a cascade of models at different levels of aggregation (De Vriend, 1998).

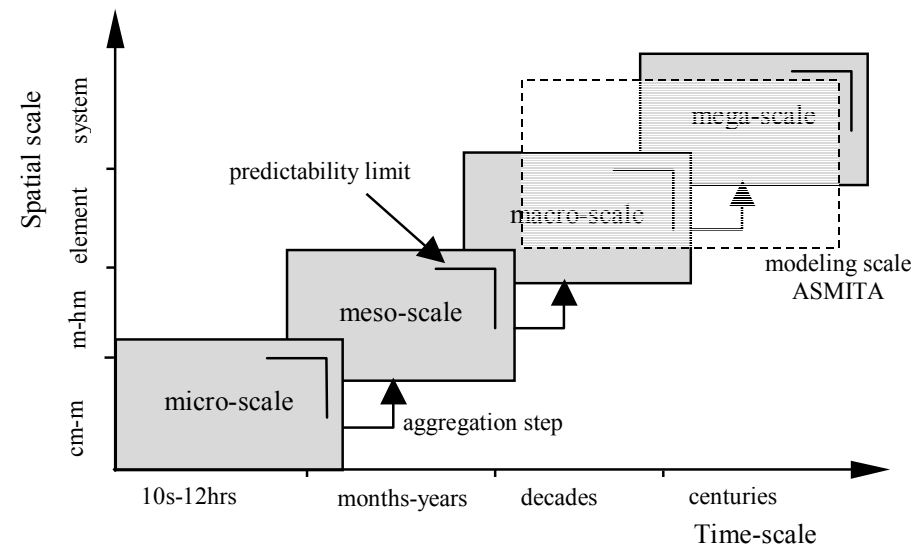

Figure 3.1: Cascade of model scales

According to the present insights, the transitions in the above mentioned scale cascade approximately correspond with the points where predictability limits are to be expected. Hence this cascade should be reflected in the cascade of models. On the macro-scale (which matches our modelling scale of interest) one typically reverts to more aggregated modelling approaches (e.g. ASMITA), while the process-based modelling (e.g. Delft3D) is typically relevant on the micro- and meso-scale. 


\subsection{Long-term modelling}

\subsection{Introduction}

If we want to do some long-term modelling (in accordance with the time and space-scale level belonging to the morphological response of a tidal inlet system to a rise of the sea level) we need to focus on comparatively large length-scales. Looking at a tidal inlet, we may try and derive length-scales prevailing in its long-term morphological evolution from the geometry and size of characteristic morphological features. In particular, we may distinguish between tidal flats, channels, the outer delta and the adjacent coastal stretches (see Section 2.3). If the area further seaward is smooth (more or less flat sloping bed), it is likely that this area evolves at a larger time-scale then the inlet. Hence, this area acts as a boundary condition for the morphological evolution of the inlet.

A second schematisation in the coastal morphodynamics is the definition of possible equilibrium states. An inlet in equilibrium is due to the balance between the wave energy which tends to close the inlet and the tidal energy which maintains the opening. It is important to keep in mind that no absolutely stable or in equilibrium inlet exists in a situation of significant longshore sediment transport; it is always subject to changes in its planform as well as in its cross-sectional area and geometry. Starting point for our long-term modelling approach is that we accept the existence of a (quasi-) equilibrium state, and that we are specifically interested in the response of the system to disturbance of the equilibrium state. The long-term model approach is based on the use of morphological equilibrium relations and equilibrium assumptions that, however, are still subject of active research investigation.

The above mentioned rationale form the basis for the model ASMITA, an aggregation and an extension of the ESTMORF model formulation for tidal basins (Wang et al., 1998). Hereafter, we discuss the ASMITA concept and model formulation.

\subsubsection{The ASMITA concept}

In ASMITA, the degree of schematisation is determined by the element of the system, which delivers the lower boundary to the relevant spatial scale. This concerns typically the ebb-tidal delta, for which there is presently no other option than to consider its volume as an integral state variable (see Dean and Walton, 1975). Hence the ebb-tidal delta is modelled as a single element, which makes it not very sensible to model the tidal basin and/or the adjacent coast in more detail.

Starting with the same level of schematisation and thus using the same spatial scales for all the elements in a tidal inlet system, the following basic elements are included in the model: the ebb-tidal delta as whole, the total inter tidal flat area in the basin, the total channel volume in the basin and the adjacent coasts at either side of the inlet, see Figure 3.2. A specific definition of element dimensions/volumes is given in Appendix A. 


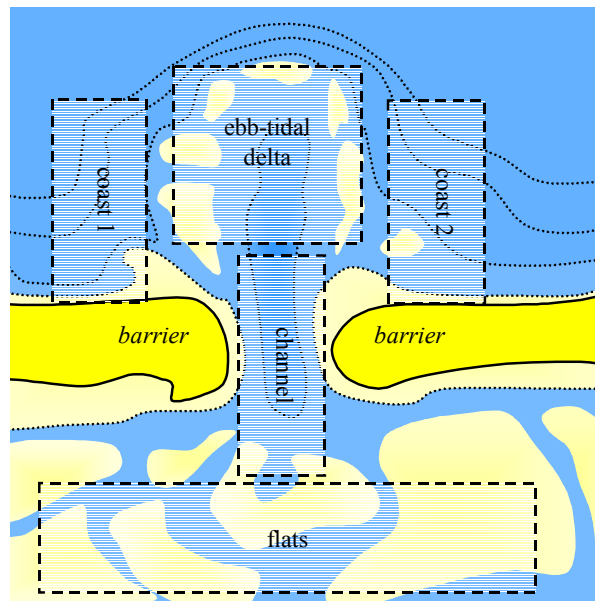

Figure 3.2: $\quad$ Elements used in ASMITA concept

The most important hypothesis used in the model concept is that a morphological equilibrium can be defined for each element depending on the hydrodynamic conditions (e.g. tidal prism, tidal range) and morphometric (e.g. basin area) it is subjected to. The existence of such an equilibrium has been supported by various field investigations, which have resulted also in empirical relations between state variables and parameters of the governing hydrodynamic and morphometric conditions (see Section 2.4). In general, the (dry or wet) volume $V_{e}$ of an element in a state of morpho-dynamic equilibrium, has appeared to be highly correlated to the tidal range $\mathrm{H}$, the tidal prism $\mathrm{P}$ and the basin area $A_{b}$.

$$
V_{e}=V_{e}\left(P, H, A_{b}\right)
$$

If length-scales of elements (especially that of the tidal flat) are small compared to the length of the tidal wave, then we may neglect spatial variations in water level and compute the tidal prism from:

$$
P=H \cdot A_{b}-V_{f}
$$

where $A_{b}$ equals the total basin area $\left[\mathrm{m}^{2}\right]$ and $V_{f}$ the total volume $\left[\mathrm{m}^{3}\right]$ of the flats between mean low water level (MLW) and mean high water level (MHW).

A second hypothesis used in the model concept is based on studies of De Vriend (1996), where it is shown that the different elements cannot be isolated from each other when their morphological development is considered. The interaction between the different elements through sediment exchange plays an important role for the morphological development of the whole system as well as of the individual elements. It is assumed that a long-term residual sediment exchange occurs between the tidal flat and the channel, the channel and the ebb-tidal delta and between the ebb-tidal delta and the adjacent coast. The sediment exchange with the surrounding zones, e.g. the foreshore and the coastal stretches further away, is assumed not to play a key role in the morphodynamic interactions considered. Furthermore it is assumed the development of surrounding zones (the so-called 'outside world') has no influence on the development of the tidal inlet and acts as a boundary condition for the morphological evolution of the inlet. 


\subsubsection{Model formulation}

The evolution of a tidal inlet element/system towards a state of equilibrium can be described in terms of the need and the availability of sediment in the element/system, which is typical for behaviour oriented modelling.

The first factor governing the evolution towards a state of equilibrium, is the need of sediment in an element. This need of sediment is represented by the difference in local equilibrium concentration $c_{e}$ in the element and the overall equilibrium concentration $c_{E}$. The local equilibrium concentration $c_{e}$ indicates to what extent the element volume $V$ deviates from its equilibrium $V_{e}$ and thus gives an indication of the elements need of sediment. To represent this behaviour a simple power relation is used for the local equilibrium concentration:

$$
c_{e}=c_{E} \cdot\left(\frac{V}{V_{e}}\right)^{n}
$$

where the power $n$ is larger than one, must commonly taken as 2 in compliance with a third power for the sediment transport as a non-linear function of the mean flow velocity. The sign of the power $n$ depends on the definition of the element volume $V$ (and thus on $V_{e}$ ). When the element volume represents a 'wet' volume, the sign of $n$ is negative, in case the volume represents a 'dry' volume, the sign of $n$ is positive. A 'wet' volume represents a water volume (e.g. the water volume of the channels below MLW), a 'dry' volume describes a sediment volume (e.g. the sediment volume of the flats above MLW), see also Appendix A.

The overall equilibrium concentration $c_{E}$ is defined by the following argument: when all the elements in the morphological system are in equilibrium a constant sediment concentration is present in the whole system; the overall equilibrium concentration $c_{E}$. As the surrounding zones (the so-named 'outside world') of the inlet are assumed always in a state of equilibrium (meaning that the development of the tidal inlet has no influence on the development of the 'outside world') they act as the boundary of the system with the overall equilibrium concentration $c_{E}$ as boundary condition.

In case an element is in equilibrium (and thus has equilibrium volume $V_{e}$ ), there is no need of sediment in that element and $c_{e}$ is equal to $c_{E}$. When all elements in the tidal inlet system are in equilibrium, there is no need of sediment in the system and the overall equilibrium concentration $c_{E}$ is present in the whole system. However, in case the actual volume $V$ of an element deviates from its equilibrium volume $V_{e}$, no morphological equilibrium is present and the need of sediment changes. In case the local equilibrium concentration $c_{e}$ of an element is larger than the overall equilibrium concentration $c_{E}$, a 'negative' need of sediment and so a tendency of erosion exists (e.g. the volume $V_{d}$ of the ebb-tidal delta is larger than its equilibrium volume $V_{d e}$ ). In the geological context this is considered as a negative accommodation space. In case the local equilibrium concentration $c_{e}$ is smaller than the overall equilibrium concentration $c_{E}$, a 'positive' need of sediment and so a tendency of sedimentation exists in the element. In the geological context this is considered as a positive accommodation space.

Whether the need of sediment actually results in erosion or sedimentation of the element depends on the second factor governing the morphological development, the availability of sediment in the surrounding elements. The change of element volume, representing the 
erosion or sedimentation, depends on the availability of sediment which is assumed proportional to the difference in local equilibrium concentration $c_{e}$ and the actual sediment concentration $c$. The volume change for an arbitrary element reads:

$$
\frac{d V}{d t}=w_{s} \cdot A \cdot\left(c-c_{e}\right)
$$

where $w_{s}[\mathrm{~m} / \mathrm{s}]$ is the vertical exchange rate and $A\left[\mathrm{~m}^{2}\right]$ is the horizontal area of the element. Erosion occurs when the actual sediment concentration is smaller than the equilibrium concentration, sedimentation occurs when the actual sediment concentration is larger than the equilibrium concentration. The availability of sediment depends on the sediment mass balance of the element. Assuming the residual diffusive transport dominating, the sediment balance of an arbitrary element is expressed by:

$$
\sum \delta \cdot \Delta c=w_{s} \cdot A \cdot\left(c-c_{e}\right)
$$

where the left-hand side reflects diffusive sediment exchange summed over all elements neighbouring the one at hand. This diffusive exchange, representing the long-term residual transport, is controlled by the difference in actual local sediment concentrations $\Delta c$ of adjacent elements and the horizontal exchange rates $\delta$.

With respect to the external forcing of a rising sea level in the system, we focus on a timeinvariant sea level rise $(S L R)$. The rate of the volume increase / decrease $V I\left[\mathrm{~m}^{3} /\right.$ year $]$ of an element caused by this sea level rise, can be written as:

$$
V I=A \cdot \frac{d \zeta}{d t}
$$

where $d \zeta / d t=$ rate of sea level rise or $S L R$ [m/year]. Whether sea level rise results in a volume increase or decrease of the element depends on the definition of its volume. In case the element volume is defined as 'wet' (e.g. the channel), the sea level rise results in an increase of 'wet' volume. In case the element is defined as 'dry' (e.g. the flats), the sea level rise results in a decrease of 'dry' volume. Superimposing this volume increase / decrease to the evolution described by (3.4) gives:

$$
\frac{d V}{d t}=w_{s} \cdot A \cdot\left(c_{e}-c\right)+/-A \cdot \frac{d \zeta}{d t}
$$

This concludes the basic ASMITA model formulation, which we apply in the next sections where we investigate the response of a tidal inlet to a rising sea level and derive the maximum rate of sea level rise a tidal inlet system is able follow without drowning (stability limit).

\subsection{Stability limit analysis of modelled tidal inlet systems}

\subsection{Introduction}

History teaches us that tidal inlets (such as in the Dutch Wadden Sea) are able to adapt themselves to a rise of the sea level (see Section 2.1.2). This dynamic adaptive behaviour is 
one of the key characteristics of tidal inlets and it can be explained by the phenomenon of sediment demand (see Section 2.2.6). If the coastal stretch and offshore waters ('outside world') adjacent to the tidal inlet can satisfy the demand, the system is likely to follow the sea level rise (probably at a new state of dynamic equilibrium). If the 'outside world' is not able to satisfy the sediment demand, drowning of the system is a serious threat. Hereafter we will deploy ASMITA to quantitatively investigate the response of a tidal inlet to a rising sea level and to find the maximum rate of sea level rise a tidal inlet can follow without drowning (called stability limit). This analysis starts with looking only at that element of the inlet that presumably dominates the response of the entire system. Subsequently, the analysis will be expanded to the more complicated three-element approach.

\subsubsection{Single element model}

As the channel element of the tidal inlet system is a central element physically, it is taken as the basis for the single element model. In this model we presume that channel evolution is dominated by diffusive transport between channel and 'outside world' (see Figure 3.3) and that this 'outside world' is always in a state of equilibrium. The external 'outside world' thus represents adjacent elements such as ebb-tidal delta, adjacent coasts and tidal flats.
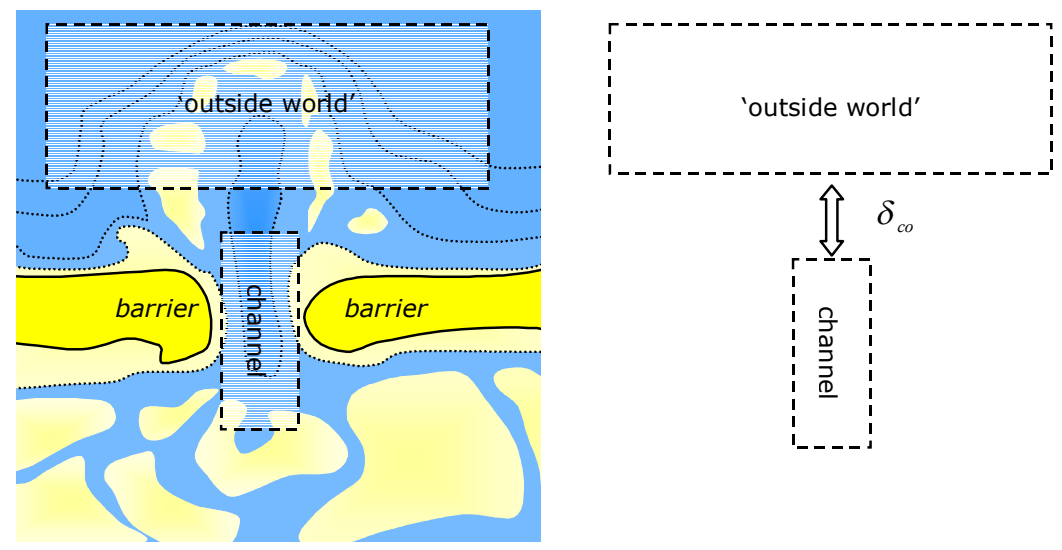

Figure 3.3: $\quad$ Single element model

In this channel-outside world model, the equilibrium state for the channel is derived from the equilibrium relation for the channel volume which depends on the tidal prism:

$$
V_{c e}=V_{c e}(P)
$$

where $V_{c e}$ stands for the equilibrium volume for channel element $\left[\mathrm{m}^{3}\right]$ and $P$ the tidal prism $\left[\mathrm{m}^{3}\right]$. In the present analysis of stability limits, temporal changes in tidal prism are considered as a secondary effect and therefore neglected.

Analogously to model formulations presented in Section 3.3.3, a disturbance of the channel volume causes a change in the need of sediment in the element. This need is expressed by the difference in the local equilibrium concentration of the channel $c_{c e}$ and the overall equilibrium concentration $c_{E}$. Based on model formulation (3.3), the equation determining the local equilibrium concentration in the channel element yields:

$$
c_{c e}=c_{E} \cdot\left(\frac{V_{c e}}{V_{c}}\right)^{n}
$$


The overall equilibrium concentration $c_{E}$ serves as a boundary condition of the system and is assumed time-invariant. Whether the need of sediment in the element results in sedimentation or erosion of the channel element also depends on the availability of sediment in the surrounding elements. This availability is represented by the difference in local equilibrium concentration $c_{c e}$ and the actual local sediment concentration $c_{c}$ and results in changes in the morphology of the channel. According to model formulation (3.4), this morphological change of the channel element yields:

$$
\frac{d V_{c}}{d t}=w_{s} \cdot A_{c} \cdot\left(c_{c e}-c_{c}\right)
$$

where $w_{s}$ is the vertical exchange coefficient $[\mathrm{m} / \mathrm{s}]$ and $A_{c}$ the horizontal area $\left[\mathrm{m}^{2}\right]$ of the channel. The availability of sediment in the channel element depends on the sediment massbalance of the element. Assuming the diffusive transport dominating and considering the 'outside world' as the only neighbour of the channel, the mass balance of sediment for the channel is expressed by:

$$
\delta_{c o} \cdot\left(c_{c}-c_{E}\right)=w_{s} \cdot A_{c} \cdot\left(c_{c e}-c_{c}\right)
$$

where $\delta_{c o} \cdot\left(c_{c}-c_{E}\right)$ represents the horizontal diffusive sediment exchange between the channel and the 'outside world'.

From equation (3.11) we can derive:

$$
c_{c}=\frac{\delta_{c o} \cdot c_{E}+w_{s} \cdot A_{c} \cdot c_{c e}}{\delta_{c o}+w_{s} \cdot A_{c}}
$$

which gives:

$$
c_{c e}-c_{c}=\frac{\delta_{c o}}{\delta_{c o}+w_{s} \cdot A_{c}} \cdot\left(c_{c e}-c_{E}\right)=\frac{\delta_{c o} \cdot c_{E}}{\delta_{c o}+w_{s} \cdot A_{c}}\left(\left(\frac{V_{c e}}{V_{c}}\right)^{n}-1\right)
$$

Equation (3.13) in combination with equation (3.10) yields:

$$
\frac{d V_{c}}{d t}=\frac{w_{s} \cdot A_{c} \cdot \delta_{c o} \cdot c_{E}}{\delta_{c o}+w_{s} \cdot A_{c}}\left(\left(\frac{V_{c e}}{V_{c}}\right)^{n}-1\right)
$$

which reflects the elements evolution towards a state of equilibrium.

Superimposing the volume increase of an element as caused by sea level rise (see model formulations), the elements evolution towards a possible state of equilibrium described by (3.14) results in:

$$
\frac{d V_{c}}{d t}=\frac{w_{s} \cdot A_{c} \cdot \delta_{c o} \cdot c_{E}}{\delta_{c o}+w_{s} \cdot A_{c}}\left(\left(\frac{V_{c e}}{V_{c}}\right)^{n}-1\right)+A_{c} \cdot \frac{d \zeta}{d t}
$$


Equation (3.15) describes the morphological behaviour of the single element system. Either the system erodes $\left(d V_{c} / d t>0\right)$ or the system accretes $\left(d V_{c} / d t<0\right)$ or the system is in dynamic equilibrium $\left(d V_{c} / d t=0\right)$. In case of dynamic equilibrium we assume that the considered element can undergo a self-organisation leading to a (quasi-) equilibrium morphology for the element under relatively constant hydrodynamic forcing conditions. If we consider a situation of (quasi-/dynamic) equilibrium the volume changes of the element should be zero. This results in:

$$
\frac{d V_{c}}{d t}=0=\frac{w_{s} \cdot A_{c} \cdot \delta_{c o} \cdot c_{E}}{\delta_{c o}+w_{s} \cdot A_{c}}\left(\left(\frac{V_{c e}}{V_{c}}\right)^{n}-1\right)+A_{c} \cdot \frac{d \zeta}{d t}
$$

which may be solved for the dynamic equilibrium state volume $V_{c e}^{*}$ :

$$
V_{c e}^{*}=\left.V_{c}\right|^{\frac{d V_{c}=0}{d t}=}=\frac{V_{c e}}{\left(1-\frac{d \zeta}{d t} \cdot \frac{\delta_{c o}+w_{s} \cdot A_{c}}{w_{s} \cdot \delta_{c o} \cdot c_{E}}\right)^{\frac{1}{n}}}
$$

Equation (3.17) gives the channel volume in the case of a dynamic equilibrium under the external forcing of a constant sea level rise. In the case of no sea level rise $(d \zeta / d t=0)$ equation (3.17) results in (as expected) $V_{c e}^{*}=V_{c e}$. However, in the case of sea level rise $(d \zeta / d t>0)$ equation (3.17) gives us a 'new' dynamic equilibrium volume which is larger the original equilibrium volume $\left(V_{c e}^{*}>V_{c e}\right)$. Apparently there is a permanent difference between the equilibrium volume with $\operatorname{SLR}\left(V_{c e}^{*}\right)$ and the equilibrium volume without $\operatorname{SLR}\left(V_{c e}\right)$. This difference in equilibrium volume is necessary to maintain the need of sediment that causes a sediment import into the system to such an extent that the system does not drown.

Equation (3.17) also shows that the equilibrium volume $V_{c e}^{*}$ becomes infinitely large when:

$$
\frac{d \zeta}{d t}=\frac{w_{s} \cdot \delta_{c o} \cdot c_{E}}{\delta_{c o}+w_{s} \cdot A_{c}}
$$

This is the maximum SLR an inlet can keep pace with (at least according to the present singleelement schematisation). It is called the stability limit as it indicates the transition between preservation of drowning of the inlet. For a fictitious case this is shown in Figure 3.4. 


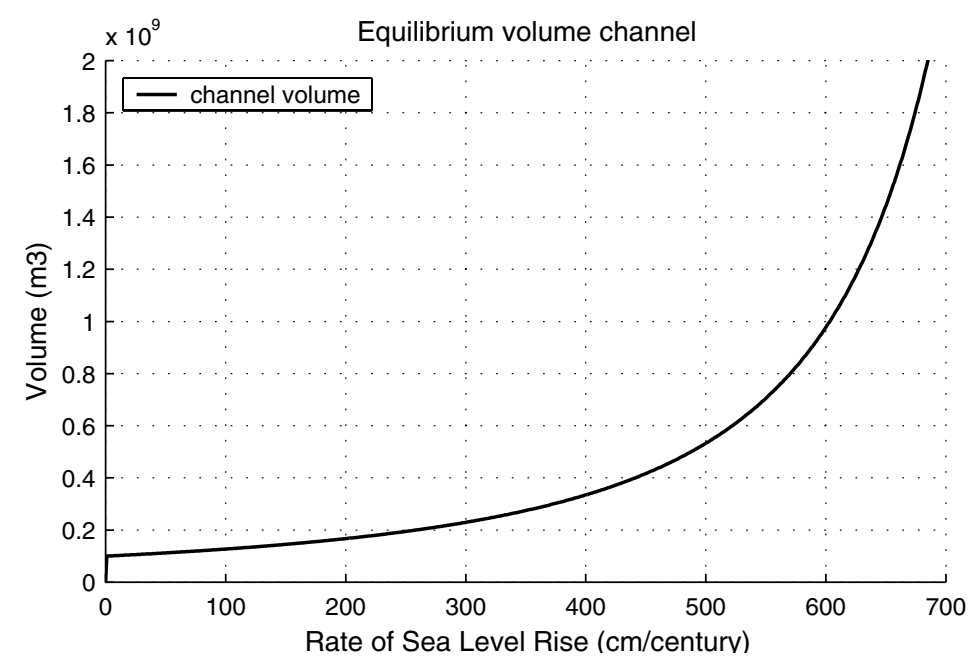

Figure 3.4 Dynamic equilibrium volume channel element as function of a constant external forcing; the accelerated rate of sea level rise.

In this case, the sediment entrapment in the channel element gradually becomes insufficient and the increase in 'wet' volume is due to the rate of sea level rise. Furthermore, it can be seen that before the theoretical stability limit is reached a considerable increase of volume is needed to reach a 'new' dynamic equilibrium state.

The input values used for this fictitious case are shown in Table 3.1.

Table 3.1: Element characteristics fictitious single-element system

\begin{tabular}{lccccc}
\hline Element & $\begin{array}{c}\text { Area } \\
{\left[\mathrm{m}^{2}\right] \cdot 10^{6}}\end{array}$ & $\begin{array}{c}\text { Volume } \\
{\left[\mathrm{m}^{3}\right] \cdot 10^{6}}\end{array}$ & $\begin{array}{c}\mathrm{W}_{\mathrm{s}} \\
{[\mathrm{m} / \mathrm{s}]}\end{array}$ & $\begin{array}{c}\delta_{c o} \\
{\left[\mathrm{~m}^{3} / \mathrm{s}\right]}\end{array}$ & $\begin{array}{c}c_{E} \\
{[-]}\end{array}$ \\
\hline Channel & 61.5 & 100 & 0.0001 & 1000 & 0.0002 \\
\hline
\end{tabular}

\subsubsection{Two-element model}

Expanding our model to two-elements, we focus on the elements channel and flat (see Figure 3.5). Analogously to the single-element model, the morphological evolution is presumed dominated by diffusive transport, the flat connected to the channel, the channel connected to the 'outside world' and this 'outside world' always in a state of equilibrium.
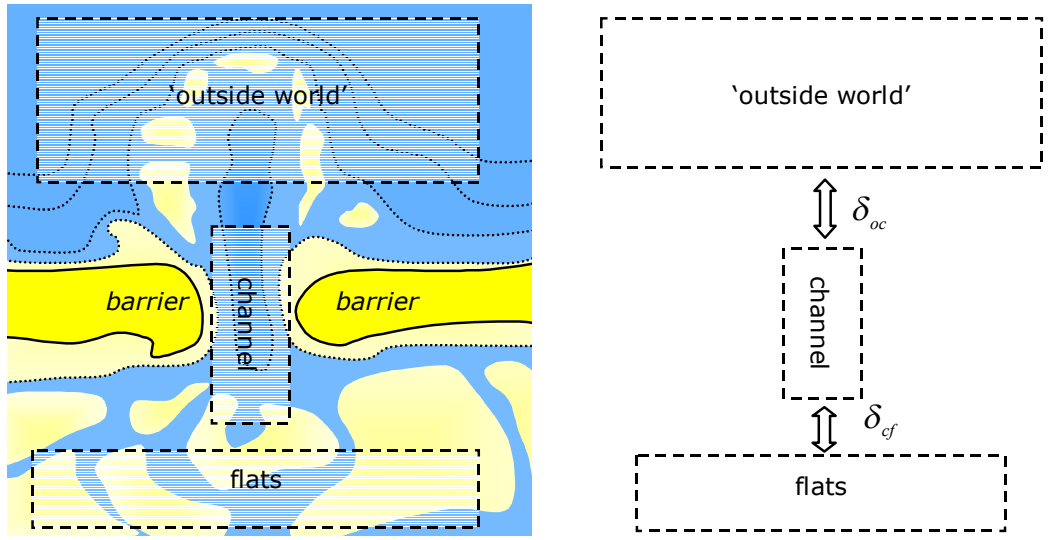

Figure 3.5: Two-element model 
The flat area and the tidal range govern the equilibrium tidal flat volume (see Section 2.4.6):

$$
V_{f e}=V_{f e}\left(A_{b}, H\right)
$$

Analogously to the model formulations given in Section 3.3.3, the volume changes of the elements are given by:

$$
\begin{aligned}
& \frac{d V_{f}}{d t}=w_{s} \cdot A_{f} \cdot\left(c_{f}-c_{f e}\right)-A_{f} \cdot \frac{d \zeta}{d t} \\
& \frac{d V_{c}}{d t}=w_{s} \cdot A_{c} \cdot\left(c_{c e}-c_{c}\right)+A_{c} \cdot \frac{d \zeta}{d t}
\end{aligned}
$$

where the availability of sediment in the elements depends on the sediment mass balances:

$$
\begin{aligned}
& \delta_{c f} \cdot\left(c_{f}-c_{c}\right)=w_{s} \cdot A_{f} \cdot\left(c_{f e}-c_{f}\right) \\
& \delta_{c f} \cdot\left(c_{c}-c_{f}\right)+\delta_{o c} \cdot\left(c_{c}-c_{E}\right)=w_{s} \cdot A_{c} \cdot\left(c_{c e}-c_{c}\right)
\end{aligned}
$$

and the need of sediment in the elements is indicated by the local equilibrium concentrations which are given by:

$$
\begin{aligned}
& c_{f e}=c_{E} \cdot\left(\frac{V_{f}}{V_{f e}}\right)^{n} \\
& c_{c e}=c_{E} \cdot\left(\frac{V_{c e}}{V_{c}}\right)^{n}
\end{aligned}
$$

For the stability analysis we consider the case of dynamic equilibrium where we assume that the considered elements can undergo a self-organisation leading to a (quasi-) equilibrium morphology for each element under relatively constant hydrodynamic forcing conditions. If we consider a situation of (quasi-) equilibrium the volume changes of the element should be zero ( $\left.d V_{f} / d t=d V_{c} / d t=0\right)$. When we implement this is equation (3.20) and (3.21) we may derive with equations (3.20)-(3.25) the following relations for the element volumes $\left(V_{f e}^{*} ; V_{c e}^{*}\right)$ in the case of a dynamic equilibrium under the external forcing of a constant sea level rise:

$$
\begin{aligned}
& \left(\frac{V_{f e}^{*}}{V_{f e}}\right)^{n}=1-\left(\frac{A_{f}}{c_{E} \cdot \delta_{c f}}+\frac{A_{f}+A_{c}+\delta_{o c} / w_{s}}{c_{E} \cdot \delta_{o c}}\right) \cdot \frac{d \zeta}{d t} \\
& \left(\frac{V_{c e}}{V_{c e}^{*}}\right)^{n}=1-\frac{A_{f}+A_{c}+\delta_{o c} / w_{s}}{c_{E} \cdot \delta_{o c}} \cdot \frac{d \zeta}{d t}
\end{aligned}
$$

Apparently, the flat element degenerates faster than the channel element. Hence, the flat element is determinative for the stability in this two-element schematisation.

We can also determine dynamic equilibrium volumes under the external forcing of a constant sea level rise graphically. To do so we use the following method: 
In case of dynamic equilibrium in, for instance, the flat $\left(d V_{f} / d t=0\right)$ we derive from equation (3.20) that:

$$
c_{f}=\frac{d \zeta}{d t} \cdot \frac{1}{w_{s}}+c_{f e}
$$

Furthermore, we can eliminate the channel sediment concentration $c_{c}$ from equation (3.22) and (3.23), which results in the following relationship between the flat sediment concentration $c_{f}$ and the flat equilibrium concentration $c_{f e}$ :

$$
c_{f}\left(\frac{w_{s} \cdot A_{f}}{\delta_{c f}}+1-\frac{\delta_{c f}}{\delta_{c f}+\delta_{o c}+w_{s} \cdot A_{c}}\right)=\frac{w_{s} \cdot A_{c} \cdot c_{c e}+\delta_{o c} \cdot c_{E}}{\delta_{c f}+\delta_{o c}+w_{s} \cdot A_{c}}+\frac{A_{f} \cdot w_{s}}{\delta_{c f}} \cdot c_{f e}
$$

Implementing equation (3.28) in equation (3.29) results in a relationship between the channel equilibrium concentration $c_{c e}$ and the flat equilibrium concentration $c_{f e}$ with the $S L R(d \zeta / d t)$ as parameter. When we successively use equation (3.24) and (3.25) for $c_{c e}$ and $c_{f e}$, we derive a relationship between $V_{f}$ and $V_{c}$ for which holds that, in the light of the interaction between flat, channel and 'outside world', the flat element is just able to keep pace with the rise in sea level. We can represent this relationship as a curve in the $V_{f}-V_{c}$ plane. Analogously, we may derive a curve in the $V_{f}-V_{c}$ plane which represents $d V_{c} / d t=0$. Equilibrium volumes for both elements which represent the marginal stability of the system $\left(d V_{f} / d t=d V_{c} / d t=0\right)$ belong to the point of intersection of both curves $\left(d V_{f} / d t=0\right.$ and $\left.d V_{c} / d t=0\right)$.

Using equations (3.20)-(3.25) we may determine for all points in the $V_{f}-V_{c}$ plane the vector:

$$
\left(\begin{array}{l}
d V_{f} / d t \\
d V_{c} / d t
\end{array}\right)
$$

The direction of this vector indicates in which direction the system will develop from the position $\left(V_{f}, V_{c}\right)$ and the length of this vector is a measure for the rate of its development. Figures 3.6-3.9 show, for a fictitious case and various scenarios of $S L R$, the directions of these vectors belonging to various combinations of $\left(V_{f}, V_{c}\right)$. Also the curves for $d V_{f} / d t=0$ and $d V_{c} / d t=0$ are drawn. By following the directions of these vectors we obtain insight how the system develops from an arbitrary state $\left(V_{f}, V_{c}\right)$ to a state of dynamic equilibrium $\left(d V_{f} / d t=d V_{c} / d t=0\right)$.

When the curves representing $d V_{f} / d t=0$ and $d V_{c} / d t=0$ do not intersect in the first quadrant (see Figure 3.9), the system is unable to keep pace with the present $S L R$. Hence, the system is unstable and will drown. 

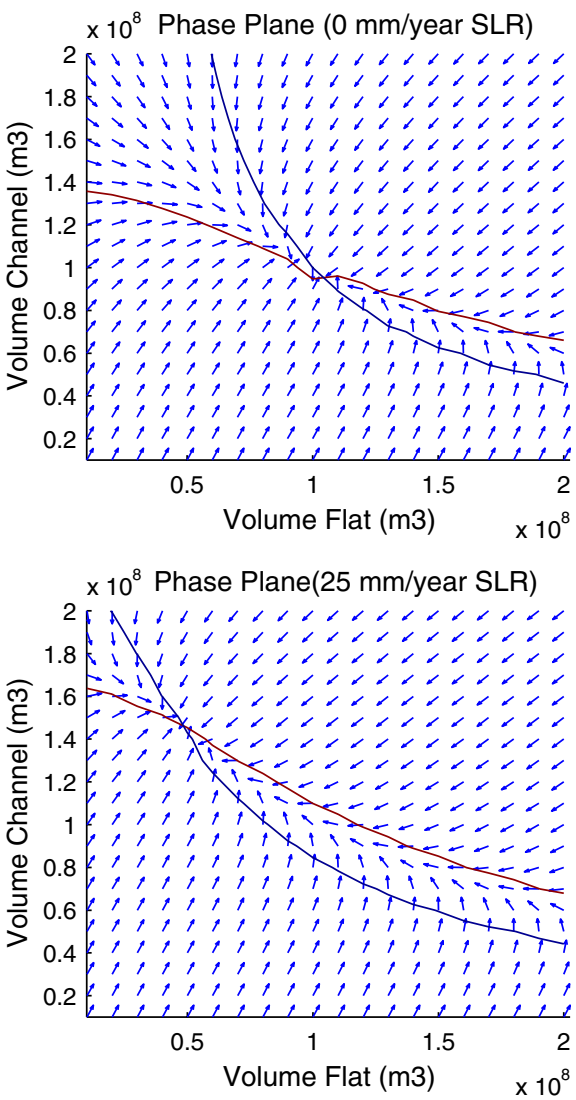

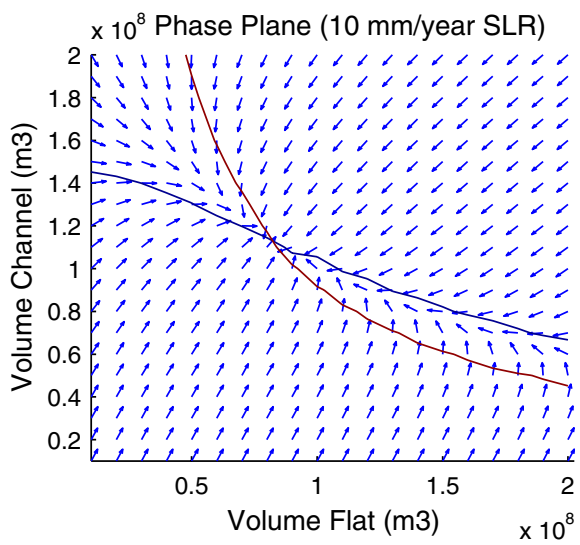

x $10^{8}$ Phase Plane $(40 \mathrm{~mm} /$ year SLR)

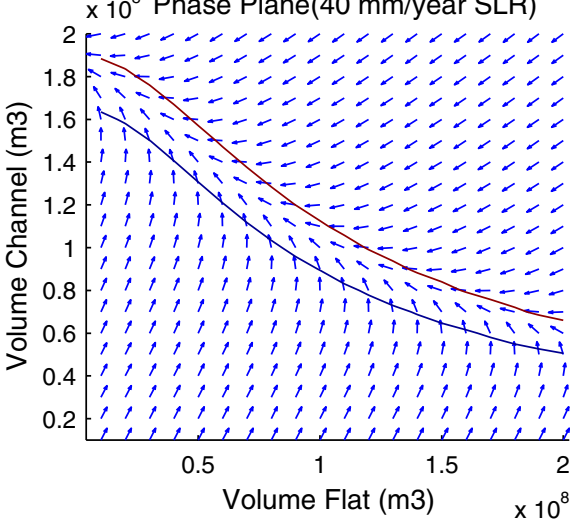

Figure 3.6 - 3.9: Phase planes of dynamic equilibrium states for two-element model under the external forcing of $0 \mathrm{~mm} /$ year SLR, $10 \mathrm{~mm} /$ year SLR, $25 \mathrm{~mm} /$ year SLR and $40 \mathrm{~mm} /$ year SLR

The input values used for this fictitious two-element model are shown in Table 3.2.

Table 3.2: Element characteristics fictitious two-element model

\begin{tabular}{lcccccc}
\hline Element & $\begin{array}{c}\text { Area } \\
{\left[\mathrm{m}^{2}\right] \cdot 10^{6}}\end{array}$ & $\begin{array}{c}\text { Volume } \\
{\left[\mathrm{m}^{3}\right] \cdot 10^{6}}\end{array}$ & $\begin{array}{c}\mathrm{w}_{\mathrm{s}} \\
{[\mathrm{m} / \mathrm{s}]}\end{array}$ & $\begin{array}{c}\delta_{c o} \\
{\left[\mathrm{~m}^{3} / \mathrm{s}\right]}\end{array}$ & $\begin{array}{c}\delta_{c f} \\
{\left[\mathrm{~m}^{3} / \mathrm{s}\right]}\end{array}$ & $\begin{array}{c}c_{E} \\
{[-]}\end{array}$ \\
\hline $\begin{array}{l}\text { Channel } \\
\text { Flat }\end{array}$ & 61.5 & 100 & 0.0001 & 1000 & 1000 & 0.0002 \\
\hline
\end{tabular}

\subsubsection{Three-element model}

In this second expansion of the ASMITA model we put the ebb-tidal delta in a separate element. See Figure 3.10.
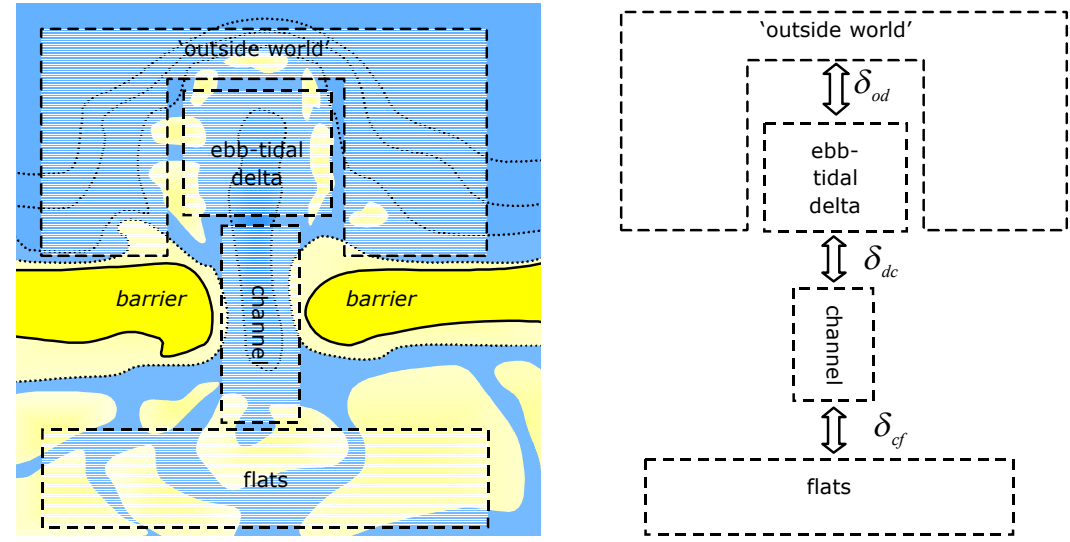

Figure 3.10: Three-element model 
The parameter governing the equilibrium sediment volume of the ebb-tidal delta is the tidal prism (see Section 2.4.6):

$$
V_{d e}=V_{d e}(P)
$$

Analogously to the model formulations given in Section 3.3.3, the volume changes of the elements are given by:

$$
\begin{aligned}
& \frac{d V_{d}}{d t}=w_{s} \cdot A_{d} \cdot\left(c_{d}-c_{d e}\right)-A_{f} \cdot \frac{d \zeta}{d t} \\
& \frac{d V_{c}}{d t}=w_{s} \cdot A_{c} \cdot\left(c_{c e}-c_{c}\right)+A_{c} \cdot \frac{d \zeta}{d t} \\
& \frac{d V_{f}}{d t}=w_{s} \cdot A_{f} \cdot\left(c_{f}-c_{f e}\right)-A_{f} \cdot \frac{d \zeta}{d t}
\end{aligned}
$$

where the availability of sediment in the elements depends on the sediment mass balances:

$$
\begin{aligned}
& \delta_{o d} \cdot\left(c_{d}-c_{E}\right)+\delta_{d c} \cdot\left(c_{d}-c_{c}\right)=w_{s} \cdot A_{d} \cdot\left(c_{d e}-c_{d}\right) \\
& \delta_{c f} \cdot\left(c_{c}-c_{f}\right)+\delta_{d c} \cdot\left(c_{c}-c_{d}\right)=w_{s} \cdot A_{c} \cdot\left(c_{c e}-c_{c}\right) \\
& \delta_{c f} \cdot\left(c_{f}-c_{c}\right)=w_{s} \cdot A_{f} \cdot\left(c_{f e}-c_{f}\right)
\end{aligned}
$$

and the need of sediment in the elements is indicated by the local equilibrium concentrations which are given by:

$$
\begin{aligned}
& c_{f e}=c_{E} \cdot\left(\frac{V_{f}}{V_{f e}}\right)^{n} \\
& c_{c e}=c_{E} \cdot\left(\frac{V_{c e}}{V_{c}}\right)^{n} \\
& c_{d e}=c_{E} \cdot\left(\frac{V_{d}}{V_{d e}}\right)^{n}
\end{aligned}
$$

Again, for a situation of dynamic equilibrium, the volume change with time of the delta, channel and flat should equal zero $\left(d V_{d} / d t=0 ; d V_{c} / d t=0 ; d V_{f} / d t=0\right)$. For this three-element model we can derive three stability limits for the relative sea level rise $(d \zeta / d t)$, respectively for the ebb-tidal delta, the channel and the flat. The smallest of the given limits is determinative for the system. As in the two-element system, the smallest limit is the one associated with the flat element.

Figure (3.11) gives the dynamic equilibrium volumes of the ebb-tidal delta, channel and flat as function of rate of sea level rise. The input values for this fictitious three-element case are shown in Table 3.3. 


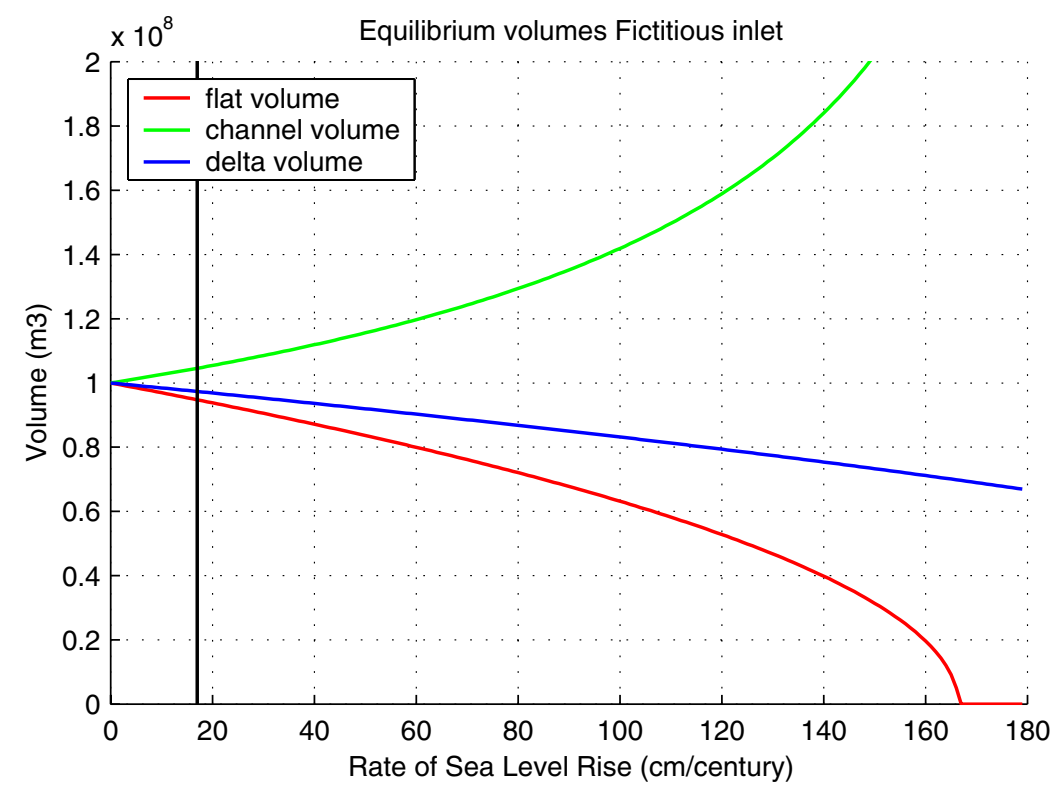

Figure 3.11: Dynamic equilibrium volumes of a fictitious three-element model as a function of rate of sea level rise.

Table 3.3: Element characteristics fictitious three-element model

\begin{tabular}{lccccccc}
\hline Element & $\begin{array}{c}\text { Area } \\
{\left[\mathrm{m}^{2}\right] \cdot 10^{6}}\end{array}$ & $\begin{array}{c}\text { Volume } \\
{\left[\mathrm{m}^{3}\right] \cdot 10^{6}}\end{array}$ & $\begin{array}{c}\mathrm{w}_{\mathrm{s}} \\
{[\mathrm{m} / \mathrm{s}]}\end{array}$ & $\begin{array}{c}\delta_{c o} \\
{\left[\mathrm{~m}^{3} / \mathrm{s}\right]}\end{array}$ & $\begin{array}{c}\delta_{c f} \\
{\left[\mathrm{~m}^{3} / \mathrm{s}\right]}\end{array}$ & $\begin{array}{c}\delta_{c f} \\
{\left[\mathrm{~m}^{3} / \mathrm{s}\right]}\end{array}$ & $\begin{array}{c}c_{E} \\
{[-]}\end{array}$ \\
\hline Ebb-tidal delta & 61.5 & 100 & & & & & \\
Channel & 61.5 & 100 & 0.0001 & 1000 & 1000 & 1000 & 0.0002 \\
Flat & 61.5 & 100 & & & & & \\
\hline
\end{tabular}

In the case of a three-element model we have no phase plane but instead a three-dimensional phase space $\left(V_{f}, V_{c}, V_{d}\right)$. It is difficult to create a clear visualisation of such a phase space and therefore three cross-sections are made in this phase space. This shown in Figure 3.12 in case of $d \zeta / d t=0$ and for the cross-sections:

$$
\begin{aligned}
& \left(V_{c}, V_{d} ; V_{f}=V_{f e}\right) \\
& \left(V_{f}, V_{d} ; V_{c}=V_{c e}\right) \\
& \left(V_{f}, V_{c} ; V_{d}=V_{d e}\right)
\end{aligned}
$$

Further we can derive from, for instance, $d V_{f} / d t=0$, a relationship between $V_{f}, V_{c}$ and $V_{d}$, which describes a curved plane in the phase space. This way we can derive three curved planes (for $d V_{f} / d t=0, d V_{c} / d t=0$ and $d V_{d} / d t=0$ ) which have, in case of stability, one point in common. The volumes belonging to this point are the equilibrium volumes for the regarded $S L R$. The drawn lines in Figure 3.12 are the intersecting lines of the curved planes with the plane of the presented cross-section. 

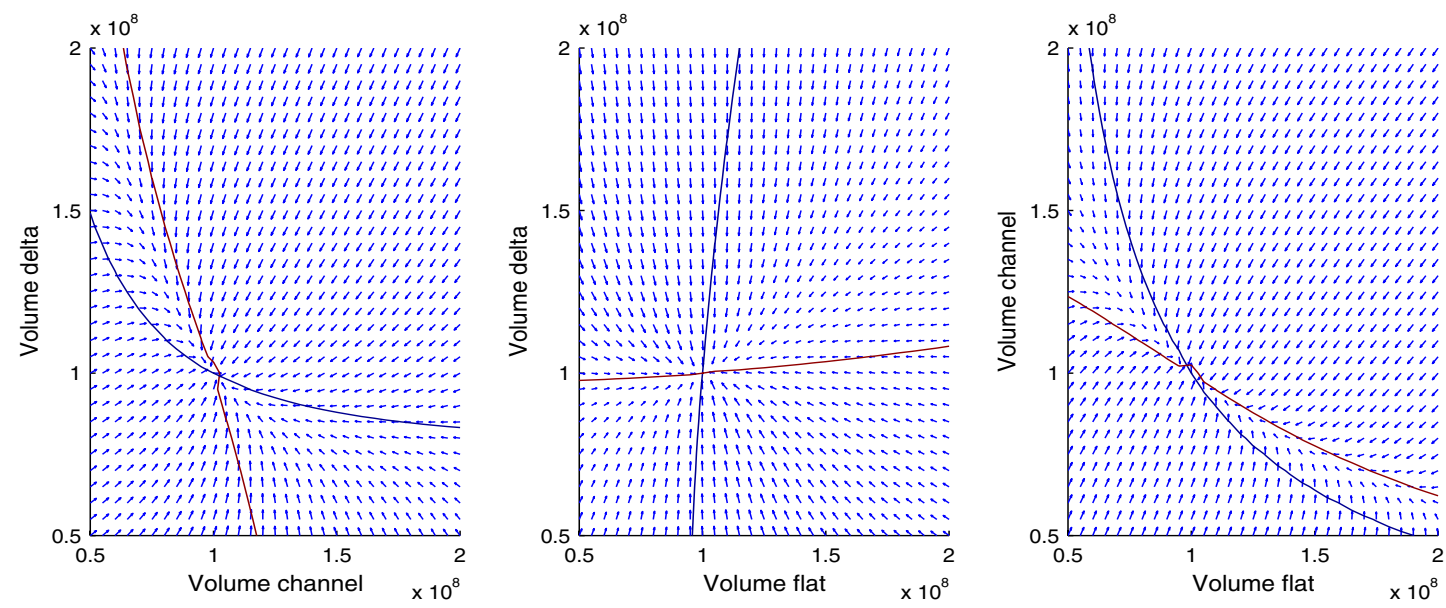

Figure 3.12: Cross-sections of phase space at dynamic equilibrium states of three-element model, no sea level rise.

\subsubsection{Main Results of Stability Limit Analysis}

From the foregoing sections we may conclude that in case of sea level rise the morphological elements of the tidal inlet system have to alter their volume (representing their morphological state) permanently to reach a 'new' state of dynamic equilibrium (represented by volume $V_{e}^{*}$ ). This difference in volume $\left(V_{e}^{*}-V_{e}\right)$ is necessary to maintain the need of sediment which incites a sediment import into the system to such an extent that the system does not drown.

Further we derived that for the modelled tidal inlet systems an upper boundary exists for the Sea Level Rise (SLR), the so-called 'stability limit'. When the SLR exceeds this stability limit, the system will no longer regain a state of dynamic equilibrium and drown. This stability limit depends on the geomorphological characteristics of the system. In the schematisation of a two or three-element system we may derive a stability limit for each element. The smallest of these three stability limits is determinative for the system. For both cases (the two and three element system) the flat element determines the stability of the system. This determinative limit is henceforth referred to as SLRlimit.

\subsection{Sensitivity analysis on the stability limit}

\subsection{Introduction}

In the previous section we have modelled a fictitious three-element tidal inlet system in which the properties of each element are the same (same area, equilibrium volume etc; see Table 3.3). This situation of equivalent elements is not likely to be seen in a natural barrier coast. Therefore it is of interest if variation of geometrical properties has impact on the limit of stability (SLRlimit) of the modelled tidal inlet system.

In Section 3.5.2 the structure of the sensitivity analysis and a summary of the variables that might influence the stability-related outcomes of the model are given. The following section deals with the impact of these variable variations and their morphological explanation. The present sensitivity analysis differs from the sensitivity analysis performed by Buijsman (1997) 
because in this research the stability limit of the tidal inlet system is subject of study instead of the model run results.

\subsubsection{Input coefficients three-element model}

Analogously to the stability limit for the single and two element model in Section 3.4.2 and 3.4.3 we may derive that the limit of stability in the three-element model depends on the variables presented in Table 3.4. These variables may be categorised as element areas, horizontal exchange rates, vertical exchange rates and 'outside world' equilibrium concentration.

Table 3.4: Variables viable for sensitivity analysis

\begin{tabular}{llcc}
\hline Coefficient & Description & unit & Fictitious case \\
\hline $\mathrm{A}_{\mathrm{f}}$ & Tidal flat area & $\mathrm{m}^{2}$ & $61.5 \cdot 10^{6}$ \\
$\mathrm{~A}_{\mathrm{c}}$ & Channel area & $\mathrm{m}^{2}$ & $61.5 \cdot 10^{6}$ \\
$\mathrm{~A}_{\mathrm{d}}$ & Ebb-tidal delta area & $\mathrm{m}^{2}$ & $61.5 \cdot 10^{6}$ \\
$\delta_{\mathrm{cf}}$ & Horizontal exchange rate between channel and flat & $\mathrm{m}^{3} / \mathrm{s}$ & 1000 \\
$\delta_{\mathrm{dc}}$ & Horizontal exchange rate between delta and channel & $\mathrm{m}^{3} / \mathrm{s}$ & 1000 \\
$\delta_{\mathrm{od}}$ & Horizontal exchange rate between 'outside world' & $\mathrm{m}^{3} / \mathrm{s}$ & 1000 \\
$\mathrm{w}_{\mathrm{s}}$ & and delta & $\mathrm{m} / \mathrm{s}$ & 0.0001 \\
$\mathrm{c}_{\mathrm{E}}$ & Vertical exchange rate & - & 0.0002 \\
\hline
\end{tabular}

\subsubsection{Sensitivity Analysis}

In the following sections the impact on the SLRlimit by variation of input values is assessed. For each category of variables two questions are posed: does changing the variable value have impact on the determinative stability limit and what is the morphological explanation of these SLRlimit changes?

In the sensitivity analysis we will vary the variables of each category one by one around their fictitious value presented in Table 3.4. This way we assess the impact of the variation of the variable on the $S L R$ limit. The results of the sensitivity analysis are presented in figures which all have the same structure:

- The varied variable is presented on the horizontal axis (normalised for the variable value presented in Table 3.4)

- The accompanying $S L R$ limit is presented on the vertical axis

- The horizontal line represents the $S L R$ limit for the variable values presented in Table 3.4.

For the fictitious three-element tidal inlet model, the variable values presented in Table 3.4 result in a $S L R$ limit of $166 \mathrm{~cm} /$ century (see Figure 3.11).

\section{Sensitivity to change of area}

Varying the area of the elements seems to have great impact on the stability limit of the tidal inlet. The flat area is determinative and has the greatest impact on the stability limit when increased or decreased (flat area, Figure 3.13). When the flat area is increased the stability limit decreases, when decreased the stability limit increases. The same applies to change of channel area (see channel area, Figure 3.13) and delta area (see delta area, Figure 3.13) but the impact on the stability limit of these changes is less significant. 
SA Fictitious inlet; Area change

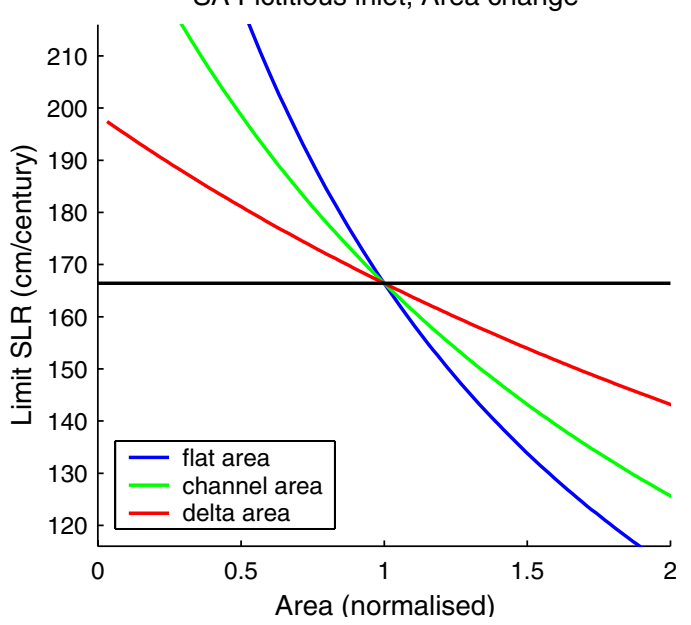

Figure 3.13: Sensitivty of the SLRlimit to change of element area.

To explain this sensitivity we have to consider the model as a serial system. Because the elements are connected serially and the external sediment source is only connected to the ebbtidal delta, the flat element (last element in the system/row) finds it most difficult to satisfy the sediment demand resulting from the sea level rise. If the flat area increases, the flats increased sediment demand results in a decrease of the SLRlimit and visa versa. Towards the ebb-tidal delta the impact on the SLRlimit of an area change decreases because we move closer to the sediment source.

\section{Sensitivity to change of horizontal exchange rate}

The long-term residual diffusive transport between two adjacent elements is controlled by the difference in local sediment concentrations and the horizontal exchange rate (see Section 3.3.3). The larger the horizontal exchange rate, the more sediment will be exchanged is case of difference in local sediment concentration between two adjacent elements. A change of the horizontal exchange rate between the 'outside world' and the ebb-tidal delta seems to have the greatest impact on the stability limit of the system (horizontal exchange od, see Figure $3.14)$.

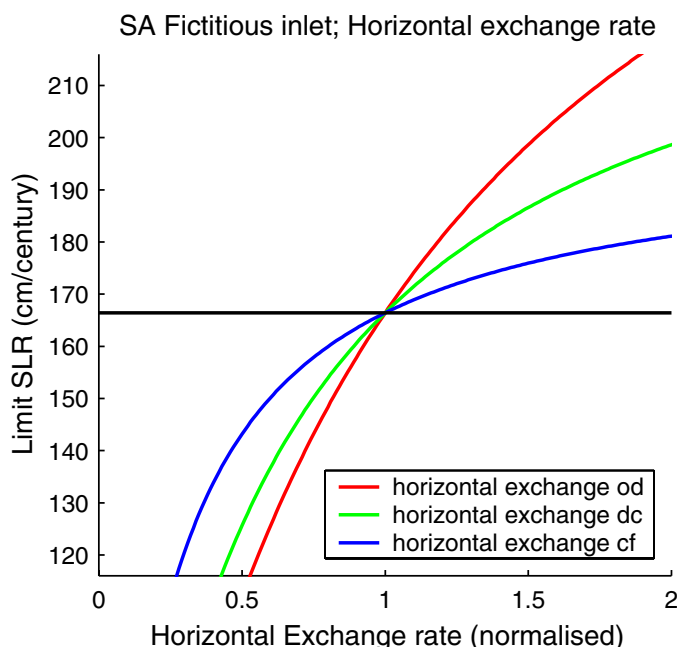

Figure 3.14: Sensitivty of the SLR limit to change of horizontal exchange rates 
If the horizontal exchange rate is increased more sediment is allowed to enter the system and satisfy the sediment demand resulting from the sea level rise. This effect is less pronounced for the horizontal exchange rate between the channel and the flat (horizontal exchange cf, see Figure 3.14) and therefore varying this rate has relatively less impact on the stability limit. Again, if we want to explain this sensitivity we consider the inlet as a serial system. The sediment exchange between the 'outside world' and the system is governed by the horizontal exchange rate of the 'outside world' with the ebb-tidal delta. If this exchange rate is decreased it works as a bottleneck and deprives the system of the sediment necessary to satisfy its demanded. Therefore a change in this variable has the greatest impact on the stability limit of the system.

\section{Sensitivity to change of equilibrium concentration}

The equilibrium concentration in the 'outside world' is the sediment provider of the system. In our three-element model this outside world covers the coastal stretch and the deeper offshore waters. The sediment available in this 'outside world' comes mainly from the coastal stretches, at either side of the outer delta. The equilibrium concentration reflects the sediment concentration made available by wave-induced sediment motion. The transport to the inlet is performed by wave induced longshore currents. Near the inlet, tidal currents take over the sediment transport, transporting it into the basin. Therefore the 'outside world' equilibrium concentration is dependent on the wave action (for the up-stirring process), the longshore current and of course the availability of sediment along the coastal stretches.

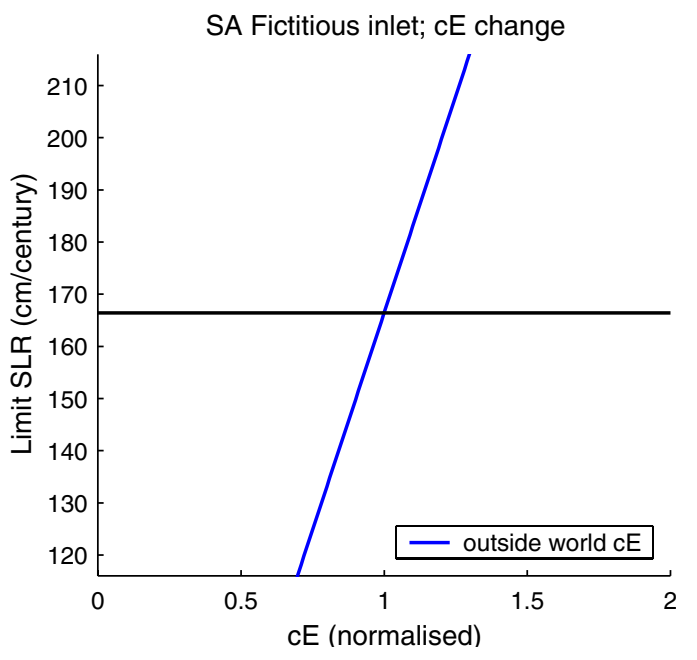

Figure 3.15: Sensitivty of the SLRlimit to change of 'outside world' equilibrium concentration

Figure 3.15 shows that compared to the other analysed variables, the largest sensitivity of the SLRlimit is to variations in the 'outside world' equilibrium concentration. An increase of the concentration provides more sediment to the system and thus makes the system more resistant to a sea level rise. A decrease of the concentration deprives the system of its necessary nourishment capacity and lowers the stability limit of the system.

\section{Sensitivity to change in vertical exchange rate}

As Figure 3.16 shows, a change in the vertical exchange rate $w_{s}$ has a relatively small impact on the stability limit of the system. Only a variation in the vertical exchange rate in the flat element causes noticeable change in the stability limit, though it only becomes significant close to zero, decreasing the ability of the flats to accrete. 
SA Fictitious inlet; Vertical exchange rate

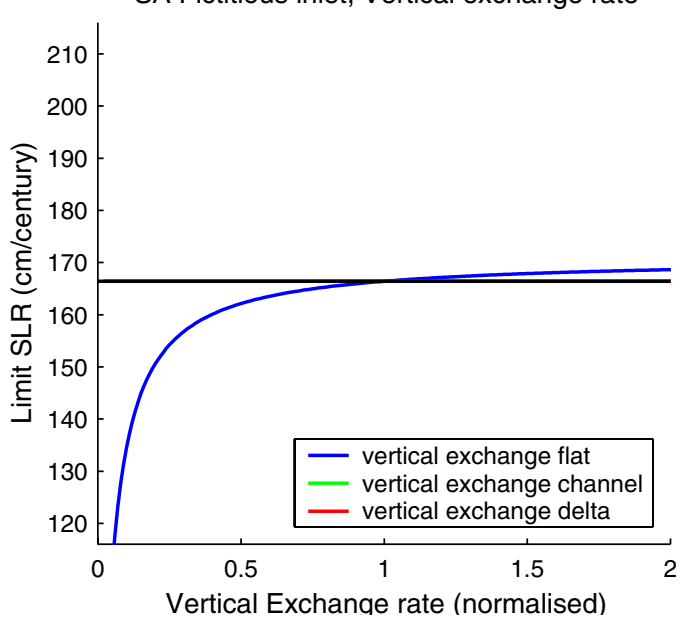

Figure 3.16: Sensitivty of the SLRlimit to change of vertical exchange rate (normalised)

\subsection{Conclusions}

In the preceding sections we have discussed the long-term morphological response of a fictitious tidal inlet to a sea level rise $(S L R)$. Because of the space and time-scales of interest (belonging to this $S L R$ ) we have reverted to an aggregated-scale modelling approach (ASMITA) in order not to be bothered by the predictability limits inherent to presently operational process-based modelling.

In Section 3.3 the modelling concepts of ASMITA have been explained and in Section 3.4 an analytical analysis results in an upper boundary limit for the SLR. When the $S L R$ exceeds this limit value (SLRlimit), the tidal inlet system will no longer regain a state of dynamic equilibrium and drown gradually.

Section 3.5 deals with a sensitivity analysis of the SLRlimit, investigating the impact of changing system variables on the SLRlimit. This analysis reveals that the 'outside world' equilibrium concentration has the most significant impact on the $S L R$ limit, followed by the element area and horizontal exchange rate between adjacent elements. A change of vertical exchange rate seems to have a comparatively negligible effect on the SLRlimit.

To translate the findings of the fictitious inlet case into predictions for actual tidal inlets, in Chapter 4 a couple of actual tidal inlets are subjected to a stability analysis. The resulting stability limits are subjected to a sensitivity analysis and the long-term morphological response of the latter inlets to a rise of the sea level is simulated with the use of ASMITA model runs. 


\section{Stability of actual tidal inlets in the Dutch Wadden Sea}

\section{I Introduction}

The present chapter contains the results of a stability analysis of some actual tidal inlets in the Dutch Wadden Sea in contrast to Chapter 3, where only a fictitious tidal inlet was modelled. In Chapter 3 we acquired insight in the capability of the modelled tidal inlet system to follow a rise of the sea level. This capability primarily depends on three factors:

- The availability of sediment at the seaward boundary of the system

- The sediment demand of the system

- The capability of the system to distributed the imported sediment internally

Here, the first factor applies to the 'outside world' equilibrium concentration $c_{E}$. The second factor, the sediment demand needed to keep pace with the rise of the sea level, depends on the horizontal area $(A)$ of the elements. The third factor applies to the horizontal $(\delta)$ and vertical $\left(w_{s}\right)$ exchange rates, which distributed the imported sediment internally and cause sedimentation of the element areas.

With this knowledge it is interesting to test some actual inlets against their stability under the external forcing of a rising sea level. Furthermore, as we use in the latter stability analysis estimates for the above mentioned element properties and assume that it is reasonable to approximate these properties as time-invariant, an assessment on the impact of variation of the element properties on the SLRlimit seems in place.

For the intended tests, we focus on inlets for which sea level rise plays a presumably dominant role in the evolution. This is outlined in Section 4.2, where a selection of inlets for the tests is given also. The actual tests are described in Section 4.3 and in Section 4.4 the sensitivity analysis is performed to determine to what extent the system variables are decisive for the SLRlimit. Finally, in Section 4.5 we validate the stability analysis against some actual ASMITA runs.

\subsection{Inlet consideration for testing}

\subsection{Introduction}

For the selection of actual tidal inlets appropriate for testing we present some considerations which serve as criteria for the selection. The first criterion is given by the background of the project and means that the research area is focussed on the Dutch Wadden Sea. Section 4.2.2 describes the available inlets in the Dutch Wadden Sea and the considerations that are used for further selection of the inlets. In Section 4.2.3 a brief description is given of the selected inlets. 


\subsubsection{Available Inlets and considerations}

In Table 4.1 a summary of the tidal inlets of the Dutch Wadden Sea is given. It is clear that Wadden Sea has a large diversity in basin areas and tidal prisms, making it an excellent research area.

Table 4.1: Tidal inlets of the Dutch Wadden Sea and their main characteristics

\begin{tabular}{lccc}
\hline Tidal Inlet / Basin & $\begin{array}{c}\text { Basin area } \\
{\left[\mathrm{km}^{2}\right]}\end{array}$ & $\begin{array}{c}\text { Tidal Range } \\
{[\mathrm{m}]}\end{array}$ & $\begin{array}{c}\text { Tidal prism } \\
{\left[10^{6} \mathrm{~m}^{3}\right]}\end{array}$ \\
\hline Marsdiep & 656 & 1.65 & 1015 \\
Eierlandse gat & 161 & 1.65 & 205 \\
Vlie & 719 & 1.90 & 1190 \\
Amelander Zeegat & 269 & 2.15 & 475 \\
Pinkegat & 52 & 2.15 & 80 \\
Zoutkamperlaag & 123 & 2.25 & 195 \\
Eijerlanderbalg & 35 & 2.40 & 48 \\
Lauwers & 128 & 2.45 & 210 \\
Schild & 31 & 2.45 & 42 \\
Eems-Dollard & 467 & 2.70 & 1095 \\
\hline
\end{tabular}

Because the morphology of some basins has been seriously affected by human interference, not all inlets are suitable for testing. This can be related to their 'out of dynamic equilibrium' state. For example the construction of the Afsluitdijk (1932) has largely affected the Marsdiep and Vlie inlets. Also closure works in the eastern Wadden Sea, for example the damming of the Lauwers Zee (1969), has affected the inlets of the Friesche Zeegat (Pinkegat and Zoutkamperlaag). Because we are not sure if these inlets have returned to their morphological dynamic equilibrium state, these inlets are less qualified for the intended tests.

Another consideration concerns the availability of field data. Such data are essential for the tests, but their availability differs considerably from one inlet or region to another. For the western Wadden Sea a relatively large data collection is available, while the data for the eastern Wadden Sea, with relatively smaller inlets, is sparser (except for the Pinkegat and Zoutkamperlaag).

A final consideration for testing is to select (morphology like) different inlets where we can expect different stability limits. This may result in selecting a tidal inlet with a large tidal basin area and one with a small tidal basin area.

These considerations are all taken into account and in agreement with Stive(2000), two inlets are chosen for further testing.

\subsubsection{Tidal Inlets used for further testing}

From the considerations above, two inlets have come forward as most eligible for testing. These two are the Amelander Zeegat inlet (also known as the Borndiep inlet) and the Eierlandse Gat inlet.

\section{Amelander Zeegat}

The inlet of the Amelander Zeegat is situated between the barrier islands of Terschelling and Ameland (see Figure 4.1). Its basin area is situated between the basin areas of the Vlie and the Zoutkamperlaag and has, on a time-scale of centuries, a relatively (morphological) stable 
history, without too much interference by man (negligible sand mining and no closure works). Yet there is a noticeable change in flat area due to the eastward-moving watershed between the Amelander Zeegat and Pinkegat. According to Biegel (2000) the watershed should have reached it's most easterly position by now, squeezing the Pinkegat basin to a minimum size.
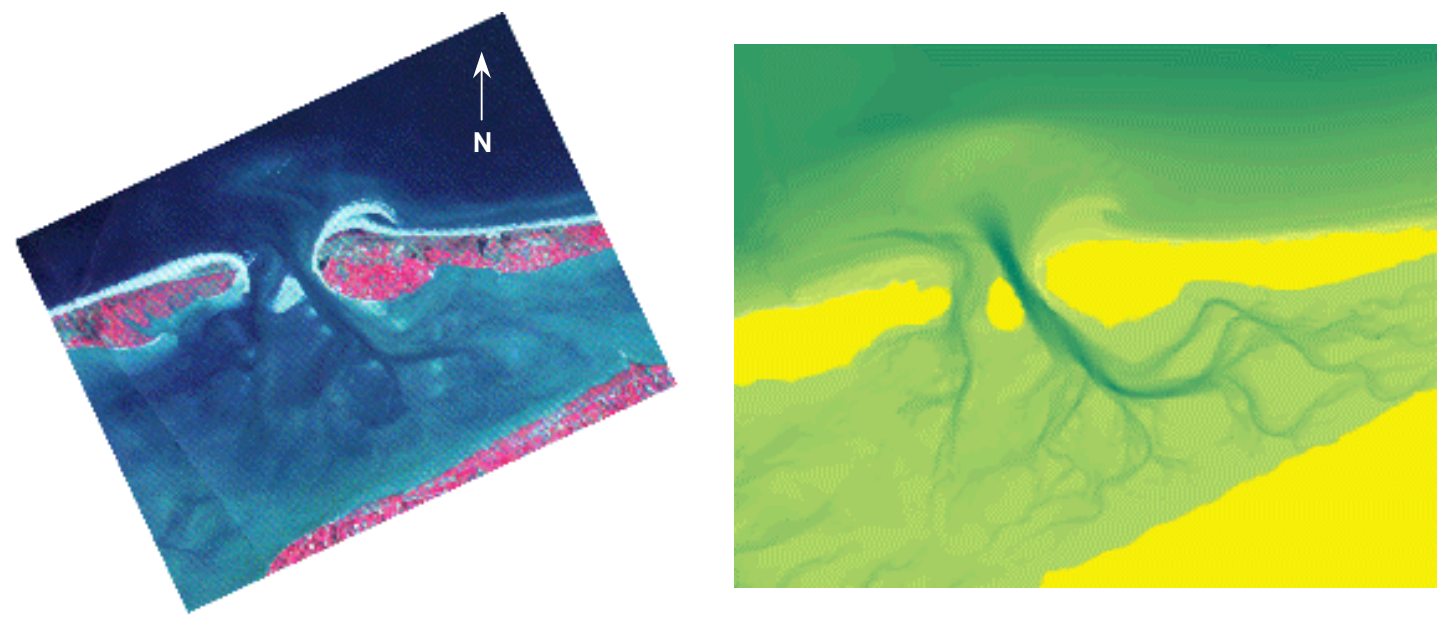

Figure 4.1: Satellite view (left) and depth sounding (right) of the Amelander Zeegat inlet, situated between the barrier islands Terschelling (west) and Ameland (east)

The morphology of the inlet is monitored via regular depth soundings performed since the year 1926, so there is a relatively large data set available for testing. The available data are collected and interpreted in various research projects Biegel (1993); Rakhorst (2000) and are summarised in Appendix C.

\section{Eierlandse Gat}

The inlet Eierlandse Gat is situated between the barrier islands of Texel and Vlieland (see Figure 4.2). The basin area is enclosed between the basin of the Marsdiep and that of the Vlie. Although the latter two basins are subjected to some dramatic morphological changes due to the closure of the Zuider Sea, no significant changes to the Eierlandse Gat basins have been reported. There have been some changes in the tidal range and some displacement of the watershed though. Whether these changes have had significant consequences for the morphology of the Eierlandse Gat, is uncertain and in this study these effects are assumed negligible.

The tidal flat area is compared to that of the Amelander Zeegat inlet, relatively small which makes it an interesting counterpart of the Amelander Zeegat case. As for the latter, the morphology of the Eierlandse Gat inlet is regularly monitored with the first available depth soundings in 1933. A summary of the available data can be found in Appendix C. 

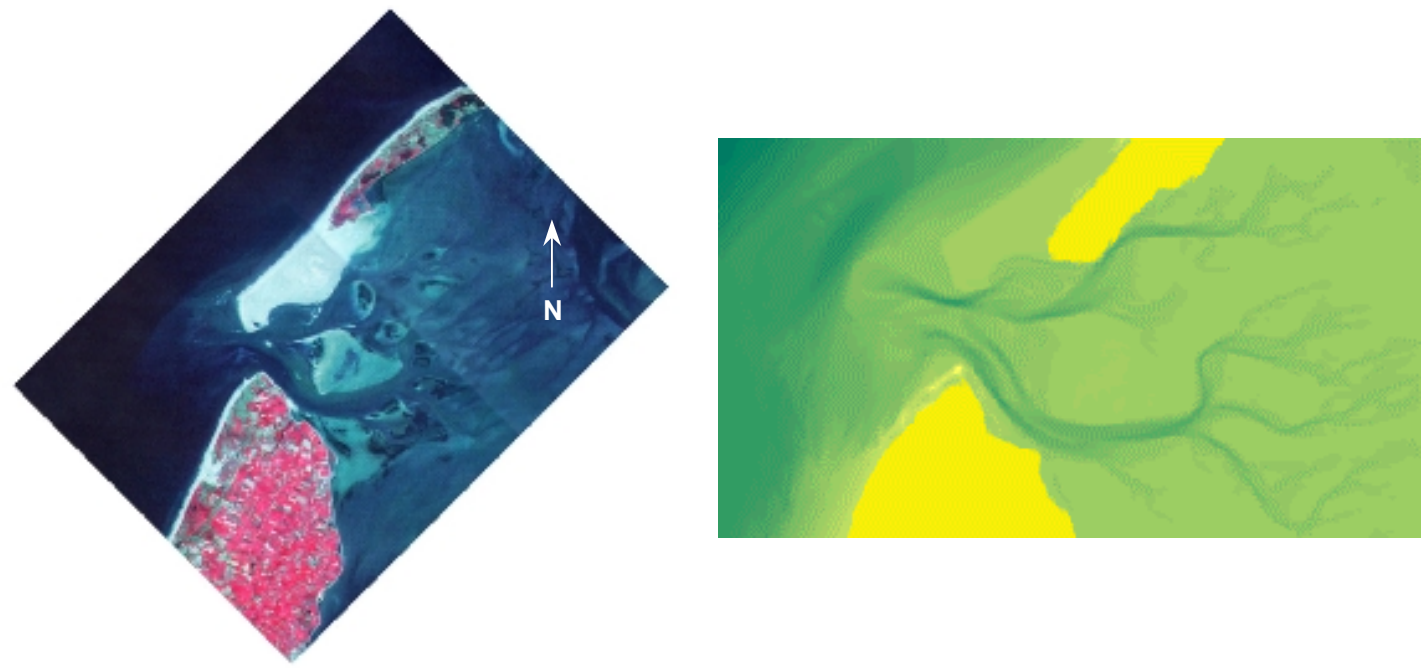

Figure 4.2: Satellite view (left) and depth sounding (right) of the Eierlandse gat inlet, situated between the barrier islands Texel (west) and Vlieland (east)

\subsection{Stability analysis}

\subsection{Introduction}

As in Section 3.4.4, the stability analysis for the two case-study inlets systems is performed using a schematised three-element model. The system variables are derived from Biegel (1993), see Appendix C. We assume that the considered inlet systems have been more or less in a state of equilibrium over the past three decades. Therefore, the areas and volumes of the elements are taken as the mean over those observations that cover this period.

\subsubsection{Amelander Zeegat}

For the stability analysis the following properties of the Amelander Zeegat inlet are used:

Table 4.2: Element characteristics Amelander Zeegat

\begin{tabular}{lccccccc}
\hline Element & $\begin{array}{c}\text { Area } \\
{\left[\mathrm{m}^{2}\right] \cdot 10^{7}}\end{array}$ & $\begin{array}{c}\text { Volume } \\
{\left[\mathrm{m}^{3}\right] \cdot 10^{8}}\end{array}$ & $\begin{array}{c}\mathrm{W}_{\mathrm{s}} \\
{[\mathrm{m} / \mathrm{s}] \cdot 10^{-4}}\end{array}$ & $\begin{array}{c}\delta_{\text {od }} \\
{\left[\mathrm{m}^{3} / \mathrm{s}\right]}\end{array}$ & $\begin{array}{c}\delta_{d c} \\
{\left[\mathrm{~m}^{3} / \mathrm{s}\right]}\end{array}$ & $\begin{array}{c}\delta_{c f} \\
{\left[\mathrm{~m}^{3} / \mathrm{s}\right]}\end{array}$ & $\begin{array}{c}c_{E} \\
{[-] \cdot 10^{-4}}\end{array}$ \\
\hline Ebb-tidal delta & 7.47 & 1.31 & 0.1 & & & & \\
Channel & 9.83 & 3.02 & 0.5 & 1500 & 1500 & 1000 & 2.0 \\
Flat & 17.8 & 1.20 & 1.0 & & & & \\
\hline
\end{tabular}

The above values represent the morphological dynamic equilibrium of the elements at the present rate of sea level rise. The values for the horizontal and vertical exchange rates are estimates used based on a calibration by Buijsman (1997).

In Figure 4.3 the current state of dynamic equilibrium (under the external forcing of $17 \mathrm{~cm}$ sea level rise per century) is represented by the vertical line. With a lager rate of sea level rise (moving further to the right in the in plot) we see that the dynamic equilibrium volume of the channel element increases (wet volume) and that the dynamic equilibrium volumes of the flat and ebb-tidal delta element decrease (sediment volume). 


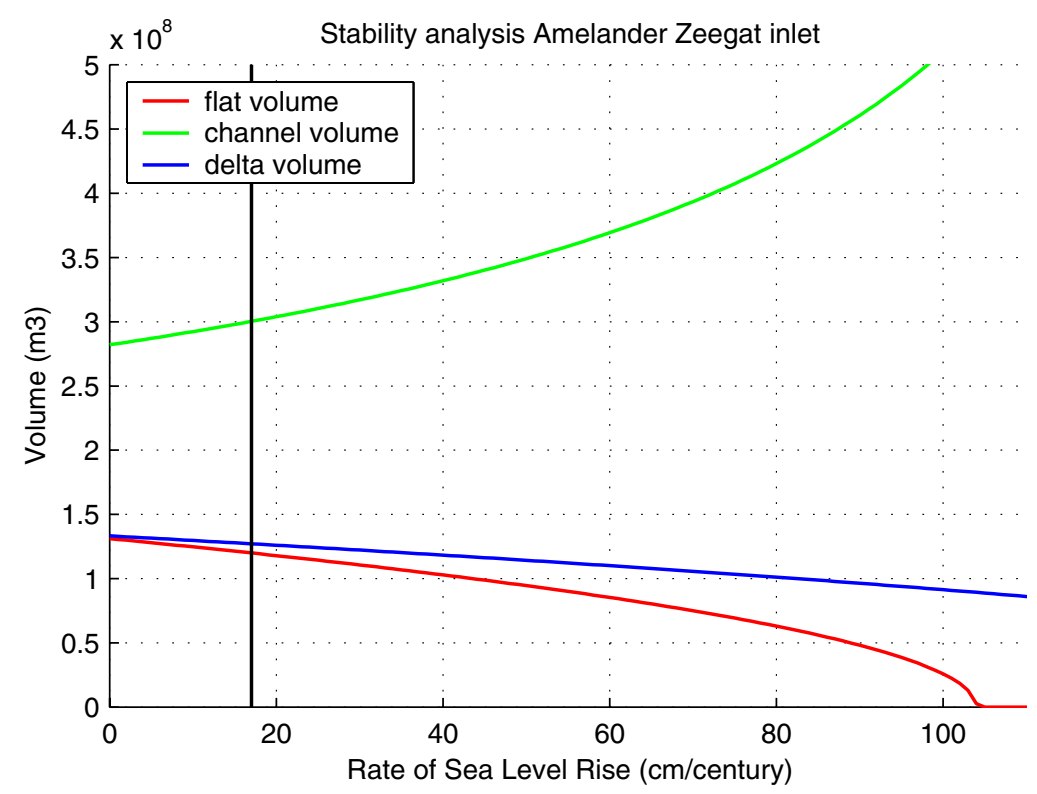

Figure 4.3: Dynamic equilibrium volumes of Amelander Zeegat inlet as function of a constant external forcing; the accelerated rate of sea level rise.

The faster the sea level rises, the more the element volumes have to deviate from the equilibrium volumes $\left(V_{e}\right)$ belonging to a constant sea level $(d \zeta / d t=0)$. This deviation stimulates the system to follow the rising sea level (see also sediment retention mechanism, Section 2.2.6). In the case of a constant sea level rise rate $\left(d^{2} \zeta / d t^{2}=0\right)$ the change in element volumes might reduce in time towards zero $(d V / d t=0)$. In that case the system has reached a stable situation (a state of 'dynamic' equilibrium), in which the elements have reached a new 'dynamic' equilibrium volume $\left(V_{e}^{*}\right)$. The difference in equilibrium volume $\left(V_{e}-V_{e}^{*}\right)$ is necessary to maintain the need of sediment which causes a sediment import into the system to such an extent that the system does not drown.

The tidal inlet drowns in case the element volumes increasingly deviate from $V_{e}$ and no new stable situation is formed (no 'new' state of dynamic equilibrium). For the Amelander Zeegat case, with the element properties as shown in Table 4.2, Figure 4.3 shows that the stability limit (SLRlimit) lies at a rise of the sea level of $105 \mathrm{~cm}$ per century.

\subsubsection{Eierlandse Gat}

For the stability analysis of the Eierlandse Gat inlet, the following properties are used:

Table 4.3: Element characteristics Eierlandse Gat

\begin{tabular}{lccccccc}
\hline Element & $\begin{array}{c}\text { Area } \\
{\left[\mathrm{m}^{2}\right] \cdot 10^{7}}\end{array}$ & $\begin{array}{c}\text { Volume } \\
{\left[\mathrm{m}^{3}\right] \cdot 10^{8}}\end{array}$ & $\begin{array}{c}\mathrm{W}_{\mathrm{s}} \\
{[\mathrm{m} / \mathrm{s}] \cdot 10^{-4}}\end{array}$ & $\begin{array}{c}\delta_{o d} \\
{\left[\mathrm{~m}^{3} / \mathrm{s}\right]}\end{array}$ & $\begin{array}{c}\delta_{d c} \\
{\left[\mathrm{~m}^{3} / \mathrm{s}\right]}\end{array}$ & $\begin{array}{c}\delta_{c f} \\
{\left[\mathrm{~m}^{3} / \mathrm{s}\right]}\end{array}$ & $\begin{array}{c}c_{E} \\
{[-] \cdot 10^{-4}}\end{array}$ \\
\hline Ebb-tidal delta & 3.78 & 1.32 & 0.1 & & & & \\
Channel & 5.27 & 1.06 & 0.5 & 1500 & 1500 & 1000 & 2.0 \\
Flat & 10.5 & 0.55 & 1.0 & & & & \\
\hline
\end{tabular}

Similar to the Amelander Zeegat case, the element properties shown in Table 4.3 represent the morphological dynamic equilibrium of the inlet at the present rate of sea level rise.

In Figure 4.4 the current state of dynamic equilibrium (under the external forcing of $17 \mathrm{~cm}$ sea level rise per century) is represented by the vertical line. A larger rate of sea level rise 
(moving further to the right in the in plot) results in a dynamic equilibrium volume increase of the channel element (wet volume) and a dynamic equilibrium volume decrease of the flat and ebb-tidal delta element (sediment volume).

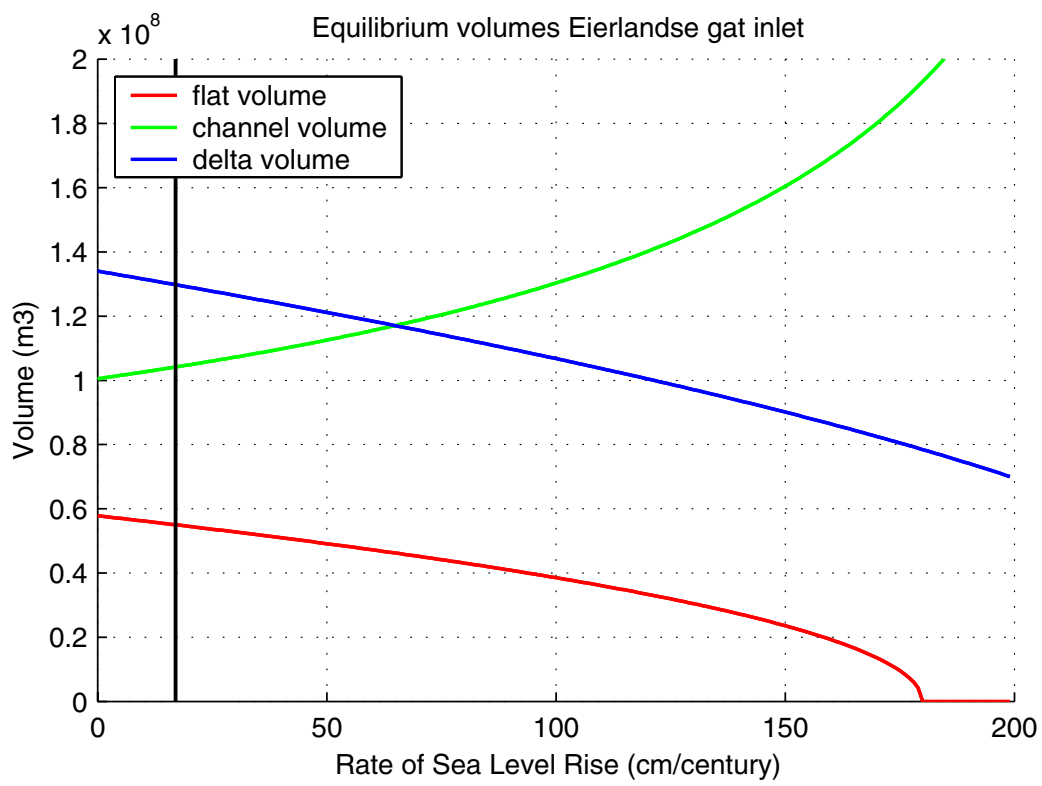

Figure 4.4: Dynamic equilibrium volumes of Eierlandse Gat inlet as function of a constant external forcing; the accelerated rate of sea level rise.

Analogously to the Amelander Zeegat inlet, for a faster rise in sea level the elements of the Eierlandse Gat have to deviate more from their equilibrium volumes $\left(V_{e}\right)$ belonging to a constant sea level $(d \zeta / d t=0)$. Due to this deviation the system is stimulated to follow the rising sea level and develops an increased demand for sediment. In the case of a constant sea level rise rate $\left(d^{2} \zeta / d t^{2}=0\right)$ the system might reach a stable situation $(d V / d t=0)$, in which the elements have reached a 'new' dynamic equilibrium volume $\left(V_{e}^{*}\right)$. The difference in equilibrium volume $\left(V_{e}-V_{e}^{*}\right)$ is necessary to maintain the need of sediment and thus the necessary sediment import.

The tidal inlet drowns in case the element volumes increasingly deviate from $V_{e}$ and no new stable situation is formed (no 'new' state of dynamic equilibrium). For the Eierlandse Gat case, with the element properties as shown in Table 4.3, Figure 4.4 shows that the stability limit (SLRlimit) lies at a rise of the sea level of $180 \mathrm{~cm}$ per century.

\subsection{Sensitivity Analysis}

\subsection{Introduction}

To investigate which element properties dominate the SLRlimit of the two studied inlets, a sensitivity analysis is performed. In the figures representing the sensitivity analysis, the element properties are normalised for their initial equilibrium value (as presented in Table 4.2 and 4.3) The horizontal line in the following figures represents the SLRlimit for the element properties as presented in Table 4.2 and 4.3. 


\subsubsection{Sensitivity to a change of the area}

From the results presented in the Figures 4.5 and 4.6, it can be seen that the SLRlimit shows a significant sensitivity to a change of the area. An increase of the element area results in a decrease of the SLRlimit and visa versa. Analogous to the sensitivity analysis performed Section 3.5.3, the stability limit is more sensitive to a change of flat area then to a change of ebb-tidal delta area. This is probably due to the element positions relative to the sediment supplying 'outside world'.
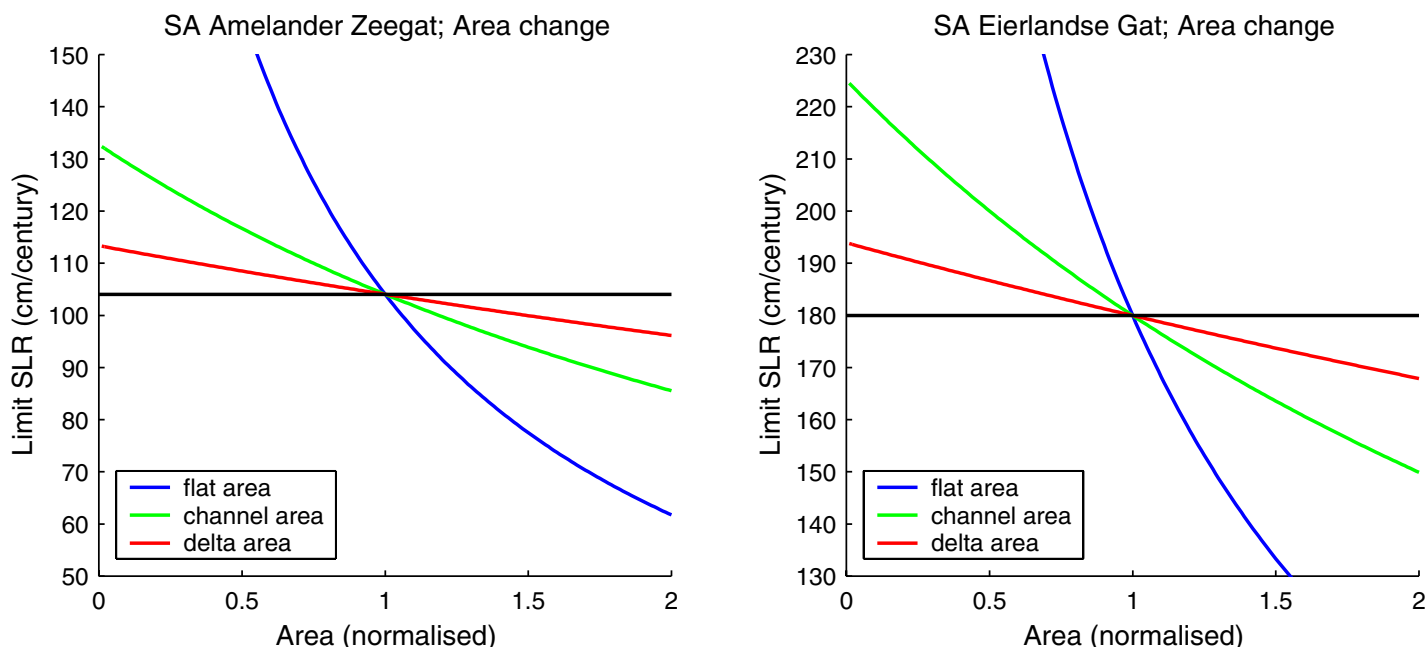

Figure 4.5, 4.6: Sensitivty of SLRlimit to change of element area for Amelander Zeegat (left) and Eierlandse Gat (right).

As shown in Figures 4.5 and 4.6, the smaller of the two basins (Eierlandse Gat) has a higher stability limit but is more sensitive to a change in area than the largest basin (Amelander Zeegat).

We may derive from this analysis that a change of area has significant impact on the stability limit. Presently, the element areas are well known to us (by satellite and depth soundings) and introduce small uncertainties. However, the future developments of the basin areas are less known to us and might cause significant uncertainties to the SLRlimit predictions. It is conceivable that due to a rise of the sea level the basin area expands and thus the SLRlimit decreases. On the other hand, a rising sea level might cause a migration of barrier islands towards the mainland (see Section 2.1.3, development of the eastern Wadden Sea) and thus a decrease in the basin area which results in an increase of the SLRlimit. As the future developments of the tidal basin areas are unfeasible to predict, we presume that it is reasonable to approximate the basin areas as time-invariant at their present size.

\subsubsection{Sensitivity to change of horizontal exchange rate}

The sensitivity analysis on variation of horizontal exchange rate shows that, just like in the fictitious case, the $S L R$ limit is highly sensitive to a change of the horizontal exchange rate. The stability limit increases or decreases with increasing or decreasing horizontal exchange rate. As can be seen from the Figures 4.7 and 4.8, the rate of exchange between the ebb-tidal delta and its surrounding 'outside world' has a larger influence on the stability limit than the rates of exchange between delta and channel and between channel and flat. This is probably because the exchange with the 'outside world' provides the inlet system with the sediment it needs to adapt continuously to the rising sea level. 

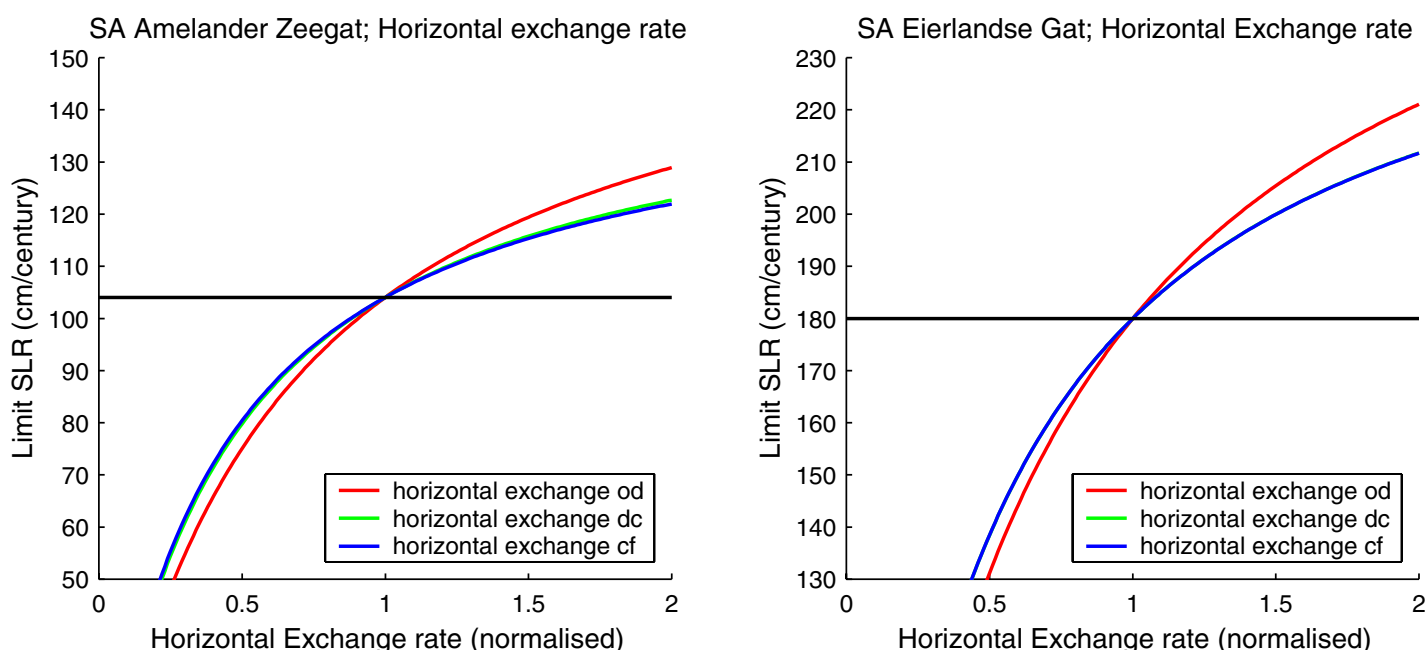

Figure 4.7, 4.8: $\quad$ Sensitivty of SLR limit to change of horizontal exchange rate for Amelander Zeegat (left) and Eierlandse Gat (right). Horizontal exchange od refers to 'outside world'- delta, de to delta channel and cf to channel-flat.

From comparing the steepness of the curves in the above figures that reflect the analysed sensitivity, it follows that the smaller of the two inlets (Eierlandse Gat) is more sensitive to a change than the largest inlet (Amelander Zeegat).

In the sensitivity analysis we have varied the horizontal exchange rates around the estimates given by Buijsman (1997). Because the horizontal exchange rates are impracticable variables to measure in the field and the underlying processes of the long-term residual sediment exchange are not exactly known to us, a considerable lack of knowledge exists towards the estimates of the horizontal exchange rate. The relatively large sensitivity of the SLR limit to a change of these variables combined with the considerable lack of knowledge that exists towards the estimates of these variables result in a significant uncertainty in the SLRlimit predictions.

\subsubsection{Sensitivity to change of equilibrium concentration}

In estimating the maximum rate of sea level rise an inlet can keep pace with (see Section 4.3 'stability analysis'), we have assumed a time-invariant equilibrium concentration for the 'outside world'. Figure 4.9 and Figure 4.10 show that a higher 'outside world' equilibrium concentration $c_{E}$ leads to a significant higher $S L R$ limit and a lower $c_{E}$ leads to a significant smaller SLRlimit. Again, the stability limit of the smaller of the two studied inlets (Eierlandse Gat) is more sensitive to a change in $c_{E}$ than the larger inlet (Amelander Zeegat).

In Section 3.5.3 ('Sensitivity to change of equilibrium concentration'), we presume the 'outside world' equilibrium concentration dependent of wave-induced sediment transport and longshore currents. This presumption makes it likely that a change in wave climate results in a change of the potential sediment supply to the system. The large uncertainties that exist towards the present longshore sediment transport and the future wave climate (related to a possible change of NAO index due to global warming, see Section 5.2.3) result in a significant uncertainty in the $c_{E}$. This uncertainty combined with the significant sensitivity of the SLRlimit for a change of the $c_{E}$ results in a significant uncertainty in the predicted SLRlimit. 

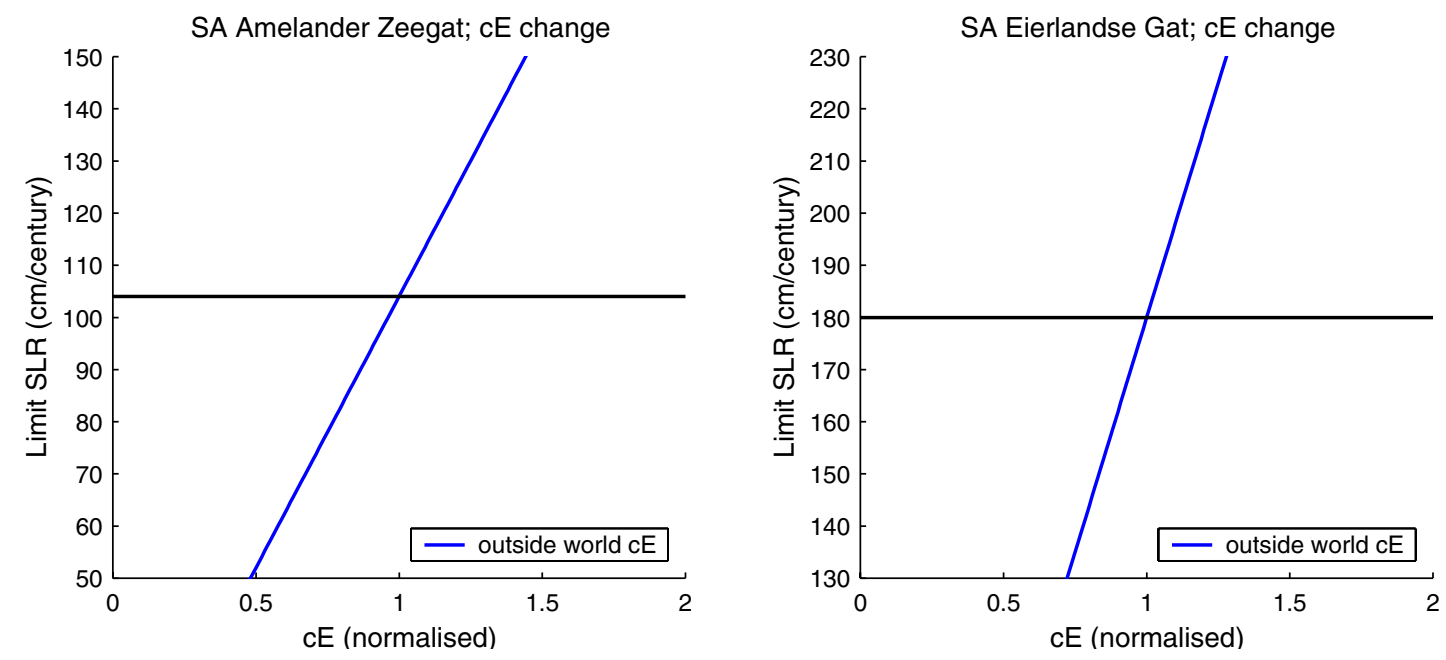

Figure 4.9, 4.10 : Sensitivty of SLRlimit to change of 'outside world' equilibrium concentration for Amelander Zeegat (left) and Eierlandse Gat (right).

\subsubsection{Sensitivity to change in vertical exchange rate}

The last variable subjected to the sensitivity analysis is the vertical exchange rate. As expected from Section 3.5.3, the impact on the SLRlimit of a change of the vertical exchange rate is relatively small. This is shown in Figures 4.11 and 4.12.

For the SLRlimit, only the vertical exchange rate for the flat element seems to matter, though the sensitivity becomes significant only for values close to zero, in which case hardly any sedimentation can take place at the flats. Again, the SLRlimit of the smaller inlet (Eierlandse Gat) seems to be more sensitive to a variation of the vertical exchange rate than the larger of the two inlets (Amelander Zeegat).
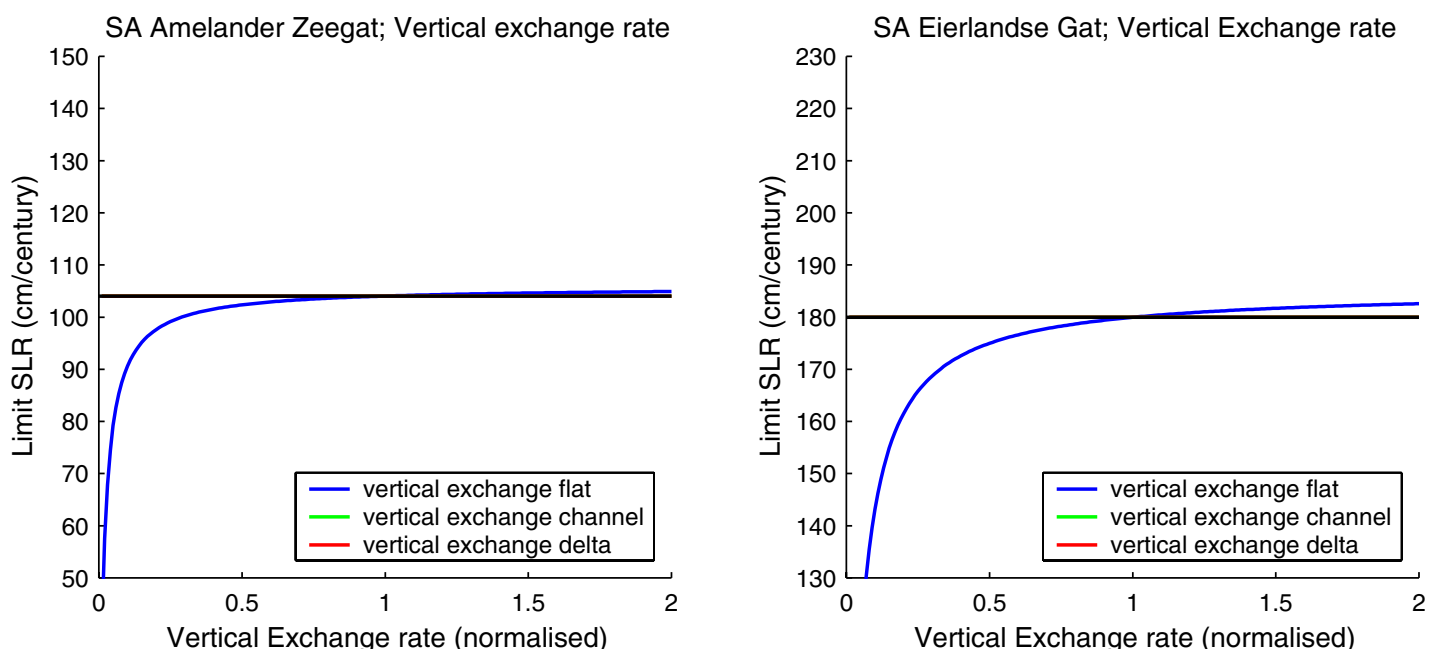

Figure 4.11, 4.12: Sensitivty of SLRlimit to change of vertical exchange rate for Amelander Zeegat(left) and Eierlandse Gat (right).

Compared to what has been found for the horizontal exchange and the 'outside world' equilibrium concentration, the stability limit (SLRlimit) appears to be not very sensitive to a variation of the vertical exchange rate, at least not within a presumably physically realistic range. If we combine this with the expectation that this rate will not show much variation over the coming centuries, we may conclude that uncertainties in the applied estimate of this particular parameter will hardly affect the reliability of the predicted stability limit. 


\subsection{ASMITA runs}

\subsection{Introduction}

In the stability analysis performed in Section 4.3 we have solved the ASMITA equations for the special case of dynamic equilibrium $(d V / d t=0)$ and subsequently derived for which sea level rise $d \zeta / d t$ the tidal inlet system becomes unstable (which resulted in the SLRlimit). In the present section we will monitor, for three scenarios of sea level rise, the volume development of the elements in time towards their 'new' state of dynamic equilibrium ( $d V / d t=0$ with volume $V_{e}^{*}$ ). The volume development in time is of interest to us as it gives insight in the development towards a 'new' state of dynamic equilibrium and gives us an indication of the accompanying morphological time-scales.

Runs have been made for the present rate of sea level rise, the most likely scenario rate of sea level rise and the worst case scenario rate of sea level rise (see Section 2.2.5). The element properties are based on the system variables as presented in Tables 4.2 and 4.3.

\subsubsection{Present rate of sea level rise}

For the present rate of sea level rise $(17 \mathrm{~cm} /$ century $)$ we assume the considered inlets in dynamic equilibrium, meaning no volume changes take place. For both inlets we start the simulation in the year 2000 and make a run for 500 years to the year 2500. See Figure 4.13, 4.14, and Appendix D1, E1 for results.
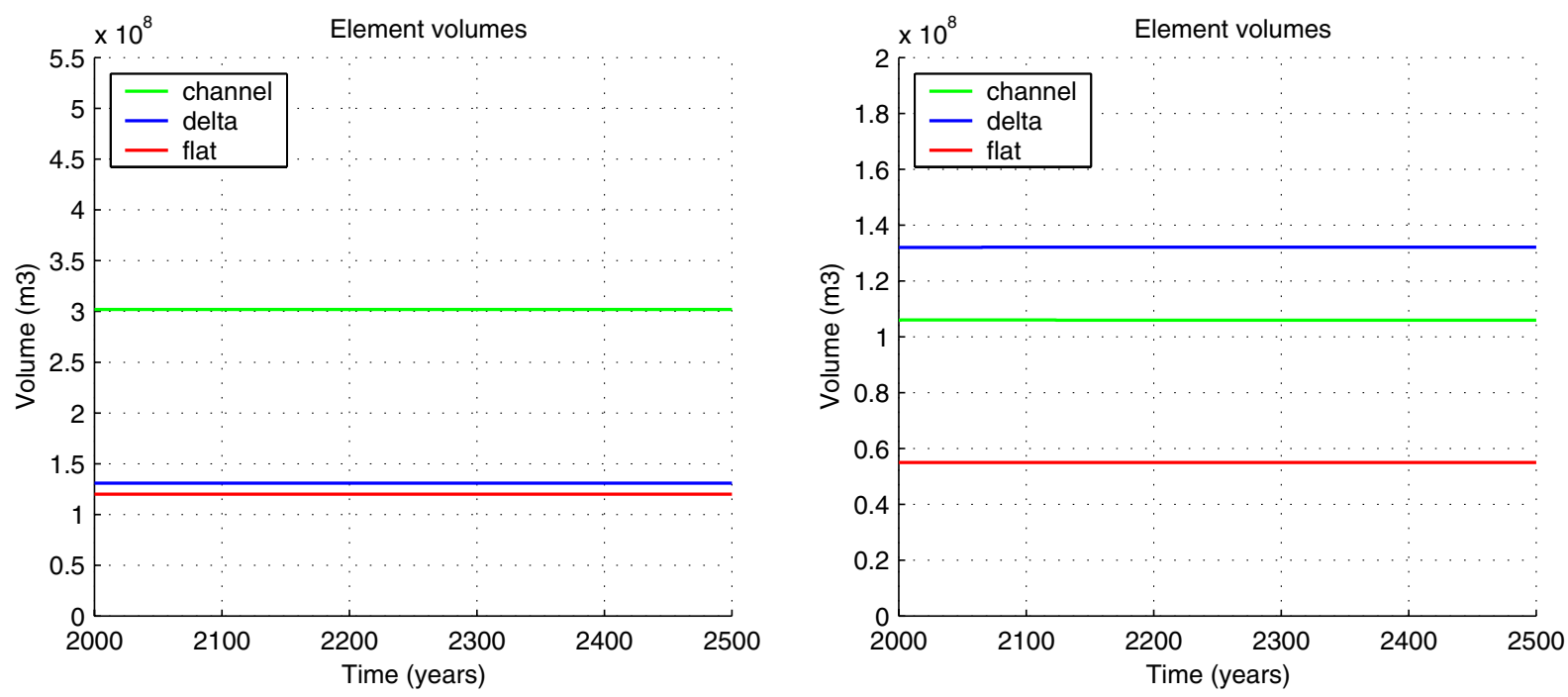

Figure 4.13, 4.14: Volume development for the Amelander Zeegat (left) and the Eierlandse Gat (right) for the present sea level rise $(17 \mathrm{~cm} /$ century).

As both inlets have been calibrated for dynamic equilibrium under the present rate of relative sea level rise, we see a constant volume of the elements in time. In Appendix D1 and E1 the development of the tidal prism is shown. Because the element volumes do not vary with time, the tidal prism does not either.

In Appendix D2 and E2 the long-term residual diffusive sediment transports are shown for both inlets. As expected, sea level rise yields an inward the residual sediment transport. The 'outside world' provides the ebb-tidal delta with respectively about 0.6 and 0.3 million $\mathrm{m}^{3}$ of 
sediment per year. This is the total sediment supply to the system, which is used partly for accretion of the ebb-tidal delta (to maintain its dynamic equilibrium volume) and the remaining part is transported further into the system. In the channels, a part of the sediment accretes so that the dynamic equilibrium volume of the channels can be maintained. The other part is transported to the flats to maintain their dynamic equilibrium volume. As mentioned before, in case of stability, the actual accretion matches the sea level rise induced sediment demand. Table 4.4 shows the amount of sediment transported between the elements.

$\underline{\text { Table 4.4: Equilibrium sediment transports between elements; rate of sea level rise } 17 \mathrm{~cm} / \mathrm{century}}$

\begin{tabular}{lcc}
\hline & \multicolumn{2}{c}{ Transport [million $\mathrm{m}^{3} /$ year] } \\
Transport direction & Amelander Zeegat & Eierlandse Gat \\
\hline $\begin{array}{l}\text { Outside world to } \\
\text { ebb-tidal delta }\end{array}$ & 0.596 & 0.332 \\
\hline $\begin{array}{l}\text { Ebb-tidal delta to } \\
\text { channels }\end{array}$ & 0.466 & 0.268 \\
\hline Channels to flats & 0.302 & 0.179 \\
\hline
\end{tabular}

In Table 4.5, the equilibrium sediment accretion in the elements is given. In case of equilibrium, the actual accretion matches the rate of sea level rise and, evidently, the sum of accretion (total sediment input) equals the sediment supply from the 'outside world'.

Table 4.5: Equilibrium sediment demand/ accretion in elements; rate of sea level rise $17 \mathrm{~cm} /$ century

\begin{tabular}{lcc}
\hline Element & \multicolumn{2}{c}{$\begin{array}{c}\text { Sediment demand/accretion [million } \mathrm{m}^{3} / \text { year] } \\
\text { Amelander Zeegat }\end{array}$} \\
\hline Ebb-tidal delta & 0.130 & Eierlandse Gat \\
Channels & 0.164 & 0.064 \\
Flats & 0.302 & 0.089 \\
\hline Total sediment demand & 0.596 & 0.179 \\
\hline
\end{tabular}

In Appendix D2 and E2 the local actual sediment concentration and local equilibrium concentrations are shown for each element. The difference between the actual and the equilibrium concentration is a measure for the demand of sediment of an element (see Section 3.3.4). Together with the vertical exchange rate, this difference determines the accretion rate.

The difference in actual sediment concentrations of two adjacent elements can be interpreted as a concentration gradient that incites a diffusion-type of transport between these elements. Together with the horizontal exchange rate, the local sediment concentration difference controls the amount of sediment transported between two adjacent elements per unit of time.

To preserve the dynamic equilibrium of the system, the local equilibrium concentrations must be smaller than the 'outside world' equilibrium concentration $c_{E}$ (in our cases $c_{E}$ is $2 \cdot 10^{-4}$, see Tables 4.2 and 4.3), to maintain the systems need of sediment and thus the tendency to import sediment, which is necessary to evolve in coherence with the sea level rise.

\subsubsection{Most likely scenario case}

The most likely scenario case concerns a linearly accelerating rate of sea level rise up to 56 $\mathrm{cm} /$ century in 2100. In the year 2100 the rate of sea level rise stabilises and continues at a rate 
of $56 \mathrm{~cm} /$ century. Again for both inlets we start the ASMITA simulation in the year 2000 and make a run for 500 years to the year 2500. See Figures 4.15, 4.16 and Appendix D3, E3.
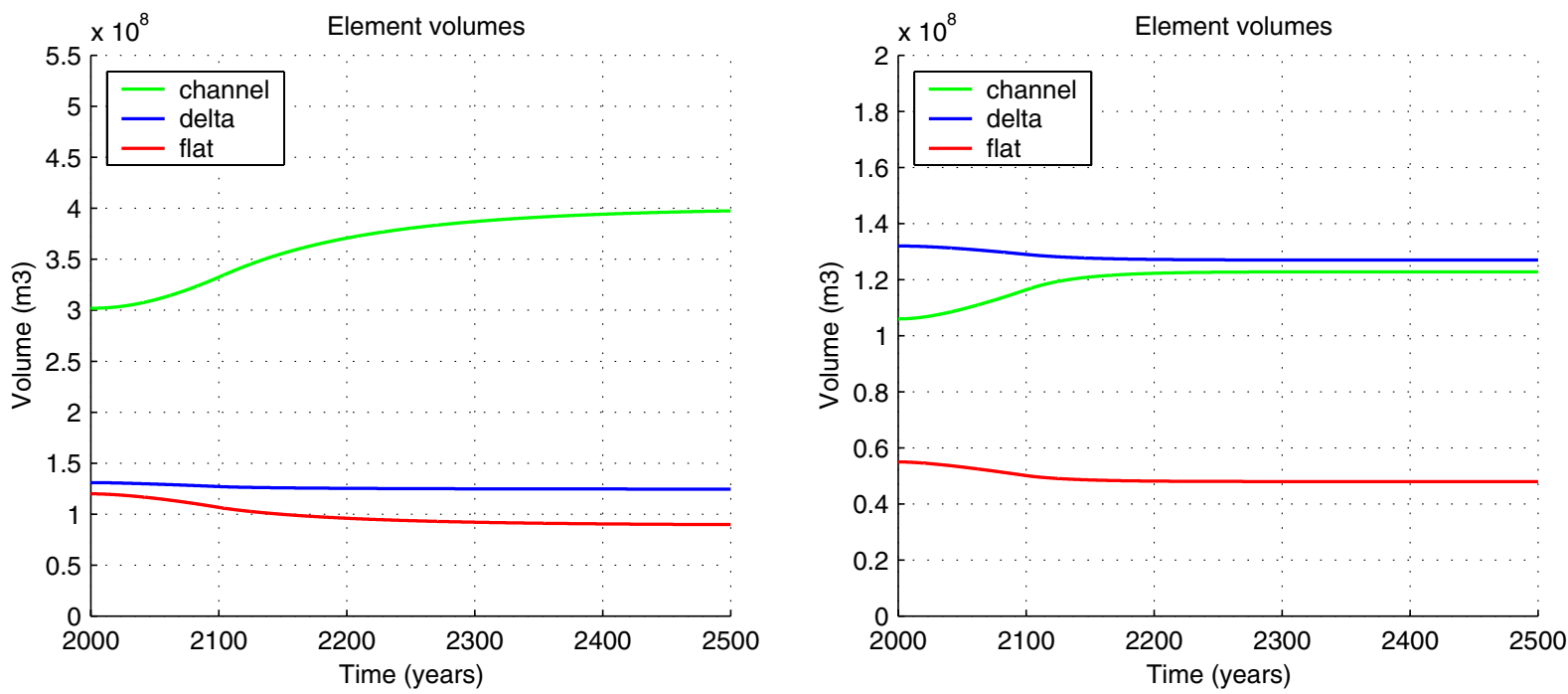

Figure 4.15, 4.16: Volume development for the Amelander Zeegat (left) and the Eierlandse Gat (right) for an accelerating rate of sea level rise up to $56 \mathrm{~cm} /$ century in 2100 .

Due to the increasing sea level rise both inlets are slightly thrown out of equilibrium and have to adapt their volumes to regain a new state of dynamic equilibrium. For both inlets we see a volume decrease of the flats (sediment volume) and a volume increase of the channels (wet volume). These volume changes represent a deepening of the tidal basins. The figures clearly show that the systems need time to adapt to the external forcing and reach a 'new' state of dynamic equilibrium. This adaptation time is considered as the morphological time-scale of the system to the external forcing of this specific acceleration of the sea level rise. As expected, for the larger system (the Amelander Zeegat) this adaptation time is larger than for the smaller system (the Eierlandse gat).

The volume measured between MLW and MHW over the entire area of the tidal basin is taken completely by the combination of tidal prism and volume of flats. If we assume that neither the area of the basin nor the difference between MHW and MLW varies with time, any change in the volume of the flats will result in an equal but opposite change in the tidal prism and vice versa. This mutual dependence is included in the ASMITA computations, but it is neglected in the stability analysis presented in Section 4.3. This explains why the ASMITA results indicate other equilibrium volumes than what has been found in the stability analysis. For the channels of, for instance, the Amelander Zeegat and a sea level rising constantly at a rate of $56 \mathrm{~cm}$ per century, the stability analysis results in a dynamic equilibrium volume of 3.5. $10^{8} \mathrm{~m}^{3}$ (see Figure 4.3) whereas according to the ASMITA output presented in Figure 4.15 , the 'new' dynamic equilibrium state will be reached at a volume of approximately $4.0 \cdot 10^{8} \mathrm{~m}^{3}$. Due to the increase in tidal prism (see Appendices D3 and E3), the volume decrease of the ebb-tidal delta will be less and the volume increase of the channels will be more than predicted in the stability analysis (Section 4.3). The prediction of the equilibrium flat volume matches the result from the ASMITA computations, as the equilibrium flat volume is not a function of the tidal prism.

In Appendix D4 and E4, the residual diffusive sediment transports and the sediment concentration development for both inlets are shown. In the figures concerning sediment transport it is shown that the inward sediment transport has to grow to satisfy the systems increased sediment demand. We can see that the 'sediment retention' mechanisms need some 
time to generate the inward sediment transport (see also Section 2.2.6). After the systems have reached their new dynamic equilibrium state, sediment transport stabilises. In the first period of the simulation for the Amelander Zeegat inlet (years 2050 - 2100), sediment transport from the channel to the flat equals the sediment transport from the ebb-tidal delta to the channel. This means that in this period of time the channel does not accrete and that its wet volume will increase rapidly. For the Eierlandse Gat this is not the case as the sediment demand of the smaller flat area is not as large as in Amelander Zeegat basin.

For the situation that the tidal inlet systems have reached a 'new' state of dynamic equilibrium, Table 4.6 shows the equilibrium sediment transports between the elements.

Table 4.6: Equilibrium sediment transports between elements; rate of sea level rise $56 \mathrm{~cm} /$ century

Transport [million $\mathrm{m}^{3} /$ year]

\begin{tabular}{lcc} 
Transport direction & Amelander Zeegat & Eierlandse Gat \\
\hline $\begin{array}{l}\text { Outside world to } \\
\text { ebb-tidal delta }\end{array}$ & 1.965 & 1.095 \\
\hline $\begin{array}{l}\text { Ebb-tidal delta to } \\
\text { channels }\end{array}$ & 1.547 & 0.883 \\
\hline Channels to flats & 0.997 & 0.588 \\
\hline
\end{tabular}

In Table 4.7, the equilibrium sediment accretion in the elements is given. Once the systems have reached their 'new' state of dynamic equilibrium, the accretion matches the rate of sea level rise and as expected, the total accretion equals the sediment supply from the 'outside world'.

Table 4.7: Equilibrium sediment demand/accretion in elements; rate of sea level rise $56 \mathrm{~cm} /$ century

\begin{tabular}{lcc}
\hline Element & \multicolumn{2}{c}{$\begin{array}{c}\text { Sediment demand/accretion [million } \mathrm{m}^{3} / \text { year] } \\
\text { Amelander Zeegat }\end{array}$} \\
\hline Ebb-tidal delta & 0.418 & Eierlandse Gat \\
Channels & 0.550 & 0.212 \\
Flats & 0.997 & 0.295 \\
\hline Total sediment demand & 1.965 & 0.588 \\
\hline
\end{tabular}

Appendix D4 and E4 show the development of local sediment and local equilibrium concentration for each element. As the systems have an increased need of sediment (compared to the present $S L R$ scenario) to satisfy the sediment demand the equilibrium concentration and actual sediment concentrations are lower than in the preceding scenario. This way the difference in sediment concentration between the 'outside world' and the system increases. As an ever-larger difference in sediment concentration results in an increasing inward sediment transport, the systems sediment demand is satisfied and a 'new' state of dynamic equilibrium is reached.

\subsubsection{Worst case scenario}

The worst case scenario involves a linearly accelerating rate of sea level rise up to 85 $\mathrm{cm} /$ century in 2100 . After the year 2100 the sea level rise stabilises at a rate of $85 \mathrm{~cm} /$ century. Again for both inlets we start the ASMITA simulation in the year 2000. As the Eierlandse Gat is smaller than the Amelander Zeegat, it requires less time to reach a new state of dynamic equilibrium. Model computations show that already after some 200 to 300 years the volumes 
of the various elements of this inlet system hardly vary with time any more. For the Amelander Zeegat, this takes up to about 800 years. See Figure 4.17, 4.18 (App. D5 and E5).
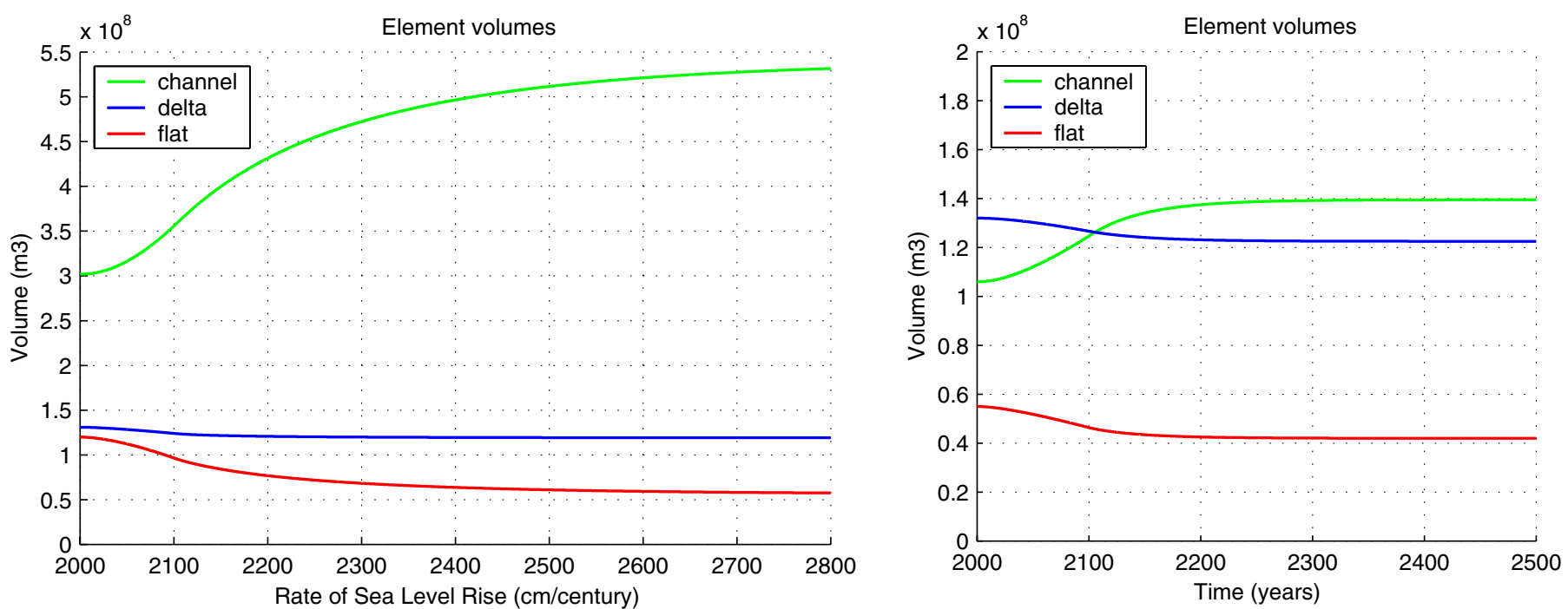

Figure 4.17, 4.18: Volume development for the Amelander Zeegat (left) and the Eierlandse Gat (right) for an accelerating rate of sea level rise up to $85 \mathrm{~cm} /$ century in 2100 .

Due to the volume decrease of the flats we see a significant increase of the tidal prisms (the largest for the Amelander Zeegat basin), see tidal prism development in Appendix D5 and E5. The increased tidal prism results in larger equilibrium volume of the channel element (wet volume) and a smaller volume decrease of the ebb-tidal delta (sediment volume), see also remark on tidal prism increase in Section 4.5.3.

In Appendix D6 and E6, the long-term residual diffusive sediment transport and the sediment concentration development for both inlets are shown. The figures on sediment transport show that the inward sediment transport grows significantly to satisfy the systems ever increasing sediment demand. As the 'sediment retention mechanisms' need time to generate the inward sediment transport, initially the elements cannot keep pace with the rise of the sea level. After the systems have reached their 'new' dynamic equilibrium state, sediment transport stabilises and fulfils the systems sediment demand.

In the worst case scenario, the simulation of the first period of the evolution of the Amelander Zeegat inlet (years 2050-2100) shows a larger sediment transport from the channel to the flat than from the ebb-tidal delta to the channel. In this period the channel element erodes excessively and 'gives' sediment to the flat element. For the Eierlandse Gat inlet this is not the case as the sediment demand of the relative smaller flat area (compared to the flat area of the Amelander Zeegat) is less. Table 4.8 shows the equilibrium sediment transports between the elements in case the systems have reached a 'new' state of dynamic equilibrium.

Table 4.8: Equilibrium sediment transports between elements; rate of sea level rise $85 \mathrm{~cm} /$ century

Transport (million $\mathrm{m}^{3} /$ year)

\begin{tabular}{lcc} 
Transport direction & Amelander Zeegat & Eierlandse Gat \\
\hline $\begin{array}{l}\text { Outside world to } \\
\text { ebb-tidal delta }\end{array}$ & 2.983 & 1.661 \\
\hline $\begin{array}{l}\text { Ebb-tidal delta to } \\
\text { channels }\end{array}$ & 2.348 & 1.340 \\
\hline Channels to flats & 1.513 & 0.892 \\
\hline
\end{tabular}


In Table 4.9, the equilibrium sediment accretion in the elements is given. Once the systems have reached their new dynamic equilibrium state the accretion matches the rate of sea level rise and, as expected, the total sediment demand equals the sediment supply from the 'outside world'.

Table 4.9: Equilibrium sediment demand/ accretion in elements; rate of sea level rise $85 \mathrm{~cm} /$ century

\begin{tabular}{lcc}
\hline & \multicolumn{2}{c}{ Sediment demand/accretion (million $\mathrm{m}^{3} /$ year) } \\
Element & Amelander Zeegat & Eierlandse Gat \\
\hline Ebb-tidal delta & 0.635 & 0.321 \\
Channels & 0.835 & 0.448 \\
Flats & 1.513 & 0.892 \\
\hline Total sediment demand & 2.983 & 1.661 \\
\hline
\end{tabular}

Because the Amelander Zeegat is a larger system (area wise) than the Eierlandse gat, the Amelander Zeegat has a larger sediment demand.

In Appendix D6 and E6 the local sediment and local equilibrium concentration are shown for each element as a function of time. As the systems have an increased need of sediment (compared to the most likely SLR scenario) to satisfy the sediment demand of the system, the equilibrium concentration and actual sediment concentrations are lower than in the preceding scenarios. This way the difference in sediment concentration between the 'outside world' and the system increases. As an ever-larger difference in sediment concentration results in an increasing inward sediment transport, the systems sediment demand is satisfied and a 'new' state of dynamic equilibrium is reached.

\subsubsection{Mean level changes in the system}

In the present section a translation is made from the element volume change as presented in foregoing sections to a level change for the flat, channel and the ebb-tidal delta area. For the 'new' states of dynamic equilibrium of each SLR scenario we have calculated the area levels and thus acquire better insight of the 'permanent' deepening of the system for a certain rate of sea level rise. In Table 4.10 and 4.11 the results of these calculations are shown for the mean bed level of the channel and the mean flat level, both relative to MLW. The mean level of the ebb-tidal delta is calculated relative to the mean bed level of the 'undisturbed coastline' (as defined by Walton and Adams, 1975). An important assumption in these calculations (and in the ASMITA concepts, see Section 3.3) is that over the centuries no significant changes in the horizontal size of the elements take place. Table 4.10 shows for the Amelander Zeegat the calculated equilibrium levels for the three scenarios of sea level rise.

Table 4.10: Equilibrium levels as a function of $S L R$

Mean Equilibrium element level as a function of $S L R$

Amelander Zeegat

\begin{tabular}{lccc}
\hline SLR & $\begin{array}{c}\text { Delta height [m] } \\
\text { above bed level }\end{array}$ & $\begin{array}{c}\text { Channel depth [m] } \\
\text { below MLW }\end{array}$ & $\begin{array}{c}\text { Flat height [m] } \\
\text { above MLW }\end{array}$ \\
\hline Present & 1.75 & 3.07 & 0.67 \\
$56 \mathrm{~cm} /$ century SLR & 1.67 & 4.04 & 0.50 \\
$85 \mathrm{~cm} /$ century SLR & 1.59 & 5.41 & 0.32 \\
\hline
\end{tabular}

For the Eierlandse gat inlet we have calculated equilibrium levels as shown in Table 4.11. 
Table 4.11: Equilibrium levels as a function of $S L R$

Mean equilibrium element level as a function of $S L R$

Eierlandse Gat

\begin{tabular}{lccc}
\hline SLR & $\begin{array}{c}\text { Delta height [m] } \\
\text { above bed level }\end{array}$ & $\begin{array}{c}\text { Channel depth [m] } \\
\text { below MLW }\end{array}$ & $\begin{array}{c}\text { Flat height [m] } \\
\text { above MLW }\end{array}$ \\
\hline Present SLR & 3.49 & 2.01 & 0.52 \\
$56 \mathrm{~cm} /$ century SLR & 3.36 & 2.33 & 0.46 \\
$85 \mathrm{~cm} /$ century SLR & 3.24 & 2.65 & 0.40 \\
\hline
\end{tabular}

Apparently, increasing the rate of sea level rise yields a significant decrease of flat height and an increase of channel depth (both measured relative to MLW) and thus a deepening of the tidal basins. For the Amelander Zeegat, where a significant increase of tidal prism takes place for an increased rate of sea level rise, we see a relative small change of the ebb-tidal delta level. Apparently, the two force components that dictate the evolution of the ebb-tidal delta, the sea level rise and the tidal prism, are more or less in equilibrium for this case.

\subsection{Conclusions}

Apparently, for the modelled tidal inlet systems the Amelander Zeegat and the Eierlandse Gat, it can be shown upper boundaries exist for a rise of the sea level (SLRlimit). From a sensitivity analysis we derived that these upper boundaries (stability limits) are very sensitive to a variation of element area, horizontal exchange rate and 'outside world' equilibrium concentration (read potential sediment supply). Because the latter two variables represent large uncertainties they are classified as uncertain variables in the SLRlimit prediction. Therefore it seems useful to accompany model results with an estimate of the reliability of these uncertain variables. In Chapter 5, we will assess these uncertain variables, resulting in a probabilistic approach, that yields quantitative insight into the reliability of the model results.

Furthermore, to obtain a better understanding of the systems evolution towards a 'new' state of dynamic equilibrium given a rising sea level, ASMITA simulations were made. The time the tidal inlet systems require to reach a new state of dynamic equilibrium is an indication of the matching morphological time-scale. From the simulations it came forward that the area wise smaller (Eierlandse Gat) of the two studied inlets evolves on significantly shorter timescale towards a new state of dynamic equilibrium than the larger Amelander Zeegat. Further we acquired insight in the 'sediment retention mechanism' of the modelled systems, which by deviating the element volumes from their original equilibrium value, lowers the equilibrium concentration in the system and thus incites an inward diffusion-type of sediment transport.

As the tidal prism development is approximated as time-invariant in the stability analysis, the equilibrium volume predictions of the stability analysis and ASMITA simulations do not match for the ebb-tidal delta and channel element as both are dependent upon the tidal prism. Due to the increase in tidal prism, the volume decrease of the ebb-tidal delta element will be less and the volume increase of the channel element will be more than predicted in the stability analysis. The evolution of the equilibrium flat volume, which is determinative for the $S L R$ limit, is independent of the tidal prism and thus the SLRlimit is not affected by the approximation of the tidal prism in the stability analysis. 


\section{Assessing uncertainties in the Sea Level Rise Stability Limit}

\section{I Introduction}

In the preceding chapters is has been shown that estimates of the SLRlimit obtained with ASMITA model are sensitive especially to two parameters of that model. It concerns the 'outside world' equilibrium concentration (reflecting the availability of sediment to the inlet system) and the horizontal exchange rates (a measure for the systems capacity to distribute sediment internally).

To this end, we write the SLRlimit as a function of the mentioned two parameters and we consider these parameters to be random variables. Statistical properties of these variables are estimated from field data and cautious extrapolation of underlying small-scale processes. These properties are used subsequently to quantify the random character of the SLRlimit.

In Section 5.2 and 5.3 we assess the statistical properties of the 'outside world' equilibrium concentration and the horizontal exchange rates between adjacent elements. In Section 5.4, we asses the reliability of the predicted SLRlimit by an estimate of the joint probability.

\subsection{Assessing the uncertainty in 'outside world' equilibrium concentration}

\subsection{Introduction}

The 'outside world' equilibrium concentration represents the long-term averaged availability of sediment to the tidal inlet system. From the perception that this availability has to do with that part of the (mainly wave-induced) transport along the barrier islands at both sides of the inlet, that can be brought into the inlet system by the tidal motion, we will derive a conceptual model for $c_{E}$ (Section 5.2.2) and we apply that model to quantify $c_{E}$ in statistical terms (Section 5.2.3).

\subsubsection{Physical concept of 'outside world' equilibrium concentration}

In the ASMITA concept, the 'outside world' equilibrium concentration (henceforth referred to as $c_{E}$ ) represents the time-invariant, boundary condition to the system. In the present section we derive a conceptual model for $c_{E}$. With this model we assess the effect of uncertainties in the sediment transport model and changes in wave climate on $c_{E}$.

To make an approximation of the 'outside world' equilibrium concentration, a very simplistic but transparent model is used. We presume that the potential sediment supply to the tidal basin is only 'generated' in the surf zone of the barrier islands and transported to the inlet via wave-induced longshore currents. Therefore the 'presented' $c_{E}$ at the boundary of the 'outside world' depends only on wave-induced transports and currents. The tidal currents, generated by the tidal prism, are not yet taken into account as these currents present themselves at the 
boundary of the ebb-tidal delta and cause the sediment transport between the 'outside world' and the ebb-tidal inlet. The latter sediment transport is responsible for the long-term averaged diffusive sediment exchange between the 'outside world' and the tidal inlet.

When we estimate the bulk sediment transport along the barrier beaches and divide it by the longshore wave generated discharge, we obtain an estimate of the 'outside world' equilibrium concentration available to the system. See equation (5.1):

$$
c_{E}=\frac{S}{Q}
$$

in which $S$ is the bulk sediment transport $\left[\mathrm{m}^{3} / \mathrm{s}\right]$ and $Q$ represents the longshore wavegenerated discharge $\left[\mathrm{m}^{3} / \mathrm{s}\right]$. The latter derived concentration is concentrated in the surf zone of which the width is dictated by the average wave height and beach slope.

Because the sediment exchange with the ebb-tidal delta takes place over a much broader region than the width of the surf zone (see Figure 5.1), the presented $c_{E}$ to the ebb-tidal delta has to be corrected with a certain correction factor $\alpha_{C E}$. This correction factor depends on the width of the surf zone and the width of the 'sediment exchanging' boundary of the ebb-tidal delta, see equation (5.2).

$$
\alpha_{c E}=\frac{w_{\text {suf }}}{w_{\text {delta }}}
$$

The correction factor multiplied by the concentration -calculated in equation (5.1)- results in the sediment concentration presented to the ebb-tidal delta. We tentatively assume that the width of the arbitrary 'sediment exchange boundary' of the ebb-tidal delta equals the width of the surf zone for high wave conditions in a reference case. In this reference case, the correction factor for high wave conditions than equals 1 . For low wave conditions the surf zone is narrower with higher concentrations. Because this narrow surf zone concentration is spread over the broader sediment exchanging boundary of the ebb-tidal delta, it results in a lower boundary concentration.

high \& low wave condition

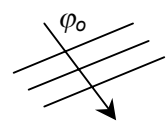

- - - - high wave condition breaker line

low wave condition breaker line

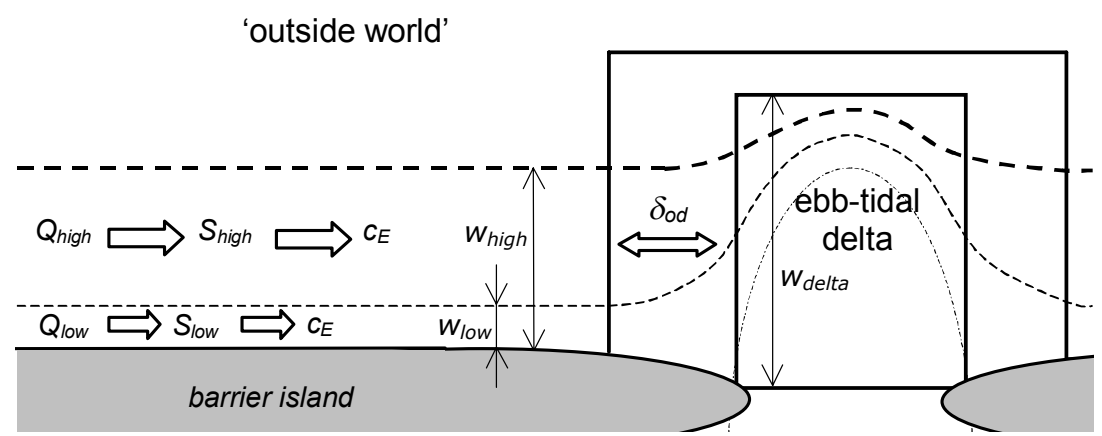

Figure 5.1: $\quad$ Longshore transport $S$ and discharge $Q$ for low and high wave conditions

For a specific wave condition the sediment transport $S^{*}\left[\mathrm{~m}^{3} / \mathrm{s}\right]$ is computed with the use of the CERC sediment transport formula (Shore Protection Manual, 1984):

$$
S^{*}=A \cdot H_{b r}^{2} \cdot n_{b r} \cdot c_{b r} \cdot \cos \left(\varphi_{b r}\right) \sin \left(\varphi_{b r}\right)
$$


with:

$\begin{array}{ll}A & \text { dimensionless coefficient [-] } \\ H_{b r} & \text { significant wave height at breaker depth [m] } \\ n_{b r} & \text { ratio of wave group velocity to wave celerity at breaker depth [-] } \\ c_{b r} & \text { wave celerity at breaker depth [m/s] } \\ \varphi_{b r} & \text { angle of wave incidence at breaker depth [degrees] }\end{array}$

When we integrate this sediment transport for joint probability of the wave conditions, we obtain the bulk longshore sediment transport $S$ :

$$
S=\int_{H_{b r}=0}^{\infty} \int_{T=0}^{\infty} \int_{\varphi_{b r}=-\frac{\pi}{2}}^{+\frac{\pi}{2}} f\left(H_{b r}, T, \varphi_{b r}\right) \cdot A \cdot H_{b r}^{2} \cdot n_{b r} \cdot c_{b r} \cdot \cos \left(\varphi_{b r}\right) \sin \left(\varphi_{b r}\right) d \varphi_{b r} d T d H_{b r}
$$

with $T$ representing the significant wave period [s] and $c_{b r}$ and $n_{b r}$ both as a function of $T$. The joint probability of the wave conditions is represented by $f\left(H_{b r}, T, \varphi_{b r}\right)$. In this bulk sediment transport formula uncertainties are related to the random errors of the transport formula parameters (e.g. $A$ ) and to the unavoidable lack of insight into the future wave climate (e.g. $H_{s o}, \varphi_{o}$, representing the offshore wave conditions).

By integration of the depth averaged, wave driven current velocity and the water depth over the width of the surfzone we derive the longshore discharge $Q^{*}$ for a specific wave condition, see equation (5.5).

$$
Q^{*}=\int_{x=0}^{\infty} V(x) \cdot h(x) d x
$$

in which $V(x)$ represents the depth averaged current velocity [m/s] (related to the deep water wave conditions) and $h(x)$ the water depth [m], both as function of the distance from shore $(x)$. Analogous to equation (5.4) we may integrate this longshore discharge $Q^{*}$ for the joint probability of the wave conditions which results in:

$$
Q=\int_{H_{s o}=0}^{\infty} \int_{T=0}^{\infty} \int_{\varphi_{0}=-\frac{\pi}{2}}^{+\frac{\pi}{2}} f\left(H_{s o}, T, \varphi_{0}\right) \cdot Q^{*} \cdot d \varphi_{0} d T d H_{s o}
$$

However, in the present research the longshore discharge for a specific wave condition is approximated by:

$$
Q^{*}=A_{\text {surf }} \cdot \overline{\bar{u}}
$$

in which $\stackrel{\bar{u}}{u}$ represents the depth and width averaged longshore current velocity [m/s] and $A_{\text {surf }}$ $\left[\mathrm{m}^{2}\right]$ the cross-sectional area of the surfzone, estimated by assuming a flat sloping bed in the surfzone zone. Hence,

$$
A_{\text {suf }}=\frac{h_{b r}{ }^{2}}{2 m}
$$

with $m[-]$ the cross-shore bed slope.

The longshore current is presumed to depend on the two force components which are nearly always present in the breaker zone, viz. the bottom friction (resistance force) and the radiation 
shear stress gradient (driving force), see Van der Velden (1990). The longshore current velocity results from an equilibrium of these two forces. Solving the equilibrium yields for the depth averaged current velocity $V$ as a function of water depth $h$ :

$$
V(h)=1.388 \cdot \frac{\sin \left(\varphi_{o}\right)}{c_{o}} \cdot \frac{C}{\sqrt{f_{w}}} \cdot \gamma \cdot \sqrt{g} \cdot h \cdot m
$$

In this equation:

$\begin{array}{ll}\varphi_{0} & \text { offshore wave angle [degrees] } \\ c_{o} & \text { offshore wave celerity }[\mathrm{m} / \mathrm{s}] \\ C & \text { Chezy coefficient }\left[\mathrm{m}^{1 / 2} / \mathrm{s}\right] \\ \gamma & \text { breaker depth coefficient [-] } \\ f_{w} & \text { wave friction term [-] } \\ h & \text { water depth [m] } \\ m & \text { beach slope }[-]\end{array}$

The approximation of Van der Velden gives us a wave-driven current velocity that linearly increases with the distance from the shore. The current velocity reaches its maximum $\left(V_{b r}\right)$ at the breaker line (see Figure 5.2) and seaward of this breaker line the wave-driven currents are absent.

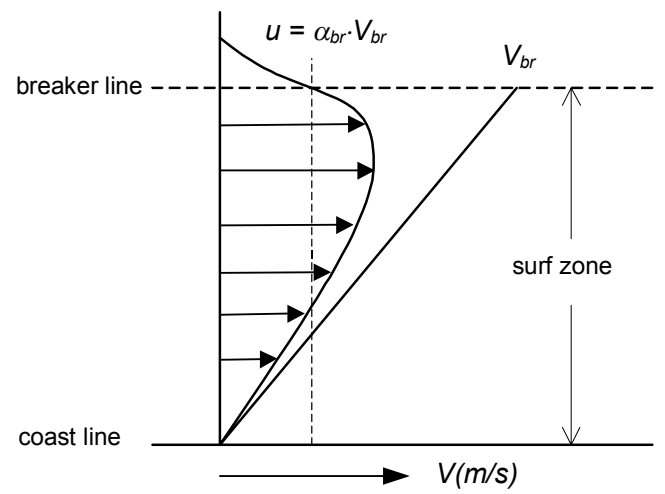

Figure 5.2: Longshore current velocity profile in surf zone

However, in an actual breaker zone wave irregularity and effects of turbulence will widen and flatten the current velocity profile in the surf zone, as shown in Figure 5.2. Despite the apparent inaccuracy in the approximation of Van der Velden, we assume $V_{b r}$ to be a reasonable measure for the wave-driven longshore current. To derive the mean longshore current velocity $\stackrel{=}{u}$ from $V_{b r}$, we apply a reduction factor $\alpha_{b r}[-]$. The approximation of the longshore current for a specific wave condition results in:

$$
Q^{*}=A_{s u r f} \cdot \bar{u}=\left(\frac{h_{b r}^{2}}{2 m}\right) \cdot V_{b r} \cdot \alpha_{b r}
$$

In this longshore current formula uncertainties are related to the random errors of the formula parameters (e.g. $\alpha_{b r}$ and $\gamma$ ) and the unavoidable lack of insight into the future wave climate (e.g. $H_{s o}$ and $\varphi_{o}$ ).

The proposed method to comprehend the 'outside world' equilibrium concentration is a conceptual one and does not necessarily represent any kind of actual sediment concentration. The uncertainties of the 'outside world' equilibrium concentration are due to random errors in our sediment transport and longshore current formulae and unavoidable lack of insight into the future wave climate. In Section 5.2.3 we assess these terms. 


\subsubsection{Estimates for 'outside world' equilibrium concentration}

In the approximation of the wave driven bulk sediment transport and longshore currents we may distinguishes two sources of uncertainty. The first source is the random error/variation of the formula parameters (such as $A$ and $\alpha_{b r}$ ). These uncertainties demonstrate themselves on small spatial- and time-scales and thus may be estimated from (field) observations. The second source of uncertainty is related to the unavoidable lack of insight into the future wave climate $\left(H_{s o}, T\right.$ and $\left.\varphi_{o}\right)$, which demonstrates itself on (very) long time-scales. Therefore, estimates of these latter uncertainties cannot be obtained from observations and have to be dealt with using future wave climate scenarios.

To investigate the effect of the uncertainties introduced by our model/formula approximations and the future wave climate, we define a reference case for the present wave climate. In this reference case we refer to morphodynamic calculations for the barrier island Texel, performed by Alkyon and WL | Delft Hydraulics, see Steijn (1997). For this investigation a wave climate is composed based on wave buoy observations $(E L D)$, offshore the Eierlandse gat. This wave climate is presented in Table 5.1. As shown, four classes of wave conditions are defined, each with a mean significant wave height $\left(H_{s}\right)$, deep water angle of incident $\left(\varphi_{o}\right)$, wave period $\left(T_{m 02}\right)$ and percentage (of time) of occurrence. A fifth condition represents the period of time in which insignificant wave conditions and thus insignificant sediment transports take place.

Table 5.1: Representative reference wave conditions

\begin{tabular}{lcccc}
\hline Wave condition & $\begin{array}{c}H s \\
{[\mathrm{~m}]}\end{array}$ & $\begin{array}{c}\varphi_{o} \\
{[\mathrm{degr}]^{*}}\end{array}$ & $\begin{array}{c}T_{m 02} \\
{[\mathrm{~s}]}\end{array}$ & $\begin{array}{c}\text { \% of occurrence } \\
{[-]}\end{array}$ \\
\hline South low & 1.48 & 235 & 4.63 & 26.44 \\
South high & 3.30 & 255 & 6.09 & 6.12 \\
North low & 1.35 & 355 & 4.83 & 47.90 \\
North high & 3.30 & 315 & 5.99 & 6.13 \\
Insignificant & - & - & - & 13.41 \\
\hline
\end{tabular}

relative to north, clockwise positive

The orientation of the Texel shoreline (relative to north) is $192^{\circ}$ south $-12^{\circ}$ north, which results in a shore normal of $282^{\circ}$. For the CERC computation in FBASE we use the deep water angle of wave incidence, measured relative to the shore normal.

The computational procedure for the calculation of the reference $c_{E}$ is as follows: for each class of wave condition FBASE computes the sediment transport $S^{*}$ and the breaker depth $h_{b r}$. The longshore current $Q^{*}$, which is related to the longshore current velocity at the breaker line $V_{b r}$, is calculated with equation (5.10). With the calculated discharge $Q^{*}$ and sediment transports $S^{*}$ we calculate the concentration $c_{\text {surf }}$ in the surf zone for each wave condition. Multiplying this concentration with correction factor $\alpha_{c E}$ results in the concentration $c_{b n d}$ presented at the boundary of the ebb-tidal delta for each wave condition. By calculating the average of these concentrations (with the percentage of time of occurrence as weight factor) we derive the long-term averaged 'outside world' equilibrium concentration, see Table 5.2. 
Table 5.2: Long-term averaged 'outside world' equilibrium concentration $c_{E}$

\begin{tabular}{lcccccc}
\hline Wave condition & $\begin{array}{c}S^{*} \\
{\left[\mathrm{~m}^{3} / \mathrm{year}\right]}\end{array}$ & $\begin{array}{c}Q^{*} \\
{\left[\mathrm{~m}^{3} / \mathrm{s}\right]}\end{array}$ & $\begin{array}{c}c_{\text {surf }} \\
{[-]}\end{array}$ & $\begin{array}{c}\alpha_{c E} \\
{[-]}\end{array}$ & $\begin{array}{c}c_{\text {bnd }} \\
{[-]}\end{array}$ & $\begin{array}{c}\%^{*} c_{\text {bnd }} \\
{[-]}\end{array}$ \\
\hline South low & $2.05 \cdot 10^{6}$ & 118 & 0.00055 & 0.41 & 0.00023 & 0.000063 \\
South high & $1.31 \cdot 10^{7}$ & 911 & 0.00046 & 1.00 & 0.00046 & 0.000027 \\
North low & $7.99 \cdot 10^{5}$ & 38 & 0.00066 & 0.27 & 0.00018 & 0.000085 \\
North high & $1.45 \cdot 10^{7}$ & 1037 & 0.00044 & 0.98 & 0.00043 & 0.000025 \\
Insignificant & - & - & - & - & - & - \\
\hline \multicolumn{2}{l}{ Long-term averaged 'outside world' equilibrium concentration $c_{E}$} & & 0.00020 \\
\hline
\end{tabular}

\section{Uncertainty of CERC transport formula}

The $C E R C$ formula provides a rough estimate of the actual wave-driven sediment transport. In the Shore Protection Manual (1984), a confidence interval for the calculated transport is given, see the dashed lines Figure 5.3. Considering the constant confidence bandwidth $\beta$ on the double logarithmic-scale of Figure 5.3, it seems reasonable to approximate the actual sediment transport by:

$$
S_{\text {actual }}=\beta \cdot S_{\text {CERC }}
$$

As the area between the dashed lines (corresponding to $0.5 \cdot \mathrm{S}$ and $1.5 \cdot \mathrm{S}$ ) covers most of the data points in Figure 5.3, it seems reasonable to assume that the CERC formula yields estimates of the longshore sediment transport rate up to an accuracy of about $50 \%$. If we associate this with a $95 \%$ confidence interval and assume $\beta$ to be normally distributed, it follows that:

$$
\beta \approx N\left(1, \frac{1}{2 \cdot 1.96}\right)
$$

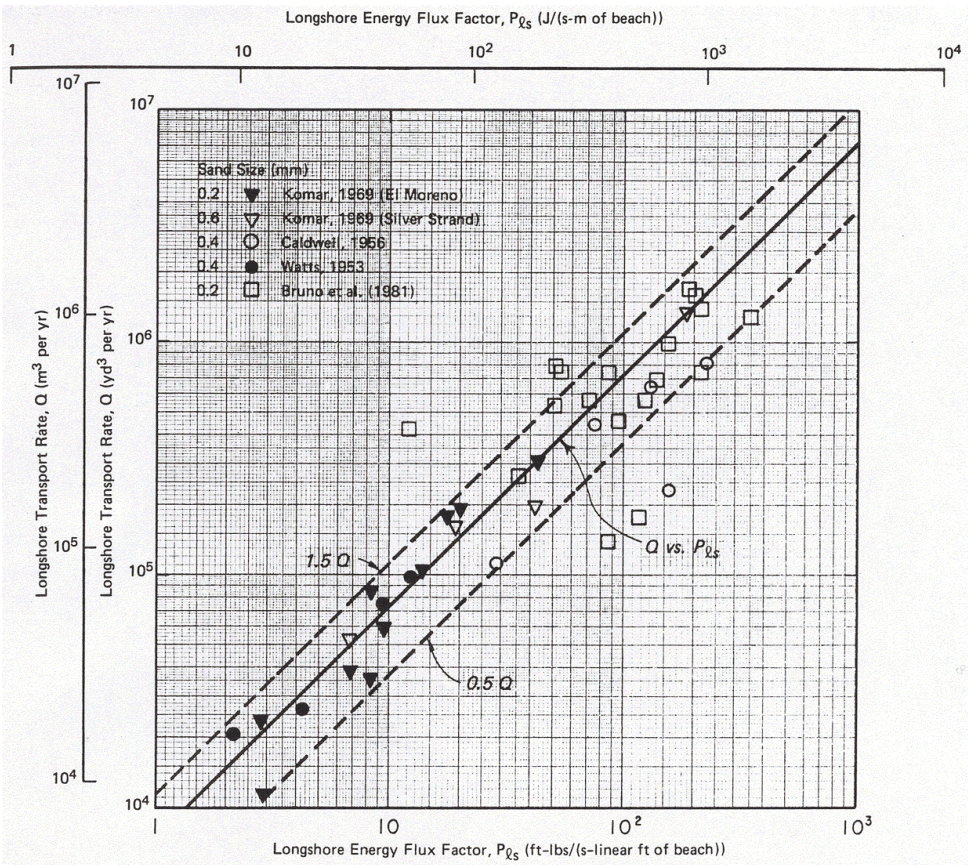

Figure 5.3: $\quad$ CERC design curve for longshore sediment transport $Q$ versus energy flux factor (wave height related) with dashed lines representing $1.5 \cdot Q$ and $0.5 \cdot Q$ (Shore Protection Manual, 1984). 
The estimate of the uncertainty in the longshore discharge may be derived analogously. The wave generated longshore discharge for a specific wave condition is given by equation (5.10):

$$
Q=A_{s u f} \cdot \vec{u}=\left(\frac{h_{b r}^{2}}{2 m} \cdot V_{b r}\right) \cdot \alpha_{b r}
$$

When we reasonably assume that $\alpha_{b r}$ introduces (compared to the other formula parameters) the most significant uncertainty in our approximation of the longshore discharge and we therefore combine all parameter related uncertainties in this factor, we may express the actual discharge by:

$$
Q_{a c \text { culal }}=Q_{a p p r o x .} \cdot \alpha_{b r} ; \quad Q_{a p p r o x .}=\frac{h_{b r}^{2}}{2 m} \cdot V_{b r}
$$

However, in order to derive a quick assessment of the model uncertainties, we assume $\alpha_{b r} \approx N(0.35,0)$ and thus neglect any variation in $\alpha_{b r}$.

With the above approximations we may find an estimate of uncertainty in the 'outside world' equilibrium concentration $c_{E}$ related to uncertainties in our transport/current model. From equations (5.1), (5.11) and (5.14) we derive that:

$$
c_{E}=\frac{\beta}{\alpha_{b r}} \cdot \frac{S_{C E R C}}{Q_{a p p r o x}}
$$

and with the $95 \%$ confidence interval outlined in Figure 5.3 we derive that:

$$
\begin{aligned}
& P\left(c_{E}>\frac{1.5 \cdot S_{\text {CERC }}}{\alpha_{b r} \cdot Q_{\text {approx }}}\right)=97.5 \% \\
& P\left(c_{E}<\frac{0.5 \cdot S_{\text {CERC }}}{\alpha_{b r} \cdot Q_{\text {approx }}}\right)=2.5 \%
\end{aligned}
$$

When we assume $c_{E}$ to be normally distributed we find that:

$$
c_{E} \approx N\left(\frac{S_{C E R C}}{\alpha_{b r} \cdot Q_{a p p r o x}}, \frac{S_{C E R C}}{\alpha_{b r} \cdot Q_{a p p r o x}} \cdot \frac{1}{2 \cdot 1.96}\right)
$$

which results in a variation $V$ for $c_{E}$ of:

$$
V_{c_{E}}=\frac{\sigma_{c_{E}}}{\mu_{c_{E}}}=\frac{1}{2 \cdot 1.96} \approx 0.25
$$

The probability that $c_{E}$ is smaller than zero (which is physically unrealistic) is for the given variation less than $4 \cdot 10^{-5}$. In the following probabilistic calculations we exclude negative values of $c_{E}$ and because of the small probability $\left(4 \cdot 10^{-5}\right)$ we expect this to be of negligible 
influence. The calculated variation of $c_{E}$ is assumed to represent the uncertainty in the CERC transport model for the present and future wave climate scenarios.

\section{Wave climate scenarios}

The North Sea wave climate is related mainly to the prevailing wind patterns in the region. The regional wind patterns are related partly to the dominant pattern of wintertime atmospheric circulation variability over the North Atlantic, known as the North Atlantic Oscillation (NAO). According to Velligna (2000), this pattern is driven by a pressure difference between Iceland, a low-pressure area, and a high-pressure area near the Azores. Positive values of the NAO index indicate stronger-than-average westerlies over the middle latitudes related to pressure anomalies in the above mentioned regions. This positive correlation is associated with warmer winters over Western Europe and colder winters over the northwest Atlantic.

The NAO index has increased over the past 30 years with few exceptions, and since 1980 the NAO has tended to remain highly positive. The Royal Netherlands Meteorological Institute $(K N M I)$ suggests that global warming-induced changes in sea surface temperature and related changes in oceanic and atmospheric circulation patterns may be partly responsible for the observed persistently positive NAO index, nevertheless the $K N M I$ is cautious in its conclusions. Corti et al.(1999) on the other hand indicate that the observed warming of the Earth's surface does trigger changes in the frequency distribution of existing modes of climate variability like the observed NAO phenomenon.

As the apparent global warming may result in an increase of the NOA index, the westerly winds may tend to increase in strength and occurrence. This change of prevailing wind patterns most likely results in a change of the North Sea wave climate. Because the impact of an increasing NOA index is still part of discussion, we tentatively assume that increased westerlies results in an altered long-term averaged wave direction and an increased long-term averaged wave height and duration. Hereafter the effects of possible wave climate changes are presented.

A change of wave direction, representing stronger than average westerlies, results in relatively smaller angles of incidence with the shore normal. This results in a decrease of longshore sediment transport and a, relatively larger, decrease in longshore discharge. Due to the considerable decrease in longshore discharge, the average 'outside world' equilibrium concentration presented to the ebb-tidal delta increases (see Appendix G2, Table G2.1-G2.4).

As the NOA index increases, the prevailing wind strength probably increases. This results in an increase of wave height and wave period. Equation (5.20) and (5.21) show the relations of Bretschneider for the significant wave height $H[\mathrm{~m}]$ and period $T$ [s] to the wind speed $U_{10}$ [m/s] (see Holthuijsen, 1998).

$$
\begin{aligned}
& H=\frac{U_{10}^{2}}{g} \cdot \widetilde{H} \\
& T=\frac{U_{10}}{g} \cdot \widetilde{T}
\end{aligned}
$$


with $U_{10}$ the wind velocity 10 metres above the water level and $\widetilde{H}, \widetilde{T}$ the dimensionless wave height and wave period. When we put that the increased NOA index results in $10 \%$ increase of the significant wave height, the wave period grows with the square root of the $10 \%$ increase. The increase in wave height and wave period results in an increase of sediment transport and longshore discharge. Eventually this leads to an increase of $c_{E}$ (see Appendix G3, Table G3.1-G3.4).

Finally, the global warming and changed NAO index may result in an altered wave climate probability. An increase of $10 \%$ duration of the low and high wave climate results in a significant increase of $c_{E}$ (see Appendix G4, Table G4.1-G4.4).

Because of the present uncertainties in wind climate development due to global warming it remains difficult to compose a wave climate representing the effect of an increased NOA index. To deal with these long-term uncertainties, three arbitrary scenarios are put together. The first scenario represents the present (reference) wave climate $c_{E}(I)$, the second scenario represents a changed wave direction and increased significant wave height $c_{E}(I I)$ and a third scenario represents the latter scenario with an increased probability of the wave conditions $c_{E}(I I I)$. The accompanying 'outside world' equilibrium concentrations are calculated in Appendices G1, G5, G6 and are presented in Table 5.3.

Table 5.3: Wave climate scenarios

\begin{tabular}{lcc}
\hline Wave climate scenario & mean $c_{E}$ & variation $c_{E}$ \\
\hline Present scenario, $c_{E}(I)$ & 0.000200 & \\
Scenario 2, $c_{E}(I I)$ & 0.000231 & 0.25 \\
Scenario 3, $c_{E}(I I I)$ & 0.000254 & \\
\hline
\end{tabular}

\subsection{Assessing the uncertainty in horizontal exchange rate}

\subsection{Introduction}

In the present study, two methods have been proposed to quantitatively assess uncertainties in the horizontal exchange rate. It appeared that the first of these methods, based on a consideration of morphological time-scales, did not suit its purpose very well and it was therefore abandoned (see Appendix H). In the second method, a three-element ASMITA model is fitted to field data in a least-squares sense by varying the exchange rates. The residual difference between model results and data is used to arrive at a measure for uncertainties in the exchange rates.

The field data used in this respect concerns the Zoutkamperlaag inlet, which significantly changed after the closure of the Lauwers Zee in 1969. A brief description of the development of the Zoutkamperlaag is given in Section 5.3.2. In Section 5.3.3 the calibration is performed and in Section 5.3.4 we further assess the uncertainty in our estimates.

\subsubsection{Development of the Zoutkamperlaag inlet}

The Zoutkamperlaag inlet is part of the Friesche Zeegat, situated between the barrier islands Ameland and Schiermonnikoog (see Figure 5.4). The Friesche Zeegat consists of two inlets: 
the westerly Pinkegat inlet and the easterly Zoutkamperlaag inlet. A supratidal shoal, the Engelsmanplaat, separates the inlets and their intertidal backbarrier flood basins.
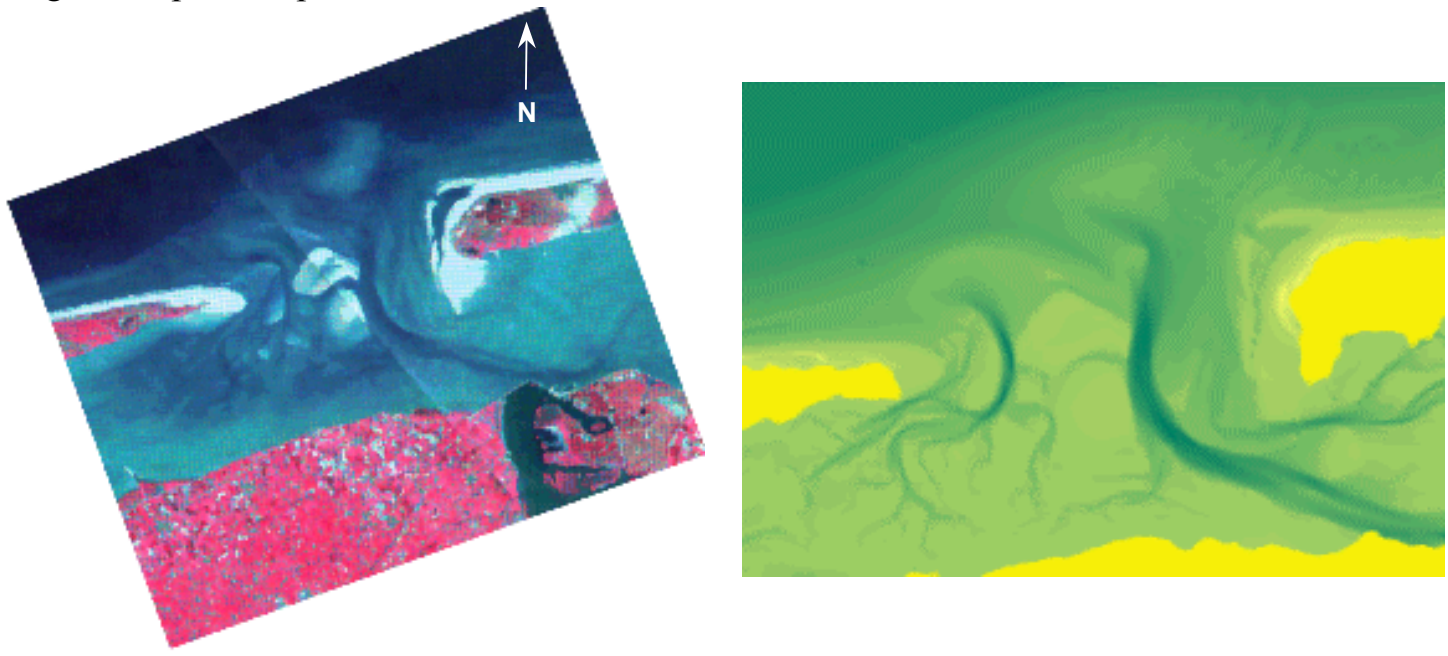

Figure 5.4: The Friesche Zeegat, situated between Ameland (west) and Schiermonnikoog (east), with in the west the Pinkegat inlet and the Zoutkamperlaag inlet in the east. The inlets are separated by the Engelsmanplaat

In the period from 1880 to 1967 the tidal inlet Zoutkamperlaag is assumed to have been in a state of dynamic equilibrium. However, in the year 1969, the tidal prism of the Zoutkamperlaag was reduced from $320 \cdot 10^{6}$ to $180 \cdot 10^{6} \mathrm{~m}^{3}$ (Biegel, 1993) as a result of the closure of the Lauwerszee. Due to this closure there was no longer a state of dynamic equilibrium. The volumes of the ebb-tidal delta (sediment) and the channel (wet) were too large in relation to the tidal prism, which resulted in a transport of sediment into the Zoutkamperlaag inlet. Directly after the closure, the channels closest to the ebb-tidal delta (a sediment source) accreted. The channels in the back of the basin accreted also but with sediment from the flats (Hoogeboom, 1996). The sedimentation occurred as a wave-like feature through the channels (Biegel, 1991).

The data presented in Table 5.4 are part of the ISOS*2 project, in which Biegel collected many bathymetric data of various tidal basins of the Dutch Wadden Sea. Biegel produced two data sets for the Zoutkamperlaag. In the first set the boundaries are considered time-invariant (fixed boundaries, shown in Table 5.4 and Appendix B, Table B1.6), whereas in the second set horizontal migration of watersheds that form the systems boundaries are taken into account (see Appendix B, Table B1.7).

Table 5.4: Volume development of the elements of the Zoutkamperlaag inlet due to the closure of the Lauwerszee

\begin{tabular}{lcccc}
\hline \multicolumn{5}{l}{ Zoutkamperlaag data } \\
Year & $\begin{array}{c}\text { Tidal prism } \\
{\left[\mathrm{m}^{3}\right] \cdot 10^{8}}\end{array}$ & $\begin{array}{c}\mathrm{V}_{\mathrm{c}} \\
{\left[\mathrm{m}^{3}\right] \cdot 10^{8}}\end{array}$ & $\begin{array}{c}\mathrm{V}_{\mathrm{f}} \\
{\left[\mathrm{m}^{3}\right] \cdot 10^{7}}\end{array}$ & $\begin{array}{c}\mathrm{V}_{\mathrm{d}} \\
{\left[\mathrm{m}^{3}\right] \cdot 10^{8}}\end{array}$ \\
\hline 1967 & 3.06 & 2.26 & 15.9 & \\
1970 & 1.75 & 1.73 & 6.78 & 1.45 \\
1975 & 1.78 & 1.60 & 6.35 & 1.35 \\
$1979^{*}$ & 1.78 & 1.53 & 6.17 & 1.36 \\
1982 & 1.73 & 1.55 & 6.48 & 1.26 \\
1987 & 1.72 & 1.51 & 6.32 & 1.19 \\
\hline
\end{tabular}

"not used in the present uncertainty analysis

Because in the present investigation any change of element area is not taken into account, we focus on the fixed boundary data set. As the volumes of the 1979 data set significantly differ 
from the expected volume development of the Zoutkamperlaag inlet, this part of the data set is excluded from the uncertainty analysis.

\section{Equilibrium state of the inlet}

Since 1969, the morphological evolution of the Zoutkamperlaag inlet exhibits a response to the closure of the Lauwers Zee. One method to describe this development is to use the coefficients of the empirical equilibrium relations (see Section 2.4) that belong to the initial state of dynamic equilibrium (before 1969) and predict the volume changes (due to the closure) with these equilibrium relations. A second method to model the volume changes is to assume that the Zoutkamperlaag has reached already a new state of dynamic equilibrium and to determine the corresponding equilibrium relations.

Buijsman (1997) found that the closure of the Lauwers Zee has had a significant impact on the equilibrium volumes of the various elements of the inlets. This significant change of equilibrium volumes could not be explained merely by the change of hydrodynamic forcing (e.g. the decrease of the tidal prism, see empirical equilibrium relationships, Section 2.4). Therefore Buijsman had to alter the coefficients of the equilibrium relations (so-named first phase, before 1969) significantly to represent the morphological development of the inlet after the closure (so-named second phase, after 1969). With this adjustment in the equilibrium relation coefficients, the purpose of fitting the tidal inlet model for the dynamic equilibrium before the closure became useless.

Therefore another method is used, which is based on the presumption that at present (i.e. 1987) the Zoutkamperlaag inlet has reached more or less a new state of dynamic equilibrium. The development of the inlet from 1969 to 1987 is described with equilibrium relations derived from this state of dynamic equilibrium. The coefficients for these equilibrium relations are shown in Appendix F, Table F1.4.

\subsubsection{Mean values of horizontal exchange rate}

To quantitatively express uncertainties in the horizontal exchange rates, we assume that they follow a lognormal probability distribution with means equal to the results of a least-squares fit of a three-element ASMITA model to field data on the Zoutkamperlaag inlet (see Table 5.4). Corresponding standard deviations are derived from differences between field data and model results that remain after the least-squares optimisation.

Other model parameters than the exchange rates are chosen according to our 'best knowledge' on the morphological development of the inlet at hand. These parameters as the values assigned to them, are mentioned in Table 5.5. The area, volume and vertical exchange $\left(w_{s}\right)$ are taken from Buijsman (1997) and for $c_{E}$ the most likely value as derived in Section 5.2 is taken.

Table 5.5: System variables Zoutkamperlaag inlet

\begin{tabular}{lcccc}
\hline Element & $\begin{array}{c}\text { Area } \\
{\left[\mathrm{m}^{2}\right] \cdot 10^{7}}\end{array}$ & $\begin{array}{c}\text { Volume } \\
{\left[\mathrm{m}^{3}\right] \cdot 10^{8}}\end{array}$ & $\begin{array}{c}\text { ws } \\
{[\mathrm{m} / \mathrm{s}] \cdot 10^{-4}}\end{array}$ & $\begin{array}{c}c_{E} \\
{[-] \cdot 10^{-4}}\end{array}$ \\
\hline Ebb-tidal delta & 7.8 & 1.51 & 0.1 & \\
Channel & 4.0 & 1.77 & 1.0 & 2.0 \\
Flat & 6.5 & 0.69 & 1.0 & \\
\hline
\end{tabular}


Hereafter the derivation of the mean values of the exchange rates is given. How the standard deviations are estimated is outlined in Section 5.3.4.

\section{Error minimisation}

For the least-squares optimisation we write the ASMITA predictions of volume development as a function of the horizontal exchange rates $\delta$. In that case it holds that

$$
V_{i, t}=\operatorname{ASMITA}_{i, t}\left(\delta_{o d}, \delta_{d c}, \delta_{c f}\right)+\varepsilon_{i, t}
$$

in which $V_{i, t}$ is the observed volume at element $i$ at time $t$ and $\varepsilon_{i, t}$ is the corresponding deviation between observation and model prediction. The least-squares estimates of the $\delta$ 's are found where the sum of squared deviations

$$
S=\sum_{i=1}^{3} \sum_{j=1}^{m} \varepsilon_{i, t_{j}}^{2}=\left(V_{i, t_{j}}-\operatorname{ASMITA}_{i, t_{j}}\left(\delta_{o d}, \delta_{d c}, \delta_{c f}\right)\right)^{2}
$$

reaches its minimum. At this minimum it holds that:

$$
\partial S / \partial \delta_{o d}=\partial S / \partial \delta_{d c}=\partial S / \partial \delta_{c f}=0
$$

from which the $\delta$ 's can be computed. The computational process is outlined in Appendix I1. The starting values for this minimisation are horizontal exchange rates of $1000 \mathrm{~m}^{3} / \mathrm{s}$.

As outlined in Appendix I1, the horizontal exchange rates $\delta_{d c}$ and $\delta_{c f}$ converge faster to an optimum $\left(\partial S / \partial \delta_{d c}=0\right.$ and $\left.\partial S / \partial \delta_{c f}=0\right)$ than the horizontal exchange rate $\delta_{o d}$. Apparently, the sum of squared deviations is less sensitive to a change of horizontal exchange rate between the 'outside world' and the ebb-tidal delta than to a variation of the other two exchange rates. Initially the $\delta_{o d}$ stabilises at approximately $1060 \mathrm{~m}^{3} / \mathrm{s}$ but later on reduces to $860 \mathrm{~m}^{3} / \mathrm{s}$. As we assume that the horizontal exchange rates are highly correlated to the tidal volume that flows through all elements, we expect the horizontal exchange rate $\delta_{o d}$ to be of the same magnitude as the horizontal exchange rate $\delta_{d c}$. Therefore the estimate of $\delta_{o d}$ is based on its initial value $\left(1060 \mathrm{~m}^{3} / \mathrm{s}\right)$. This assumption is supported by the model calibration of Buijsman(1997) of the Friesche Zeegat, where both exchange rates are of the same magnitude. The optimised horizontal exchange rates are shown in Table 5.6.

Table 5.6: Optimised horizontal exchange rates

\begin{tabular}{lc}
\hline Horizontal exchange between & $\begin{array}{c}\text { estimate } \delta_{\text {est }} \\
{\left[\mathrm{m}^{3} / \mathrm{s}\right]}\end{array}$ \\
\hline Outside world $\leftrightarrow$ Ebb-tidal delta & 1060 \\
Ebb-tidal delta $\leftrightarrow$ Channels & 1290 \\
Channels $\leftrightarrow$ Flats & 840 \\
\hline
\end{tabular}

With these optimised horizontal exchange rates, the simulated development of the volumes of the Zoutkamperlaag elements for the period 1969-1987 are shown in Figure 5.5. The solid lines represent the development of element volumes as predicted by ASMITA, the plus ' + ' signs indicate the observed volumes of the elements (see data set, Table 5.4). 


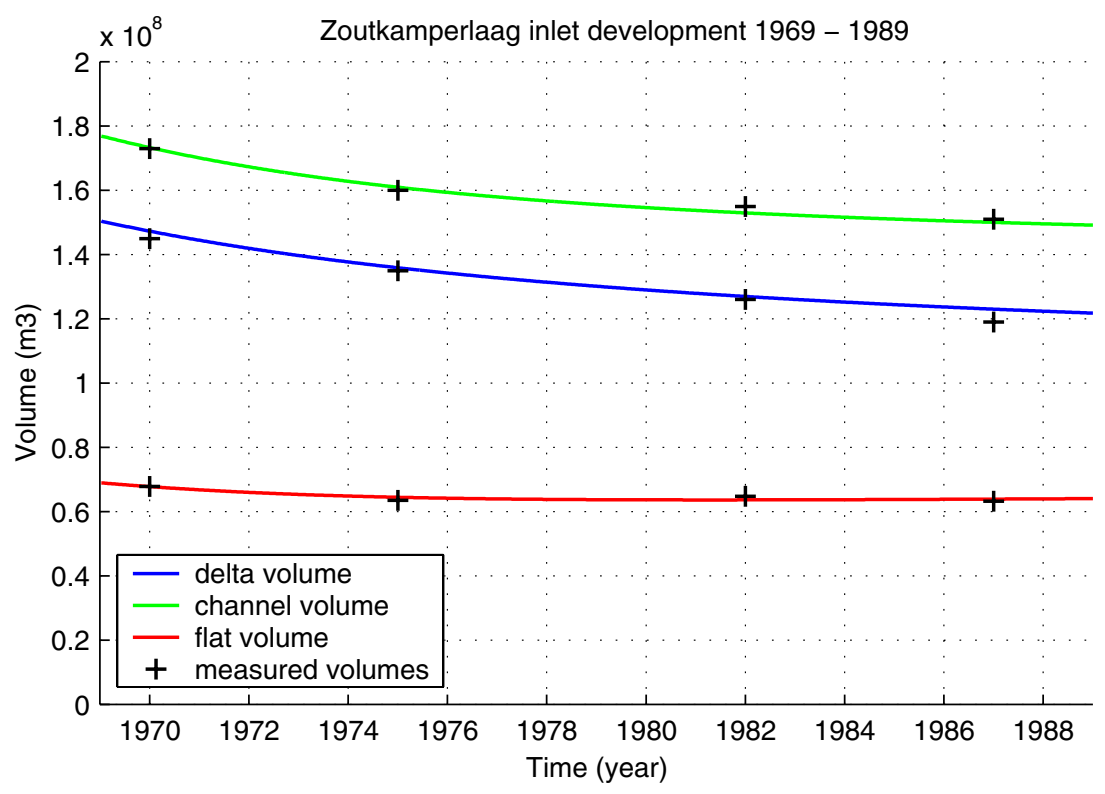

Figure 5.5: Simulation of volume development of Zoutkamperlaag inlet after closure Lauwerszee (1969).

The deviation between observation and model results made with the $\operatorname{ASMITA}_{i, t}\left(\delta_{o d}, \delta_{d c}, \delta_{c f}\right)$ model are shown in Appendix I2. For each element $i$ at observation time $t$ the deviation $\varepsilon_{i, t}$ is plotted. As shown, the deviations made in volume prediction are less than of $4 \cdot 10^{6} \mathrm{~m}^{3}$. In order to tackle the question what measure of precision can be associated to our estimates, we translate in Section 5.3.4 these deviations into a standard deviation of the horizontal exchange rates.

\subsubsection{Standard deviation of horizontal exchange rates}

As mentioned before, we assume that the horizontal exchange rates are log-normally distributed with means corresponding to a least-squares fit of a three-element ASMITA model to field data on the Zoutkamperlaag inlet. We use the latter distribution because it excludes physically unrealistic (negative) values of $\delta$ in the following (see Section 5.4) probability calculations. Equation (5.25) shows that for $\delta \neq 0$ it makes no difference whether we derive (with the least-square fit) the best values for $\ln \delta$ directly from $\partial S / \partial \ln \delta=0$ or first calculate the best values for $\delta$ from $\partial S / \partial \delta=0$ and then take the logarithms of the derived $\delta$ values.

$$
\frac{\partial S}{\partial \ln \delta}=\delta \frac{\partial S}{\partial \delta}=0
$$

The available field data (only 12 data points) is by far insufficient to properly estimate the corresponding standard deviations and correlation coefficients. To deal with this, the following simplifications have been made:

- All exchange rates have the same standard deviation

- All exchange rates are fully correlated

These simplifications are reasonable when we assume that the horizontal exchange rates are highly correlated to the tidal volume that flows through all elements. With these simplifications we may write that: 


$$
\ln \left(\frac{\delta_{m n}}{D}\right)=\mu_{m n}+u n \cdot \sigma_{\ln \delta}
$$

in which:

$\delta_{m n} \quad$ exchange rate, applicable to the exchange between element $m$ and $n$

$D \quad$ scaling factor with a dimension identical to that of $\delta_{m n}$, equal for all elements and time-invariant

$\mu_{m n} \quad$ logarithms of the scaled least-squares estimates $\left(\delta_{\text {est }}\right)$ as derived in the previous section (scaled with factor $D$ )

un presumed standard normally distributed random variable

$\sigma_{\ln \delta} \quad$ standard deviation

The standard deviation $\sigma_{\ln \delta}$ is chosen such that the model predictions show the same spreading around the least-squares optimum as the field data. The procedure to find this $\sigma_{\ln \delta}$ reads as follows: we perform a number of ASMITA runs with a tentative chosen $\sigma_{\ln \delta}$ and horizontal exchange rates resulting from equation (5.26). From these simulations we find the spreading $\sigma_{\varepsilon^{*}}$ around the least-square optimum. When this spreading matches the spreading of the field data around the least-squares fit $\left(\sigma_{\varepsilon}\right)$, the correct $\sigma_{\ln \delta}$ is chosen. If no match is found we adjust $\sigma_{\ln \delta}$ and repeat the procedure.

In Appendix J, the computational details are given of these so-named Monte Carlo simulations. The outcome of these computations is that the spreading of the Monte Carlo simulations match the spreading of the least-squares fit for a standard deviation $\sigma_{\ln \delta}$ of 0.47.

In Table 5.7 the results are shown of the quantitative assessment on the uncertainties in the horizontal exchange rate.

Table 5.7: Resulting means and standard deviation of horizontal exchange rates

\begin{tabular}{lcc}
\hline \multicolumn{3}{l}{ Resulting means and standard deviations of horizontal exchange rates } \\
\hline Horizontal exchange & $\begin{array}{c}\text { estimate } \delta_{\text {est }} \\
{\left[\mathrm{m}^{3} / \mathrm{s}\right]}\end{array}$ & $\begin{array}{r}\sigma_{\ln \delta} \\
{[-]}\end{array}$ \\
\hline Outside world $\leftrightarrow$ Ebb-tidal delta & 1060 & \\
Ebb-tidal delta $\leftrightarrow$ Channels & 1290 & 0.47 \\
Channels $\leftrightarrow$ Flats & 840 & \\
\hline
\end{tabular}

\subsection{Probability of Sea Level Rise Stability Limit}

\subsection{Introduction}

To comprehend the reliability of the predicted SLRlimit we assess the uncertainty in the prediction with an estimate of its probability. By deriving the probability a specific tidal inlet system is unable to regain a new state of dynamic equilibrium, given a certain rate of sea level rise $(S L R)$, we obtain such an estimate.

In the foregoing sections we have derived that the uncertainty in the SLRlimit predictions can be reduced to two random variables. The first one is related to the uncertainty in the model 
parameters of the 'outside world' equilibrium concentration $c_{E}$ and the second one is related to a normally distributed random variable $u n$ that relates to the horizontal exchange rates jointly, see equation (5.26). In the following section we deal with the joint probability of these random variables.

\subsubsection{The probability that the SLR exceeds the SLRlimit}

In the present section we derive the probability of the $S L R$ limit non-exceeding some given $S L R$. In Section 5.1 we stated that the SLRlimit is highly sensitive to the random variables $c_{E}$ and $\delta$ :

$$
\operatorname{SLRlimit}=\operatorname{SLR\operatorname {limit}}\left(c_{E}, \delta\right)
$$

and with the findings of Section 5.3.4 we may rewrite equation (5.27) as:

$$
\operatorname{SLRlimit}=\operatorname{SLRlimit}\left(c_{E}, u n\right)
$$

The situation that $S L R \operatorname{limit}\left(c_{E}, u n\right)<S L R$ holds for an infinite number of combinations $\left(c_{E}\right.$, $u n)$. To determine the probability that the $S L R \operatorname{limit}\left(c_{E}, u n\right)<S L R$, we have to integrate over all these combinations of $\left(c_{E}, u n\right)$ multiplied by their joint probability density (for integration area and corresponding joint probability density see Appendix K1). Corresponding integration boundaries for $u n$ are $(-\infty,+\infty)$ whereas $c_{E}$ varies between 0 and $u n$ upper boundary $c_{E}^{*}$ :

$$
\operatorname{SLR\operatorname {limit}}\left(c_{E}^{*}, u n\right)=S L R
$$

from which we derive:

$$
c_{E}^{*}=c_{E}^{*}(S L R, u n)
$$

The joint probability of the random variables ( $u n$ and $c_{E}$ ) is derived from the following argument: as both variables ( $u n$ and $c_{E}$ ) are highly correlated to different kinds of hydrodynamic forcings (tidal volume vs. waves), we assume that they are independent variables. Therefore we may write the joint probability density function (further referred to as $p d f)$ as the product of the two marginal $p d f$ 's:

$$
f_{u n, c_{E}}\left(u n, c_{E}\right)=f_{u n}(u n) \cdot f_{c_{E}}\left(c_{E}\right)
$$

Given this joint $p d f$, by integration we derive the probability that the system is unable to regain a new state of dynamic equilibrium given a $S L R$. This probability is given by:

$$
P\left(S L R \text { limit }<S L R \mid S L R, \text { un }, c_{E}\right)=\int_{-\infty}^{+\infty} f_{u n}(u n) \int_{0}^{c_{E}^{*}} f_{c_{E}}\left(c_{E}\right) d c_{E} d u n
$$

For the integration of the joint $p d f$ we make use of Hermite polynomials. To apply this integration technique we have to rewrite the $p d f$ of the standard normal distribution for $u n$ in the form $e^{-x^{2}}$. The $p d f$ of the standard normally distributed variable $u n$ is given by:

$$
f_{u n}(u n)=\frac{1}{\sqrt{2 \pi}} e^{-\frac{1}{2}(u n)^{2}}
$$


From equation (5.32) we may express the probability $P(S L R$ limit $<S L R)$ by:

$$
P(S L R \text { limit }<S L R \mid S L R, u n)=\int_{-\infty}^{+\infty} f_{u n}(u n) \cdot F_{c_{E}}(u n) d u n
$$

where $\quad F_{c_{E}}(u n)=\int_{0}^{c_{E}^{*}} f_{c_{E}}\left(c_{E}\right) d c_{E}$

When we substitute equation (5.33) into equation (5.34) we derive:

$$
\frac{1}{\sqrt{2 \pi}} \int_{-\infty}^{+\infty} e^{-\frac{1}{2}(u n)^{2}} \cdot F_{c_{E}}(u n) d u n
$$

which may be written as:

$$
\frac{1}{\sqrt{\pi}} \int_{-\infty}^{\infty} e^{-\left(\frac{u n}{\sqrt{2}}\right)^{2}} \cdot F_{c_{E}}(u n) d\left(\frac{u n}{\sqrt{2}}\right)
$$

and by putting that:

$$
y=\left(\frac{u n}{\sqrt{2}}\right)
$$

we may approximate the integral in (5.34) as:

$$
\frac{1}{\sqrt{\pi}} \int_{y=-\infty}^{\infty} e^{-y^{2}} \cdot F_{c_{E}}(y) d y \quad \approx \quad \frac{1}{\sqrt{\pi}} \sum_{i=1}^{n} w_{i} \cdot F_{c_{E}}\left(y_{i}\right)
$$

In which $y_{i}$ are the zero crossing of a Hermite polynomial and $w_{i}$ are the corresponding weight factors (see Table 25.10, Handbook of mathematical functions, Abramowitz and Stegun, 1972).

Summarising the probability of the system being unable to regain a 'new' state of dynamic equilibrium given a certain $S L R$ reads:

$$
P\left(S L R \text { limit }<S L R \mid S L R, y_{i}\right) \approx \frac{1}{\sqrt{\pi}} \sum_{i=0}^{n} w_{i} \cdot F_{c_{E}}\left(y_{i}\right)
$$

In Figures 5.6 and 5.7 (see also Appendix K2) the probability distributions of both inlets are shown for the present and the altered wave climates. The distributions are based on the uncertainty assessments as performed in the foregoing sections.

In the figures we see a clear shift in the distributions of SLRlimit for the changed wave climates. Due to the changed wave-climate there is an increase in the 'outside world' equilibrium concentration and thus an increase in the probability that the system is able to follow a certain $S L R$. 

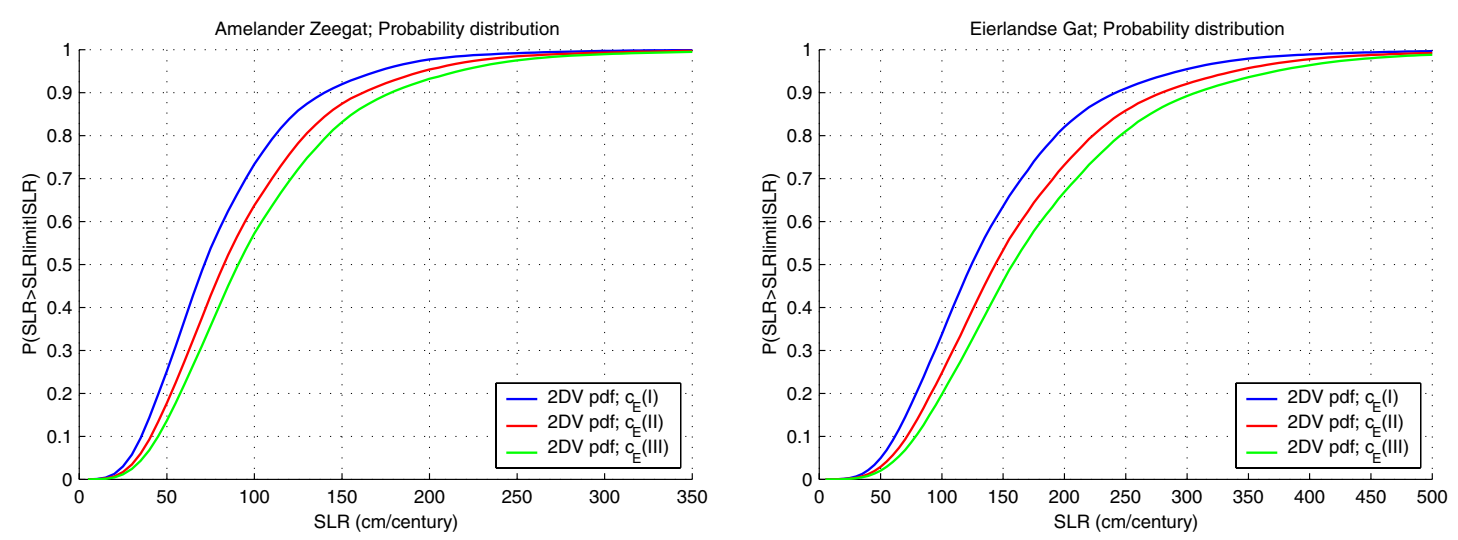

Figure 5.6-5.7: Probability distribution (2D) of Amelander Zeegat and Eierlandse Gat for present and changed wave climate scenarios.

In Table 5.8, a summation is given of the $S L R$ limit probabilities for the three scenarios of $S L R$ : the present $S L R(17 \mathrm{~cm} /$ century), the most likely scenario $(S L R 56 \mathrm{~cm} /$ century) and the worst case scenario (SLR $85 \mathrm{~cm} /$ century). Additionally we have made the distinction in 'outside world' equilibrium concentration resulting from the three wave climate scenarios. It is clear that the worst case $S L R$ scenario results in a higher probability of system instability than the present $S L R$ scenario. On the other hand, an altered wave climate may lower the probability of system instability.

Table 5.8: $\quad$ Probability $S L R>S L R$ limit for given $S L R$ scenarios and wave climates

\begin{tabular}{|c|c|c|c|c|c|c|}
\hline \multirow[b]{2}{*}{$S L R$ scenario } & \multicolumn{3}{|c|}{$\begin{array}{c}\text { Amelander Zeegat } \\
\text { wave climate }\end{array}$} & \multicolumn{3}{|c|}{$\begin{array}{l}\text { Eierlandse Gat } \\
\text { wave climate }\end{array}$} \\
\hline & $c_{E}(I)$ & $c_{E}(I I)$ & $c_{E}(I I I)$ & $c_{E}(I)$ & $c_{E}(I I)$ & $c_{E}(I I I)$ \\
\hline Present SLR & 0.006 & 0.003 & 0.002 & 0 & 0 & 0 \\
\hline Most likely & 0.319 & 0.234 & 0.186 & 0.072 & 0.044 & 0.031 \\
\hline Worst case & 0.624 & 0.522 & 0.450 & 0.238 & 0.166 & 0.126 \\
\hline
\end{tabular}

We have to keep in mind that the probabilities given in Table 5.8 are indicative. The calculated probabilities result from a limited amount of uncertainties and therefore have a limited predictive value. These limitations of the predictive value are discussed in Section 5.5 where considerations are given with respect to the SLRlimit probability.

\subsection{Consideration with respect to SLRlimit probability}

In Sections $5.1-5.3$ we assessed the reliability in the SLRlimit predictions. This assessment has been performed by determining probability ranges for those system variables that in the SLRlimit prediction is most sensitive to and which are hard to quantify. These variables have been identified in the sensitivity analysis presented in Sections 3.5 and 4.4. It concerns the 'outside world' equilibrium concentration and the inter-element horizontal exchange rates.

By limiting the probabilistic evaluation given in the previous sections, to these particular parameters, we have neglected beforehand any effect on the reliability of the computed SLRlimit of the other model parameters. Hereafter some quantitative considerations are given on these neglected effects. In addition, we will pay some attention to the (implicit) assumption that the 'outside world' concentration and the horizontal exchange rates are timeinvariant.

In Section 4.4 we stated that the tidal basin area does not bring about uncertainty as the present-day tidal basins are accurately measured. By putting this we have assumed a timeinvariant development of tidal basin area under the external forcing of sea level rise. Whether this assumption is correct is doubtful. If we were looking at an unrestricted tidal inlet system 
the assumption probably holds. Together with the onshore shift of the barrier islands the basin area will expand landward, inundating the unprotected hinterland. In this way, the tidal basin area more or less preserves its size and thus the assumption of a time-invariant basin area holds. In the case of the Dutch Wadden Sea however, we have a strictly bounded tidal basin area in which the hinterland of Friesland and Groningen is protected against inundation by dikes. This means that the expected retreat of barrier islands results in a reduction of the tidal basin area, as it is unable to expand itself landward. This reduction of the tidal basin area results according to Section 4.4 in an increase of the SLRlimit. The wadden area shrinks gradually and finds it ever easier to keep pace with the sea level rise, as the sediment demand becomes ever smaller.

A second consideration is made with respect to the assumed time-invariant behaviour of the horizontal exchange rates and their impact on the SLRlimit. In Section 4.5 we found an increase of the tidal prism due to the deepening the tidal flats under the external forcing of sea level rise. Whether this change in tidal prism/volume affects the, time-invariant assumed, horizontal exchange rates is conceivable. We may expect an increase in inter-element diffusive sediment exchange rate due to the tidal volume increase. As the magnitude of such an increase is unknown to us we can only conclude from Section 4.4 that an increase in horizontal exchange rate results in an increase of the SLRlimit.

A final consideration concerning the SLRlimit probability is made with respect to the availability of sediment to $\left(c_{E}\right)$ the tidal basin. In Section 5.2 we derived a conceptual model for $c_{E}$ in which we assumed that wave-generated processes are determinative for the 'outside world' equilibrium concentration. In this approximation we presume the sediment supply from the barrier coasts unlimited. This unlimited sediment supply is realistic as long as no 'hard' protective measures are taken to reduce the erosion of the barrier beaches. In case the barrier shoreline is protected, by for instance dikes, revetments or jetties, the longshore sediment transport will reduce considerably which results in a considerable drop of 'outside world' equilibrium concentration. The tidal basin is then deprived of sediment and will drown. 


\section{Conclusions and Recommendations}

\section{I Conclusions}

From the present research on the 'influence of relative sea level rise on coastal inlets and tidal basins' we may conclude that:

- The influence of relative sea level rise on the long-term morphological evolution of a tidal inlet system (consisting of a coastal inlet and tidal basin) may be modelled with the behaviour oriented, aggregated scale model ASMITA (Aggregated Scale Morphological Interaction between a Tidal inlet system and the Adjacent coast). This aggregated scale model covers the key morphological elements of the tidal inlet system, namely the flat, channel and ebb-tidal delta.

- The capability of the modelled tidal inlet system to follow a rise of the sea level primarily depends on three factors:

- The availability of sediment at the seaward boundary of the system;

- The sediment demand of the system;

- The capability of the system to distribute the imported sediment internally.

The first factor applies to the exchange of sediment between the inlet system on the one hand and the coastal and offshore areas that surround the ebb-tidal delta on the other hand. The second factor, the sediment demand needed to keep pace with the rise of the sea level, depends on the horizontal area of the morphological elements and is related to the need of sediment in the system. This need of sediment depends on the extent to which the actual morphology of the system deviates from its equilibrium state. Whether this need of sediment actually results in sedimentation in the system depends on the third factor, the capability of the system to distribute the imported sediment internally and make it available for sedimentation.

- In case of a rising sea level, the system has to be permanently in a state that deviates from the equilibrium state that corresponds to a zero Sea Level Rise (SLR). This is necessary to create a permanent need of sediment that incites a sediment import into the system. In case this sediment import equals the sediment demand of the system, a new state of morphological balance is reached (named the 'new' dynamic equilibrium state). In case the sediment import is insufficient, the system's morphology will increasingly deviate from its equilibrium and becomes unstable. In this case the $S L R$ has exceeded an upper boundary (named 'stability limit'), and the system will no longer regain a state of dynamic equilibrium and drowns.

- In the schematisation of a two or three-element system (consisting of flat, channel and ebb-tidal delta) we may derive a stability limit for each element. The smallest of these three stability limits is determinative for the system. For both cases (the two and three element system) the flat element determines the stability of the system. This is probably due to the serially character of the system where the flat element is situated furthest from the sediment supplying seaward boundary. This determinative flat limit is denoted as SLRlimit. We have to keep in mind that the latter SLRlimit serves as the final limit of the 
system's capability to follow a rising sea level and that before the SLRlimit is reached the morphology of the inlet system is permanently changed and probably has lost its original intertidal characteristics.

- The uncertainty in the potential sediment supply to the system and the uncertainty in the capability of the system to distribute the imported sediment internally introduce significant uncertainties in the prediction of the SLRlimit. An assessment of these uncertain system variables resulted in matching probability ranges. Application of probabilistic techniques yields a probability distribution of the $S L R$ limit, which describes the probability that a tidal inlet system is unable to keep pace with a certain SLR given this $S L R$.

- For two selected tidal inlet systems, the Amelander Zeegat and the Eierlandse Gat, stability limits exist for a rise of sea level. The probability that the Amelander Zeegat is unable to keep pace with the most likely sea level rise scenario $(56 \mathrm{~cm} / \mathrm{century})$ under the present wave climate is $32 \%$ and for the worst case sea level rise scenario (85 $\mathrm{cm} /$ century) this probability equals $62 \%$. The probability that the Eierlandse Gat is unable to keep pace with the most likely sea level rise scenario under the present wave climate is $7 \%$ and for the worst case sea level rise scenario this probability equals $24 \%$.

- We may establish an analogy between the probability of the predicted SLRlimits for the latter two tidal inlets and the available fragmentary geological data on tidal inlet evolution. This geological data suggests that under the influence of a sea level rise of 80 $\mathrm{cm}$ to a few meters per century, the former tidal inlets in the western region of the Netherlands were drowned. This similarity indicates that, in terms of orders of magnitude, the aggregated scale model ASMITA is capable of modelling the long-term morphological response of a tidal inlet to a rising sea level and that it is capable of predicting the maximum rise of sea level a tidal inlet system can follow.

\subsection{Recommendations}

The following recommendations are made based on the findings of the present study:

- We need to acquire more bathymetrical data of tidal inlet systems over longer periods of time. Especially inlets that are or have been subjected to an external forcing (whether caused by human intervention or natural processes) and thus have to evolve towards a 'new' state of dynamic equilibrium are of interest. The development of the system towards such a 'new' morphological balance reveals the morphological time-scales and thus the internal sediment exchange rates belonging to the system/element. By using the obtained volumetric data we may also increase the reliability of our empirical equilibrium relations and thus increase the reliability of our predictions.

- In the present investigation we assume that the uncertainty associated with the ASMITA model approach is smaller than the uncertainty resulting from a processes based modelling approach and therefore more applicable for long-term modelling. This assumption probably holds as the integration of small-scale process knowledge causes an accumulating error that brings significant uncertainties in our long-term prediction. Nevertheless, the ASMITA model approach also introduces uncertainties in the prediction due to the limited quantitative insight into the underlying large-scale morphological processes and the limited reliability because of the relatively small time span of measurements. In the present study we have not investigated the uncertainties in the predictions of the ASMITA model approach. Part of the ASMITA model uncertainty is 
related to the uncertainty in the empirical equilibrium relations which is basic to the concept of the ASMITA model. This uncertainty may be assessed by regression analysis resulting in a mean and standard deviation of the empirical relation coefficients. However, in the ASMITA model concept the derived SLRlimit is independent of the exact values of the empirical relations and thus independent of the uncertainty introduced by the empirical relations.

- In the present study we presumed the estimated horizontal exchange rates of the Zoutkamperlaag inlet case representative for both case study inlets; the Amelander Zeegat and the Eierlandse Gat. For the Eierlandse Gat inlet this presumption probably holds, as the magnitude of the tidal prism is similar to that of the Zoutkamperlaag inlet. However, the tidal prism of the Amelander Zeegat inlet significantly differs from that of the Zoutkamperlaag inlet and thus it is conceivable that the horizontal exchange rates of the Amelander Zeegat differ from that of the Zoutkamperlaag inlet. To what extent the horizontal exchange rates differ and the effect of this difference on the probability distribution of the SLRlimit of the Amelander Zeegat inlet is unknown and requires more research.

- In the present investigation the evolution of the adjacent coastal stretches is presumed independent of the development of the tidal inlet. Hence the adjacent coastal stretches are presumed always in a state of equilibrium and serve as a time-invariant boundary condition of the system. A more realistic approach may result in a coastal stretch that has to adapt to a rising sea level and thus may deviate from its equilibrium state. The evolution towards a 'new' dynamic state of equilibrium results in a time-variant sediment supply to the tidal basin. The extension of the tidal inlet model by an adjacent coastal stretch element may provide a better understanding of the capability of the adjacent coastal stretch to make sediment available to the tidal basin. 


\section{References}

Abramowitz, M.; and Stegun, I.A., 1972. Handbook of mathematical functions; with formulas, graphs, and mathematical tables. New York: Dover, 1972.

Biegel, E.J., 1991. Equilibrium relations in the ebb-tidal delta, inlet and backbarrier area of the Frisian Inlet system. Rapport GEOPRO 1991.028/GWAO-91.016. Rijksuniversiteit Utrecht, Vakgroep Fysische Geografie.

Biegel, E.J., 1992. ISOS*2 Project, Phase 2, Impact of sea-level rise on the morphology of the Wadden Sea in the scope of its ecological function, Investigations on empirical morphological relations, Annexes: Data reports Part 1 and Part 2, DELFT HYDRAULICS/Univ. of Utrecht, Report H1300, November 1992.

Biegel, E.J., 1993. ISOS*2 Project, Phase 3, Impact of sea-level rise on the morphology of the Wadden Sea in the scope of its ecological function, Proposed set-up of a dynamic morphological model for Wadden Sea basins and estuaries based on empirical relations, DELFT HYDRAULICS, Report H1300 - Volume II.

Buijsman, M.C., 1997. The impact of gas extraction and sea level rise on the morphology of the Wadden Sea, DELFT HYDRAULICS, Report H3099.30

Bruun, P.; and Gerritsen, F., 1959. Natural Bypassing of sand at coastal inlets. Journal of the Waterways and Harbours Div. ASCE, 85, 75-107.

Bruun, P. (editor), 1978. Stability of tidal inlets. Elsevier Sc. Publ. Cy, Amsterdam

Cleveringa, J.; Oost, A.P.; and de Boer, P.L., 1997. Fractal and hierarchical analysis of tidal-channel systems in the Dutch Wadden Sea. Barcelona Overall Workshop 3-7 March 1997.

Corti, S.; Molten, F.; and Palmer, T.N., 1999. Signature of recent climate change in frequencies of natural atmospheric circulation regimes. Nature 398: pp 799-802.

CUR, 1997. Kansen in de civiele techniek. Deel 1: probabilistisch ontwerpen in theorie. CUR, RWS, March 1997.

Davis, R.A., 1994. The evolving coast. Scientific American Library, New York.

De Vriend, H.J., 1996. Mathematical modelling of meso-tidal barrier island coast, Part I: Empirical and semiempirical models. In press.

De Vriend, H.J., 1998. On the Predictability of Coastal Morphology. In Proceedings $3^{\text {rd }}$ Marine Science and Technology Conference, 23-27 May, Lisbon, Portugal.

De Vriend, H.J.; Dronkers, J.; Stive M.J.F.; Van Dongeren, A.; Wang, Z.B., 1999. Coastal inlets and Tidal basins, . Delft University of Technology, Department of Civil Engineering, October 1999.

Dean, R.G.; and Walton, T.L., 1975. Sediment transport processes in the vicinity of inlets with special reference to sand trapping. In Estuarine Research, L.E. Cronin, Academic Press, 2, 129-150.

Dieckman, R., 1985. Geomorphologie, Stabilitats- und Langzeitverhalten von Watteinzugsgebieten der Deutschen Bucht, Mitt. Franzius-Institut, Univ. Hannover, heft 60, 1985.

Dieckmann, R.; and Partenscky, H.W., 1986. A new equilibrium analysis for nearshore tidal basins, Proceedings $20^{\text {th }}$ CEC, Taiwan, ROC (1986), pp. 1077-1091.

Eysink, W.D., 1990. Morphological response of tidal basins to change. Proc. $22^{\text {nd }}$ Coast. Eng. Conf., ASCE, Delft, July 2-6, Vol. 2, The Dutch Coast, Paper no. 8, 1990, pp. 1948-1961.

Eysink, W.D., 1991. ISOS*2 Project, Phase 1, Impact of sea-level rise on the morphology of the Wadden Sea in the scope of its ecological function. Inventory of available data and literature and recommendations on the aspects to be studied. DELFT HYDRAULICS, Report H1300, August 1991.

Eysink, W.D. and Biegel, E.J., 1992. ISOS*2 Project, Phase 2, Impact of sea-level rise on the morphology of the Wadden Sea in the scope of its ecological function. Investigation on empirical morphological relations. DELFT HYDRAULICS, Report H1300, September 1992.

Eysink, W.D., 1992. ISOS*2 Project, Phase 3, Impact of sea-level rise on the morphology of the Wadden Sea in the scope of its ecological function. Proposed set-up of a dynamic morphological model for Wadden Sea basins and estuaries based on empirical relations, DELFT HYDRAULICS, Report H1300 - Volume I, December 1992.

Eysink, W.D., 1993. ISOS*2 Project, Phase 4, Impact of sea-level rise on the morphology of the Wadden Sea in the scope of its ecological function. General considerations on hydraulic conditions, sediment transports, sand balance, bed composition and impact of sea-level rise on tidal flats, DELFT HYDRAULICS, Report H1300, July 1993.

Fenster, M.; and Dolan, R., 1996. Assessing the impact of Tidal Inlets on Adjacent Barrier Island Shorelines. In Journal of Coastal Research, 12(1),pp. 294-310.

FitzGerald, D.M., 1996. Geomorphic Variability and Morphologic and Sedimentologic Controls on Tidal Inlets. In Journal of Coastal Research, 23, pp. 47-71. 
Gerritsen, F.; de Jong, H.; and Langerak, A., 1990. Cross-sectional stability of estuary channels in the Netherlands. In Coastal Engineering, 1990, Delft

Hayes, M.O.; Goldsmith, V.; and Hobb, C.H., 1970. Offset coastal inlets. Proc. $12^{\text {th }}$ Coast. Eng. Conf. ASCE, pp 1197-1200.

Hayes, M.O., 1979. Barrier island morphology as a function of tidal and wave regime. In Barrier Islands, S.P. Leatherman (editor), Academic Press, New York, 1-28.

Holthuijsen, L.H., 1998. Windgolven, . Delft University of Technology, Department of Civil Engineering.

Hoogeboom, B., 1996. Empirical relaties voor de evenwichtshoogte van het intergetijdegebied binnen het model ESTMORF; De morfologische ontwikkeling van het intergetijdegebied van het Friesche Zeegat. R96.02. Rijksuniversiteit Utrecht, Faculteit der Ruimtelijke Wetenschappen, Vakgroep Fysische Geografie.

IPPC, 2001. Summary for Policymakers, a Report of Working Group I of the Intergovernmental Panel on Climate Change. Eight Session of Working Group I in Shanghai on 17 to 20 January 2001.

Jarret, J.T., 1976. Tidal prism-inlet area relationship, Rep. no. 3, Coastal Engineering Research Centre, Ft. Belvoir, Virginia, 1976.

Louters, T.; Gerritsen, F., 1994. The Riddle of the Sands, a Tidal System's Answer to a Rising Sea Level. Report RIKZ-94.040. RIKZ, The Hague..

Misdorp, R.; Steyaert F.;Hallie, F.; and J. de Ronde, 1990. Climate change, sea level rise and morphological developments in the Dutch Wadden Sea, a marine wetland. RWS, The Hague.

O'Brien, M.P., 1969. Equilibrium flow areas of inlets on sandy coasts. Journal of the Waterways and Harbour Div., Proceedings ASCE, 1969.

Rakhorst, H.D., 2000. Erosie en sedimentatie in de buitendelta van het Zeegat van het Vlie en de aangrenzende kuststroken 1926-1984, Deelonderzoek nr.11, Supplement deelonderzoek nr.7, Rapportage ANV-2000-20, RWS directie Noord-Holland.

Renger, E., 1976. Quatitative Analyse der Morphologie von Watteinzugsgebieten und Tidebecken, Mitt. FranziusInst., Hannover, heft 43, 1976.

Renger, E.; and Partenscky, H.W., 1974. Stability criteria for tidal basins, Proceedings $14^{\text {th }}$ Coastal Eng. Conf., ASCE, Vol 2, ch. 93, 1974, pp. 1605-1618.

Renger, E.; and Partenscky, H.W., 1980. Sedimentation processes in tidal channels and tidal basins caused by artificial constructions, Proceedings $17^{\text {th }}$ Coastal Eng. Conf., ASCE, Vol. 3, ch. 148, 1980, pp. 2481-2494.

RWS, 1989. Wadatlas, RWS Dir.-Gen. Scheepvaart en Maritieme Zaken, December 1989.

Sha, L.P.; and Van den Berg, J.H., 1993. Variation in ebb-tidal delta geometry along the coast of The Netherlands and the German Bight. In Journal of Coastal Research, 9(3), pp 730-746.

Shore Protection Manual, 1984. Coastal Engineering Research Centre, Department of the Army, Vicksburg, Mississippi.

Steijn, R.C., 1997. Morfodynamische berekeningen ZW-Texel, Fase 1: Modelopzet en calibratie. ALKYON and DELFT HYDRAULICS, July 1997.

Stive, M.J.F.;Capobianco, M.; Wang, Z.B.; Ruol, P.; and Buijsman, M.C.,1998. Morphodynamics of a Tidal Lagoon and the Adjacent Coast. $8^{\text {th }}$ International Biennial Conference on Physics of Estuaries and Coastal Seas, The Hague, September 1996, pp 397-407.

Stive, M.J.F., 2000. Personal communication, October 2000.

Van der Spek, A.J.F., 1994. Large-scale evolution of Holocene tidal basins in the Netherlands, PhD Thesis, University of Utrecht, ISBN 90-393-0664-8.

Van der Velden, E.T.J.M., 1995. Coastal Engineering Volume II. Delft University of Technology, Department of Civil Engineering.

Van Dongeren, A.R.; and De Vriend, H.J., 1994. A model of morphological behaviour of tidal basins. In Coastal Engineering, 22 (1994), 287-310.

Van Goor, M.A.; Stive, M.J.F.; Wang, Z.B.; and Zitman, T.J., 2001. Influence of relative sea level rise on coastal inlets and tidal basins, Proceedings Coastal Dynamics 2001. In press.

Van Kleef, A.W., 1991. Empirical relationships for tidal inlets, basins and deltas. Report GEOPRO 1991.19. Rijksuniversiteit Utrecht, Faculteit der Ruimtelijke Wetenschappen,Vakgroep Fysische Geografie.

Vellinga, P; and Van Verseveld, W.J., 2000. Climate Change and Extreme Weather Events. Vrije Universiteit Amsterdam, Institute for Environmental Studies. Published by WWF, Gland, Switzerland, September 2000.

Walton, T.L.; and Adams, W.D., 1976. Capacity of inlet outer bars to store sand. Proc. $15^{\text {th }}$ Coast. Eng. Conf., ASCE, Honolulu, Hawaii, 1976, Volume 2, pp 1919-1937.

Wang, Z.B., Karssen, B., Fokkink, R.J. and Langerak, A., 1998. A dynamic/empirical model for long-term morphological development of estuaries. 8th International Biennial Conference on Physics of Estuaries and Coastal Seas, The Hague, September 1996. pp 279-286.

Zagwijn, W.H., 1986. Nederland in het Holoceen, Rijks Geologische Dienst Haarlem, Staatsuitgeverij, 'sGravenhage 1986. 


\section{Appendices}

